University of Pennsylvania Carey Law School

Penn Law: Legal Scholarship Repository

Faculty Scholarship at Penn Law

2015

\title{
The American Criminal Code: General Defenses
}

\author{
Paul H. Robinson \\ University of Pennsylvania Carey Law School \\ Matthew Kussmaul \\ University of Pennsylvania Law Scbool--JD candidate \\ Camber Stoddard \\ White \& Case LLP \\ Ilya Rudyak \\ University of Pennsylvania Law School Fox Fellow \\ Andreas Kuersten \\ National Oceanic and Atmospheric Administration
}

Follow this and additional works at: https://scholarship.law.upenn.edu/faculty_scholarship

Part of the Criminal Law Commons, Law and Society Commons, Legislation Commons, and the Public Law and Legal Theory Commons

\section{Repository Citation}

Robinson, Paul H.; Kussmaul, Matthew; Stoddard, Camber; Rudyak, llya; and Kuersten, Andreas, "The American Criminal Code: General Defenses" (2015). Faculty Scholarship at Penn Law. 1425.

https://scholarship.law.upenn.edu/faculty_scholarship/1425

This Article is brought to you for free and open access by Penn Law: Legal Scholarship Repository. It has been accepted for inclusion in Faculty Scholarship at Penn Law by an authorized administrator of Penn Law: Legal Scholarship Repository. For more information, please contact PennlawIR@law.upenn.edu. 


\title{
THE AMERICAN CRIMINAL CODE: GENERAL DEFENSES
}

\author{
Paul H. Robinson*, Matthew G. Kussmaul**, Camber M. Stoddard", \\ Ilya Rudyak, and Andreas Kuersten ${ }^{\S}$
}

\section{ABSTRACT}

There are fifty-two bodies of criminal law in the USA. Each stakes out often diverse positions on a range of issues. This article defines the "American rule" for each of the issues relating to general defenses, a first contribution toward creating an "American Criminal Code".

The article is the result of a several-year research project examining every issue relating to justification, excuse, and nonexculpatory defenses. It determines the majority American position among the fifty-two jurisdictions, and formulates statutory language for each defense that reflects that majority rule. The article also compares and contrasts the majority position to significant minority positions, to the Model Penal Code, and to the National Commission's proposed code.

Using these results, in focusing on the most controversial justification defense, Defense of Persons, the article then compares patterns among the states on legal issues with a wide range of other variables - such as state population, racial characteristics, violent crime rates, and gun ownership_-highlighting many interesting correlations. Applying this kind of doctrinal correlation analysis to all of the project's existing data would be a major undertaking. The goal here is to show how such analysis can be done, and how interesting the revealed patterns can be.

American criminal codes (ACCs) are in many ways the most advanced in the world. With three-quarters of them based in large part upon the American Law Institute's Model Penal Code of 1962 (MPC), they tend to be carefully drafted and highly principled. When compared to the German Penal Code in terms of

* Colin S. Diver Professor at the University of Pennsylvania Law School. 3501 Sansom Street, Philadelphia, PA 19104-6204, Phone: 215-898-1017. Email: phr@law.upenn.edu The authors acknowledge the enormous research contributions of Penn Law's Fall 2013 Criminal Law Research Group, including Jason Thompson, Matthew Funk, Jacob Lefkowitz, Tanner Mathison, Jake Branchaud-Linsk, Matthew Celano, and Daniel Ramos.

** Member of the Class of 2015 at the University of Pennsylvania Law School.

$\dagger$ Associate at White \& Case LLP in Los Angeles, CA.

* 2013-2015 Fox Fellow and an SJD candidate at the University of Pennsylvania Law School.

$\S \quad$ Legal fellow with the National Oceanic and Atmospheric Administration, Office of General Counsel.

(C) The Author 2015. Published by Oxford University Press on behalf of The John M. Olin Center for Law, Economics and Business at Harvard Law School.

This is an Open Access article distributed under the terms of the Creative Commons Attribution Non-Commercial License (http://creativecommons.org/licenses/by-nc/4.0/), which permits non-commercial re-use, distribution, and reproduction in any medium, provided the original work is properly cited. For commercial re-use, please contact journals.permissions@oup.com doi:10.1093/jla/lav001 
influence on criminal codifications in other countries, American codes, though lacking the same long heritage, have an advantage in their comprehensiveness. Unlike the German Code, they do not depend upon a mountain of legal scholarship for their application, but rather seek to provide, within their statutory terms, a full set of the rules needed to resolve almost any criminal issue. But despite the practical appeal of American code approach, there is a serious limitation on their influence on codification in other countries, and, more importantly, within the USA: how can one know what the American rule is when there are in fact fifty-two American rules?

Each of the fifty states, the District of Columbia, and the federal government has its own criminal code. (Contrary to the assumption of many in other countries, the federal criminal code has little role in shaping and stating American criminal law. The U.S. Constitution gives police power to the states and, as a result, the federal criminal law has limited practical significance beyond organized crime and drug cases.) Knowing the American rule could be of enormous help to those wishing to take account of the majority American position in formulating their own criminal law.

The American rule can also have significant influence in state legislatures. At present, states are left to speculate about the rule most commonly adopted by their peers, generally acting on what is taken to be the common wisdom. But the common wisdom is commonly wrong, and understandably so. It is a major research undertaking to determine the majority rule among the fifty-two jurisdictions on any matter. Thus, state legislatures considering criminal law reform are often left to ignore what other states have done in the area, to guess what the majority rule might be, or to focus on just a few states without knowing whether those states reflect a common or an outlier position among the fifty-two jurisdictions.

This difficulty is even more severe for judges, especially judges in the federal system and in the quarter of the states in which the criminal law was never reformulated into a comprehensive modern criminal code, for these judges are sometimes left with the task of constructing the legal rules that are missing from their often-skeletal codes. An individual judge does not have the ability to appoint a criminal law codification commission or to turn to a legislative research office to undertake the major research required to reliably determine the American rule and its alternatives.

This article seeks to remedy that unfortunate situation —or at least to make a start of it - with an analysis of the American rules relating to general defenses to criminal liability. We encourage others to join in the larger project of drafting a comprehensive "ACC" that will reflect the majority position on all major topics of substantive criminal law among the U.S. jurisdictions.

In Section 1, we set out our general plan for the "majority code" provisions relating to general defenses, and in Section 2, we provide the text for three 
chapters of the ACC capturing the majority view for those defenses. For each defense, we provide commentary explaining how we reached our conclusions, reporting significant minority positions, and comparing the majority results to the two existing modern model codes: the MPC, and the proposed code of the National Commission on Reform of Federal Criminal Law (National Commission), which some states used as a model after its promulgation in 1971.

Building on the extensive research conducted in Section 2, Section 3 explores various ways in which this data can advance the study of criminal law by both uncovering previously unexamined patterns among different statutory positions and previously unknown correlations with a variety of external factors. The resulting insights can help set an agenda for further research by criminal law scholars and social scientists. Using the framework of "Doctrinal Correlation Analysis", (Robinson 2014, p. 11-14) we devise tools and begin the examination of questions such as: "What is the relationship between jurisdictions' views on different contested issues within a particular defense?"; "Are jurisdictions consistently strict or lenient in granting criminal law defenses?"; and, "Do states' characteristics-such as violent crime rate, racial composition, or population size-bear on the former questions, and to what extent?"

\section{THE CHALLENGE OF DEFINING AN ACC}

No doubt the enormity of the task helps explain why such a project has not been done before. We are in debt to the Criminal Law Research Group at the University of Pennsylvania Law School, whose devoted research efforts made this project possible. The Group collected every statute relating to criminal defenses in every ACC, filled in the statutory holes with the controlling case law, and systematically organized them to allow the analyses that follow.

In Section 2, we take up each defense recognized by a majority of American jurisdictions. The analysis of each defense offers a statutory formulation that, as best as we can tell, approximates the majority American view. Together, these provisions represent the "General Defenses" portion of the ACC.

For a broader perspective of our undertaking, consider the following outline of the project. Our codification follows this plan (Chapters 1 and 2 of the ACC are reserved for the code's general principles of liability $)^{1}$ :

CH. 3 General Principles Of Justification

$\$ 301$. Lesser Evils

\$302. Execution of Public Duty

1 See Robinson 1997, Section 2; Robinson 1982, pp. 199-291; Robinson 2009, pp. 343-53, 361-63. 
$\$ 303$. Defense of Persons

$\$ 304$. Defense of Property

$\$ 305$. Law Enforcement Authority

$\$ 306$. Authority of Persons with Special Responsibility

$\$ 307$. Mistake as to a Justification

CH. 4 General Principles of Excuse

$\$ 401$. Insanity

$\$ 402$. Involuntary Intoxication

$\$ 403$. Immaturity

$\$ 404$. Duress

$\$ 405$. Involuntary Act or Omission

$\$ 406$. Reasonable Mistake of Law

CH. 5 Other Bars to Liability

$\$ 501$. All Offenses Defined by Statute

$\$ 502$. Statute of Limitations

$\$ 503$. Entrapment

The task of determining the majority view on a defense is considerably more complicated than one might first think. A majority of jurisdictions may agree on issue A within a defense, but that group may disagree on issues B and C. We have sought to determine the majority view on each individual issue. Thus, the majority formulation of a defense will include the majority view on issues $\mathrm{A}, \mathrm{B}$, and $\mathrm{C}$, even if only a minority of jurisdictions take such a view on all three. ${ }^{2}$

A majority on an issue requires twenty-seven of the fifty-two jurisdictions, of course, but a few jurisdictions, especially those without modern codes, have incompletely defined defenses. Where there is no controlling statute in a jurisdiction, we look to the case law. But even then, some jurisdictions have simply not faced certain issues. (Notice a few empty cells in the Appendix A Summary Citation Table.) In these few instances, we have had to base our formulation of the majority view on a majority of those jurisdictions that have taken a position.

To give the reader a more in-depth sense of the diversity of opinions on an issue, we also report and analyze the significant minority positions for each defense-significant because of either the number of adherents (some majority positions are only the barest of majorities) or the theoretical issues they raise. For similar reasons, we also compare the majority view to the positions taken by the prominent model codes.

2 The classification we make concerning each jurisdiction's law on a given issue is our best approximation. For instance, while many statutory formulations use similar language, some are entirely unique. For this latter group, we make our best effort to group them with the defense formulations on the issue that have the most similar effect. 
We provide those additional analyses to show that a view being held by a majority does not make it the best view. Legislatures, drafting commissions, or judges looking to our analyses for help may find a minority view more attractive, depending upon the reasons behind its departure. The "majority view" formulation we give is purely a reporting exercise; it is not offered as a recommended provision.

Finally, in the interests of space and clear organization, many of the footnotes in this article reference only the names of the jurisdictions we cite in support of positions in the text. The specific law underlying and supporting these citations can be found in the Citation Table in the Appendix A.

\section{THE AMERICAN GENERAL DEFENSES TO CRIMINAL LIABILITY}

\subsection{Chapter 3. General Principles of Justification}

Below are our formulations that reflect the majority view of each justification defense in American criminal law. ${ }^{3}$ We have also adopted a scheme of defenses that reflects the majority view in organizing justifications. So, for example, though some jurisdictions provide separate defenses for self-defense and defense of others, the majority combine these into a single defense of persons, so that is the approach we take.

The reader will notice that certain words or phrases in our proposed justification defenses appear in brackets. This is due to our analysis of the Mistake as to Justification defense in section 307. This examination produces two possible methods for presenting this defense, either: (1) embedding it in every other justification defense through the language in brackets (typically "reasonably believes"); or (2) segregating it out into its own stand-alone defense, a draft of which is produced in section 307. Although the majority of American jurisdictions utilize the first method, we recommend the second. We had drafted the statutes using the "embedded" approach, but by adding the bracketed language we preserve the ability of jurisdictions to see how one might take the segregated-defense approach instead.

3 Naturally, the law across jurisdictions is in a nearly constant state of revision. In general, we rely on the law as it was on September 13, 2013. Nevertheless, we incorporate several more recent authorities that were brought to our attention before submitting this article for publication. See, e.g., State v. Devens, 852 N.W.2d 255 (Minn. 2014). 


\subsection{1. \$301. Lesser Evils.}

The majority view of the Lesser Evils defense among American jurisdictions might be stated as follows:

Section 301. Lesser Evils.

(1) An actor is justified in engaging in otherwise criminal conduct if [he reasonably believes] his conduct is necessary to avoid an imminent harm or evil to himself or to another, and:

(a) the harm or evil [sought to be] avoided is greater than that sought to be prevented by the law prohibiting the actor's conduct;

(b) neither the Code nor other law defining the offense provides exceptions or defenses dealing with the specific situation involved; and

(c) a contrary legislative balance does not otherwise plainly appear.

(2) The defense is not available when the actor was culpable in creating the harm or evil to be avoided.

At least forty-five jurisdictions and the MPC recognize a lesser evils defense. ${ }^{4}$ This defense requires that the actor's conduct be to prevent a harm or evil greater than that caused by violating the law. Some jurisdictions provide a very broad formulation; for example, Georgia's lesser evils defense reads, "[t]he defense of justification can be claimed... [in instances] which stand upon the same footing of reason and justice as those enumerated in this article" (Ga. Code Ann. \$ 16-3-20 (2013)); see also Tarvestad v. State, 261 Ga. 605, 606 (1991). In contrast, the typical common law formulation reads,

(1) that the defendant reasonably believed that his action was necessary to avoid an imminent threat of death or serious bodily injury to himself or others, (2) that the defendant did not intentionally or recklessly place himself in a situation in which it would be probable that he would be forced to choose the criminal conduct, (3) that there

4 See the MPC \$ 3.02. See, e.g., Alabama, Alaska, Arizona, Arkansas, California, Connecticut, Colorado, Delaware, District of Columbia, Florida, Georgia, Hawaii, Idaho, Illinois, Indiana, Iowa, Kentucky, Louisiana, Maine, Massachusetts, Michigan, Minnesota, Mississippi, Missouri, Montana, Nebraska, Nevada, New Hampshire, New Jersey, New Mexico, New York, North Carolina, North Dakota, Ohio, Oregon, Pennsylvania, South Carolina, South Dakota, Tennessee, Texas, Virginia, Vermont, Washington, West Virginia, and Wisconsin. The National Commission does not recognize a lesser evils defense because, in its view, "the so-called 'choice of evils' rule, i.e., that emergency measures to avoid greater injury may be justified, has not been included in this Chapter on the view that, while its intended application would be extremely rare in cases actually prosecuted, even the best of statutory formulations (see N.Y. Pen. L. 5 35.10) is a potential source of unwarranted difficulty in ordinary cases, particularly in the contest of the adoption of the broad mistake of fact and law provisions found in the Code". National Commission's Report, Chapter 6: Defenses Involving Justification and Excuse, p. 43. 
existed no other adequate means to avoid the threatened harm except the criminal conduct, (4) that the harm sought to be avoided was more egregious than the criminal conduct perpetrated to avoid it, and (5) that the defendant ceased the criminal conduct as soon as the necessity or apparent necessity for it ended. (Bozeman v. State, 714 So. 2d 570, 572 (Fl. Ct. App. 1998)

Finally, some jurisdictions articulate their lesser evils defenses by lumping it in with necessity, duress, or general justification defenses. See, e.g., 720 Ill. Comp. Stat. Ann. $\$$ 5/7-13; Sam v. Commonwealth, 13 Va.App. 312, 323 (Va. Ct. App. 1991); and N.Y. Penal Law $\$ 35.05$.

Jurisdictions' disagreements about lesser evils primarily revolve around five issues, namely (a) how to define the conflicting evils that must be facing the actor; (b) what temporal requirement must be met for the actor's conduct to be truly "necessary" at that time; (c) whether to codify the requirement that more specific defenses be used, instead of lesser evils, wherever they apply; (d) whether the defense ought to be available where the legislature has set a priority of harms that conflicts with the actor's choice; and (e) whether the defense is available where the actor created the situation necessitating a choice between harms.

(a) What competing evils must be facing the actor? While every jurisdiction recognizing a lesser evils defense generally requires, on balance, that the harm or evil actually caused by the defendant be less than the harm or evil prevented, jurisdictions vary widely in the language they use to describe it. A thirty-fourjurisdiction majority generally compares the harm prevented by the actor to the harm the law sought to avoid by prohibiting the action. ${ }^{5}$ Beyond that, a small minority of jurisdictions recognizes specific exceptions to the defense, although they do not agree on what those exceptions ought to be. ${ }^{6}$ For example, some jurisdictions refuse to give a defense in the case of murder. See, e.g., Ariz. Rev. Stat. Ann. $\$ 13-417$. ("An accused person may not assert [this] defense ... for offenses involving homicide or serious physical injury.”) Presumably, a jury would reach the same conclusion by simply balancing interests without relying upon a specified exception. It is also likely that the lesser evils defense would be preempted in such a case by other justification defenses, so it is unclear whether specified exceptions fundamentally alter a jury's ultimate conclusion.

5 Alabama, Arkansas, Arizona, California, Colorado, Connecticut, Delaware, District of Columbia, Florida, Hawaii, Idaho, Illinois, Indiana, Iowa, Kentucky, Maine, Minnesota, Mississippi, Missouri, Nebraska, New Hampshire, New York, North Carolina, North Dakota, Ohio, Oklahoma, Oregon, Pennsylvania, South Carolina, Tennessee, Texas, Vermont, Virginia, and Washington.

6 See, e.g., Arizona, Arkansas, Hawaii, Kentucky, Maine, Maryland, Missouri, New Hampshire, Oklahoma, Washington, and Wisconsin. 
A significant minority of seventeen jurisdictions explicitly refuses to make a lesser evils defense available if there was a readily available and less harmful alternative. ${ }^{7}$ But if there is an alternative, then the actor does not truly face a lesser evil, and his conduct is not "necessary"; thus, this restriction is already implicitly contained within the majority rule.

(b) What must be the timing of the threat when a person acts to avoid the greater evil in order for the act to be truly "necessary"? A twentyeight-jurisdiction majority requires that the impending harm be "imminent" at the time of the defendant's conduct. ${ }^{8}$ This means that the harm sought to be avoided through the actor's conduct must be just about to happen or actually happening, not a threat in the future. This view is particularly popular among jurisdictions that have not codified their lesser evils defenses.

(c) If the lesser evils defense and another more specific defense both apply to a given situation, should lesser evils be unavailable? The majority of jurisdictions probably disallow the defense in such instances, though only a few jurisdictions, like the MPC $\$ 3.02(1)(\mathrm{b})$, are explicit about this preference. ${ }^{9}$ On the contrary, no jurisdiction disagrees with the rule. One widely accepted tenet of statutory construction is that the specific controls the general. See Mesa Petroleum Co. v. F.E.R.C., 688 F.2d 1014, 1016 (5th Cir. 1982). In practice, the majority of jurisdictions give priority to the defense that most narrowly addresses the situation at hand, relegating the broad lesser evils defense to serve as a "catch-all" justification to be used only if no other applies. For clarity, the majority formulation above includes this explicit requirement in Subsection (1)(b).

(d) Should the lesser evils defense be available where the legislature has set a priority of harms or evils that conflicts with the actor's choice? A majority of jurisdictions do not allow the defense in this type of situation. ${ }^{10}$ Though only a

7 Arizona, California, Connecticut, District of Columbia, Florida, Idaho, Indiana, Iowa, Louisiana, Massachusetts, Minnesota, Mississippi, New Mexico, North Carolina, Ohio, South Carolina, and Vermont.

8 Alabama, Arizona, Arkansas, Colorado, Connecticut, Delaware, District of Columbia, Florida, Hawaii, Iowa, Kentucky, Louisiana, Maine, Massachusetts, Michigan, Minnesota, Mississippi, Missouri, Montana, New Mexico, New York, Ohio, Oregon, South Carolina, Tennessee, Texas, Vermont, and Wisconsin.

9 See, e.g., Alaska, Hawaii, Nebraska, New Jersey, New York, and Pennsylvania.

10 Alaska, Arizona, California, Colorado, Connecticut, Florida, Hawaii, Iowa, Maine, Maryland, Massachusetts, Michigan, Minnesota, Missouri, Montana, Nebraska, Nevada, New Hampshire, New Jersey, New York, North Carolina, North Dakota, Ohio, Oklahoma, Oregon, Pennsylvania, South Carolina, South Dakota, Texas, Vermont, and West Virginia. 
minority of jurisdictions codifies this preference, even jurisdictions without an explicit codification on such a rule in fact deny a lesser evils defense when it conflicts with a choice that the legislature has deliberately made. For example, defendants frequently (and unsuccessfully) raise the lesser evils defense in medical marijuana cases, see, e.g., State v. Bonjour, 694 N.W.2d 511 (Iowa 2005); State v. Hanson, 468 N.W.2d 77 (Minn. 1991); State v. Poling, 207 W. Va. 299 (2000), and to justify anti-abortion activities. See, e.g., Allison v. City of Birmingham, 580 So.2d 1377 (Ala. 1991); City of Kettering v. Berry, 567 N.E.2d 316 (Ohio 1990); and City of Helena v. Lewis, 860 P.2d 698 (Mt. 1993). The majority formulation follows the majority rule reflected in the practice of denying the applicability of the defense in such instances. Subsection (1)(c) uses the language of those jurisdictions that codify the rule, which are themselves based upon the MPC section 3.02(1)(c).

(e) Should a lesser evils defense be available for an actor who caused the situation requiring a choice between harms in the first place? A majority of twenty-seven jurisdictions agree that it should not. ${ }^{11}$ This prohibition exists both at common law and in codified jurisdictions. There is no majority consensus, however, regarding the required level of culpability, if any, the actor must have had toward the creation of the emergency. The most common approach within the majority is to simply require that the actor be "without fault" in creating the emergency. ${ }^{12}$ Another common method is the MPC's "sliding scale" approach, in which the availability of the defense is a function of both the actor's culpability in creating the situation and the required culpability of the offense committed to prevent the harm. ${ }^{13}$ An equal number of jurisdictions bar the defense in cases of reckless fault on the part of the actor. ${ }^{14}$ Other jurisdictions also bar it for those who have substantially contributed to the emergency sought to be avoided. ${ }^{15}$ Without consensus, however, a "bare" culpability requirement is included in Subsection (2) of the majority formulation.

11 Alabama, Arizona, Arkansas, California, Colorado, Delaware, Florida, Hawaii, Idaho, Illinois, Indiana, Kentucky, Maine, Maryland, Minnesota, Missouri, Montana, Nebraska, Nevada, New Hampshire, New Mexico, New York, Ohio, Pennsylvania, South Carolina, Vermont, and Washington.

12 Alabama, Colorado, Delaware, Idaho, Illinois, Missouri, Montana, New York, Ohio, South Carolina, Vermont, and Washington.

13 The MPC $\$ 3.02(2)$; Arkansas, Hawaii, Maine, Nebraska, New Hampshire, and Pennsylvania.

14 Arizona, Florida, Kentucky, Maryland, Minnesota, and New Mexico.

15 California, Indiana, and Nevada. 


\subsection{2. \$302. Execution of Public Duty.}

The majority view of the Public Duty defense among American jurisdictions might be stated as follows:

Section 302. Execution of Public Duty.

(1) Except as provided in Subsection (3) of this Section, conduct is justifiable when [the actor reasonably believes] it is required or authorized by:

(a) the law defining the duties or functions of a public officer or the assistance to be rendered to such officer in the performance of his duties; or

(b) the law governing the execution of legal process; or

(c) the judgment, order, or decree of a competent court or tribunal; or

(d) the law governing the armed services or the lawful conduct of war; or

(e) any other provision of law imposing a public duty.

(2) This Section does not apply when other more specific provisions in this Article apply to the situation.

A defense for execution of a public duty is somewhat tautological. It says, in essence, "authorized conduct is justified". It is therefore unsurprising that not all jurisdictions that apply this defense in practice bother to codify it. Even those that do codify it do not necessarily codify everything done in practice. Significantly, however, no jurisdiction embraces a position contradictory to anything in the majority formulation.

There is wide consensus among American jurisdictions concerning both the existence and general contours of the defense for execution of a public duty. In this regard, it is unique among justification defenses. The important features of the defense on which jurisdictions differ include: (a) the sources of authorization to act that the defense protects; (b) whether an actor can obtain a mistake defense if he erroneously but reasonably believes his conduct is authorized; and (c) how generally the defense applies relative to other defenses governing use of force.

(a) What sources of authority generate protected conduct? At least fifty-one jurisdictions generally agree that actions required or authorized by law are justified. ${ }^{16}$ Whether explicitly or not, jurisdictions commonly parse "by law" into five categories: authority of public officers, court orders, legal process, the armed forces, and other public duties. The National Commission does not parse specific sources of authority, choosing instead to retain a general

16 Only the federal position is unconfirmed on this point. 
defense for conduct authorized "by law", see National Commission's Report $\$ 602(1)$, as well as setting forth two additional sources of authority not expressly included in the majority rule, ${ }^{17}$ but perhaps included by its catch-all Subsection (1)(e).

(i) Public Officer: thirty-two jurisdictions explicitly justify conduct authorized by "the law defining the duties or functions of a public officer or the assistance to be rendered to such officer in the performance of his duties". ${ }^{18}$ Many additional jurisdictions arguably support this position in practice, though they do not codify it.

(ii) Court Orders: only twenty-five jurisdictions explicitly justify conduct authorized by court orders, judgments, or decrees. ${ }^{19}$ But every jurisdiction arguably supports this position in practice, though not all codify it. The provision protects the integrity of the legal process by ensuring its directives receive their full effect and ensures people can act on judgments and court orders with confidence that such will provide them legal protection.

(iii) Legal Process: only twenty-three jurisdictions explicitly justify conduct authorized by "the law governing the execution of legal process". ${ }^{20}$ Again, many additional jurisdictions arguably support this in practice, though they do not codify it. The provision largely overlaps with the justification of conduct authorized by court orders since legal processes are "[t $\mathrm{t}$ he proceedings in any action or prosecution" (Garner 2006, p. 569 (defining "process"); ibid. at 264 (defining "execution")). Conduct authorized by the law governing the execution of legal process includes, for example, issuing a summons or seizing property pursuant to a warrant. See, e.g., Jurco v. State, 825 P.2d 909, 911-12 (Alaska Ct. App. 1992) (recognizing State Troopers' authority to seize the plaintiff's vehicle pursuant to a court order). Like the "court orders" authority, this provision protects the integrity of the legal process.

17 They are: (1) conduct directed by a public servant and (2) citizens' arrests. See National Commission’s Report $\$ 602(2)-(3)$.

18 Alabama, Arkansas, Arizona, Colorado, Connecticut, Delaware, Georgia, Hawaii, Illinois, Indiana, Kansas, Louisiana, Maine, Massachusetts, Michigan, Minnesota, Missouri, Nebraska, Nevada, New Hampshire, New Jersey, New Mexico, New York, North Dakota, Oregon, Pennsylvania, South Dakota, Tennessee, Texas, Utah, Washington, and Wisconsin.

19 Alabama, Alaska, Arizona, Arkansas, California, Colorado, Connecticut, Delaware, Hawaii, Kentucky, Maine, Minnesota, Missouri, Nebraska, Nevada, New Hampshire, New Jersey, New Mexico, New York, Oklahoma, Oregon, Pennsylvania, Tennessee, Texas, and Washington.

20 Alaska, Arizona, Arkansas, California, Colorado, Connecticut, Delaware, Hawaii, Kentucky, Maine, Minnesota, Missouri, Nebraska, Nevada, New Hampshire, New Jersey, New Mexico, Oklahoma, Oregon, Pennsylvania, Tennessee, Texas, and Vermont. 
(iv) Armed Forces: only twelve jurisdictions explicitly justify conduct authorized by the law governing the armed forces or the lawful conduct of war. ${ }^{21}$ But the states do not individually wage war; only the federal government has a military, divided into several branches, that defends the USA as a whole. As a matter of federal law, no state may deny a defense to a soldier acting in obedience to a lawful order of his superior because such obedience is a legal duty (10 U.S.C. $\$ 892(1)$ ); see, e.g., Arce v. State, 202 S.W. 951, 953 (Tex. Crim. App. 1918) (releasing Mexican soldiers from liability for killing an American officer during the Mexican-American War because they were directed to fight according to lawful orders). It is proper, therefore, to include this provision in the majority formulation; though only a minority of states codify it, all are bound by it.

(v) Other Public Duties: only twenty-two jurisdictions follow the MPC by including a catch-all provision for public duties not explicitly enumerated. $^{22}$ Other jurisdictions fail to address this concern; however, there is no significant case law denying such justification. It seems likely that if a jurisdiction's statutes impose a duty, its courts will justify conduct in execution of that duty. Therefore, the majority formulation includes such a catch-all provision.

(b) Can an actor still receive a defense if he reasonably, but erroneously, believes his conduct is authorized? Seven jurisdictions with specific public duty provisions allow this defense when an actor is mistaken so long as he reasonably believes his conduct is authorized. ${ }^{23}$ Seven others with these provisions simply require the actor's subjective belief that his conduct is authorized, imposing no reasonableness requirement. ${ }^{24}$ Yet given the strong support for a reasonable belief requirement for the mistake as to justification defense in general, ${ }^{25}$ the majority rule reflects this approach by inserting the relevant language in brackets. The issue of mistake as to a justification is taken up and discussed more fully in section 307.

(c) Should other, more specifically applicable defenses supersede the general public authority defense? Like the choice of evils defense, a defense for the

21 Colorado, Connecticut, Delaware, Hawaii, Missouri, Nebraska, New Jersey, New Hampshire, Oregon, Pennsylvania, Texas, and Vermont.

22 The MPC $\$$ 3.03(1)(e); Alabama, Alaska, Arizona, Arkansas, Connecticut, Delaware, Georgia, Hawaii, Indiana, Kentucky, Louisiana, Maine, Missouri, Nebraska, New Hampshire, New Jersey, New York, Oregon, Pennsylvania, Tennessee, Texas, and Utah.

23 Alaska, Arizona, Arkansas, Missouri, New Jersey, Tennessee, and Texas.

24 Delaware, Hawaii, Kentucky, Maine, Nebraska, New Hampshire, and Pennsylvania.

25 See infra section 307. 
execution of a public duty stands as a backstop for those cases in which other more specific public duty defenses-such as law enforcement authority or the defense for persons with special responsibility—does not deal with the situation at hand. Eighteen of the nineteen jurisdictions with specific public duty provisions make this limitation explicit, ${ }^{26}$ and the statutory interpretation maxim of "the specific controls the general" would seem to reach the same result in most other jurisdictions. ${ }^{27}$ Subsection (2) makes this majority rule explicit.

\subsection{3. \$303. Defense of Persons.}

The majority view of the Defense of Persons justification among American jurisdictions might be stated as follows:

Section 303. Defense of Persons.

(1) An actor is justified in using force that [he reasonably believes] is necessary to defend himself or a third person against imminent unlawful force by an aggressor.

(2) The use of deadly force in self-defense is justified if [the actor reasonably believes that] such force is necessary to protect himself or a third person against death, serious bodily injury, sexual intercourse compelled by force, or kidnapping.

(3) An actor is not justified in using force against another person:

(a) if he intentionally provoked unlawful action by the other person in order to cause bodily injury to the person;

(b) if he is the initial aggressor, unless he has withdrawn from the encounter and effectively communicated his withdrawal to the other person, but the other person persists in continuing the conflict by force;

(c) if the force was the product of mutual combat by agreement not specifically authorized by law; or

(d) to resist an arrest that the actor knows is being made by a peace officer, even if the arrest is unlawful, except force may be used to resist an arrest that is unlawful because the officer is using excessive force.

(4) An actor has no duty to retreat from a place he has a right to be before using deadly or non-deadly force that is necessary to defend himself or a third person.

Every jurisdiction embraces a justification for both self-defense and defense of third persons. The defense of others is often included within the self-defense

26 Alabama, Alaska, Arizona, Colorado, Connecticut, Delaware, Hawaii, Kentucky, Maine, Missouri, Nebraska, New Hampshire, New Jersey, New York, Oregon, Pennsylvania, Tennessee, and Texas.

27 See supra section 301(b). 
provision but sometimes codified separately: twenty-four jurisdictions include defense of others in the same provision as self-defense ${ }^{28}$; twelve jurisdictions treat defense of others as a separate defense. ${ }^{29}$ (In sixteen jurisdictions, both are common law defenses found only in case law. ${ }^{30}$ ) Following the lead of the majority of the jurisdictions with a codified defense, the majority formulation uses a single, combined defense.

Every jurisdiction recognizes a person's right to defend himself or another against unlawful force. Jurisdictions disagree, however, regarding a wide variety of related issues, most prominently: (a) what constitutes the "unlawful force" that triggers a right to use defensive force; (b) what temporal requirement must be met for an actor's conduct to be truly "necessary" at that time; (c) what amount of force may be used; (d) when deadly force may be employed; (e) whether and in what situations initial aggressors can claim self-defense; (f) the legal effect of provocation of an encounter; (g) the legal effect of mutual combat; (h) whether there is a right to resist an unlawful arrest; and (i) whether there is a duty to retreat from unlawful aggression before using deadly force.

(a) What constitutes the "unlawful force" that triggers a right to use defensive force? It appears that there is general agreement on this point but few explicit statutory definitions codifying this shared understanding. Force that is objectively justified is not "unlawful force", but force that is only excused (such as force by a person acting under insanity, duress, or immaturity) is "unlawful force" and will trigger a right of defense even though the attacker may be excused for the attack. Similarly, force by an actor who is mistaken in his belief that his conduct is justified-he "believes" it is justified, but is wrong-is also "unlawful force" that triggers a right of defense. And force that may have a nonexculpatory defense, such as diplomatic immunity, also constitutes "unlawful force". We have found no cases that contradict this principle, but only the Mode Penal Code and a few states that follow it provide an explicit definition. See, e.g., Ariz. Rev. Stat. Ann. \$ 13-105(40); and 11 Del. C. $\S 471(\mathrm{~d})$.

28 Alabama, Arkansas, Colorado, Connecticut, Florida, Georgia, Idaho, Illinois, Indiana, Iowa, Kansas, Maine, Michigan, Minnesota, Missouri, Montana, New Hampshire, New York, Oklahoma, Oregon, South Dakota, Utah, Washington, and Wisconsin.

29 Alaska, Arizona, Delaware, Hawaii, Kentucky, Louisiana, Nebraska, New Jersey, North Dakota, Pennsylvania, Tennessee, and Texas.

30 California, District of Columbia, Maryland, Massachusetts, Mississippi, Nevada, New Mexico, North Carolina, Ohio, Rhode Island, South Carolina, Vermont, Virginia, West Virginia, Wyoming, and Federal. 
The MPC Section 3.11(1) provides:

(1) "unlawful force" means force, including confinement, which is employed without the consent of the person against whom it is directed and the employment of which constitutes an offense or actionable tort or would constitute such offense or tort except for a defense (such as the absence of intent, negligence, or mental capacity; duress; youth; or diplomatic status) not amounting to a privilege to use the force. Assent constitutes consent, within the meaning of this Section, whether or not it otherwise is legally effective, except assent to the infliction of death or serious bodily harm.

The MPC's provision is complex and obscure. It relies upon the tort concept of "privilege", which is nowhere defined, because the Code has tainted its own definition of "justified" by including it in mistakes as to justification. A person is "justified" under the code if he (even wrongly) believes that he is justified. The Code drafters cannot, then, define the triggering condition for defensive force as any "unjustified force" because, under their use of the term "justified", some forms of "justified" conduct cannot be lawfully resisted (those that are objectively, actually justified) and some forms can be lawfully resisted (those based upon a mistaken belief in justification).

If a jurisdiction were to draft justifications objectively and deal with the issue of mistake as to a justification under a separate provision-as proposed in section 307-then the triggering condition for defensive force could be simply "unjustified force", without the need for an additional, special definition. But if mistakes as to a justification are mixed with objective justifications by defining justifications subjectively, as the MPC does, then a convoluted provision like section 3.11(1) is required. It is probably the difficulty of this drafting approach by the MPC that explains why so few jurisdictions based on it provide a definition of "unlawful force". 31

(b) What temporal requirement must be met for an actor's conduct to be truly "necessary" at that time? The majority view, held by forty-four jurisdictions, requires that the unlawful force or threat be "imminent" before defense force becomes authorized. ${ }^{32}$

31 For a full discussion of the formulation and content of a Mistake as to Justification defense, see section 307.

32 Alabama, Alaska, Arkansas, California, Colorado, Connecticut, District of Columbia, Florida, Georgia, Idaho, Illinois, Indiana, Iowa, Kansas, Kentucky, Louisiana, Maine, Maryland, Massachusetts, Michigan, Minnesota, Mississippi, Missouri, Montana, Nevada, New Hampshire, New Mexico, New York, North Carolina, North Dakota, Ohio, Oklahoma, Oregon, Rhode Island, South Carolina, South Dakota, Utah, Vermont, Virginia, Washington, West Virginia, Wisconsin, Wyoming, and Federal. 
In contrast, the MPC and a minority of eight jurisdictions look to the timing of the need for the defensive force, rather than the timing of the threat: it requires that the use of force be "immediately necessary". ${ }^{33}$ Under this view, a person may use force when and only when it becomes necessary. Thus, if waiting for the threat to become imminent would make it difficult for the actor to defend himself, he may act earlier: at the moment just before his defensive force would become ineffective.

(c) What amount of force may be used in defense of persons? A majority of thirty-one jurisdictions require that an actor uses only the level of defensive force that he reasonably believes is necessary. ${ }^{34}$ Eight jurisdictions drop the reasonableness requirement and simply require the actor to "believe" that the force is necessary - a completely subjective criterion. ${ }^{35}$ Thirteen others make no mention of the actor's belief, essentially requiring that the defensive force used be objectively necessary. ${ }^{36}$ (The issue of mistake as to justification is taken up and discussed more fully in section 307.) Furthermore, there are typically special limitations on the use of deadly force.

(d) When may deadly force be used in defense of persons? A majority of thirty jurisdictions allow an actor to use deadly force against threats of death, serious bodily injury, rape, and kidnapping. This majority includes: four jurisdictions, following the MPC, that allow deadly force against the explicit crimes listed $^{37}$; seven jurisdictions that embrace those specified crimes, but add robbery $^{38}$; thirteen jurisdictions that allow deadly force against any forcible felony ${ }^{39}$; and six jurisdictions that allow it against any felony. ${ }^{40}$ The National Commission allows use of deadly force against all forcible felonies (National Commission’s Report $\$ 607(2)(b))$. A significant minority of twenty jurisdictions provides a more narrow defense that allows deadly defensive force only

33 The MPC $\$$ 3.04(1); Arizona, Delaware, Hawaii, Nebraska, New Jersey, Pennsylvania, Tennessee, and Texas.

34 Alabama, Alaska, Arizona, Arkansas, California, Colorado, Connecticut, District of Columbia, Florida, Georgia, Idaho, Illinois, Indiana, Iowa, Kansas, Louisiana, Maine, Maryland, Michigan, Missouri, Montana, New Hampshire, New Jersey, New York, Oregon, Tennessee, Texas, Utah, Vermont, Wisconsin, and Federal.

35 Delaware, Hawaii, Kentucky, Nebraska, Nevada, North Carolina, Pennsylvania, and West Virginia.

36 Massachusetts, Minnesota, Mississippi, New Mexico, North Dakota, Ohio, Oklahoma, Rhode Island, South Carolina, South Dakota, Virginia, Washington, and Wyoming.

37 The MPC $\$ 3.04(2)(b)$; Delaware, Hawaii, Nebraska, and Pennsylvania.

38 Alabama, Alaska, Colorado, Maine, New Hampshire, New York, and Texas.

39 Arkansas, Florida, Georgia, Illinois, Indiana, Iowa, Kentucky, Missouri, Montana, Nevada, North Dakota, Oregon, and Utah.

40 California, Idaho, Mississippi, Oklahoma, South Dakota, and Washington. 
against threats of death or serious bodily injury. ${ }^{41}$ Michigan allows deadly force against threats of death, serious bodily injury, and serious sexual offenses (Mi. Comp. Laws Ann. $\$ 780.972$ (West 2006)). Finally, Rhode Island embraces a "totality of the circumstances" approach to determine if deadly force is necessary in a given situation (State v. Ventre, 811 A.2d 1178 (R.I. 2002)).

Note that the fifty-two jurisdictions are split twenty-six to twenty-six as to whether robbery ought to automatically trigger the right to use deadly force in defense of persons. ${ }^{42}$ If any one jurisdiction changes its position to embrace robbery, it will become the majority view, requiring that our proposed draft text be amended to include it in Subsection (2) above. ${ }^{43}$

(e) If an initial aggressor chooses to withdraw from a fight, can he regain the right of self-defense? A thirty-six-jurisdiction majority provides that an aggressor who withdraws and effectively communicates his withdrawal may claim self-defense if the other party unlawfully continues to attack. ${ }^{44}$ The National Commission and North Dakota simply require an aggressor to "indicate" his withdrawal, National Commission’s Report $\$$ 603(b)(ii); and N.D. Cent. Code $\$ 12.1-05-03$, whereas the majority text requires he "effectively communicate" it. ${ }^{45}$ At least eleven other jurisdictions require an aggressor to withdraw before regaining the right of self-defense, but do not mention a communication requirement. ${ }^{46}$

41 Arizona, District of Columbia, Connecticut, Kansas, Louisiana, Maryland, Massachusetts, Minnesota, New Jersey, New Mexico, North Carolina, Ohio, South Carolina, Tennessee, Vermont, Virginia, West Virginia, Wisconsin, Wyoming, and Federal.

42 Cf. notes 50-52 (including robbery) with notes 49, 54-56 (excluding robbery).

43 Please note that while there is a majority of jurisdictions taking the position that deadly force is justified in the four specific cases enumerated in Subsection (2), there is no such majority to support the claim that these four are the only cases in which deadly force is justified (e.g., the even split between jurisdictions in the case of robbery). For this reason, the wording of Subsection (2) above does not preclude the possibility that deadly force may be justified in other, non-enumerated cases. The authors thank Professor Eugene Volokh for his insightful comments on an earlier draft of this Subsection, leading to its present formulation.

44 Alabama, Alaska, Arizona, Arkansas, California, Colorado, Connecticut, Delaware, District of Columbia, Florida, Georgia, Hawaii, Illinois, Indiana, Iowa, Kansas, Kentucky, Louisiana, Maine, Massachusetts, Michigan, Minnesota, Missouri, Montana, Nevada, New Hampshire, New York, North Carolina, Oregon, South Carolina, Tennessee, Texas, Utah, Washington, Wisconsin, and Wyoming.

45 The positions of Nebraska, Rhode Island, South Dakota, and Vermont could not be confirmed.

46 See, e.g., Idaho, Maryland, Mississippi, New Jersey, New Mexico, Ohio, Oklahoma, Pennsylvania, Virginia, West Virginia, and Federal. 
The majority view differs from the MPC only in form, not result. While the Code does not explicitly state such a rule, its defense requirements implicitly support it. If an aggressor withdraws, and effectively communicates this, then defensive force is no longer "immediately necessary" and the defender is no longer justified in its use. Continued use of force then becomes unlawful, which triggers a right of self-defense with the initial aggressor.

(f) Can an actor attack to provoke a response, then justifiably use force in self-defense? If an actor attacks another, provoking an attack in response, he cannot lawfully defend against that responsive force because that lawful response is not "unlawful", and thus does not trigger a right for him to use force in self-defense. However, if the defender uses excessive force, or in some other way exceeds the authorization of the defensive force justification, then the initial attacker regains the right of self-defense.

But if the initial aggressor's original attack was for the purpose of provoking an unlawful response that would then allow him to use force (perhaps expecting or hoping that the defender would overreact), a majority of forty-six jurisdictions either explicitly or implicitly bar his use of defensive force. ${ }^{47}$ The MPC and a six-jurisdiction minority deviate from the majority rule only in barring the original, provoking aggressor from defending himself with deadly force. ${ }^{48}$ That is, under the MPC, the initial aggressor may use force to defend against defensive force that he has provoked for that purpose, as long as he does not use deadly force.

(g) It is not uncommon for participants in a fight to have entered it by mutual agreement. What legal effect does mutual combat have upon the right of self-defense? A majority of at least fifty-one jurisdictions do not recognize the use of force as justified when an actor is involved in consensual mutual combat not specifically authorized by law. ${ }^{49}$ Some jurisdictions mitigate offenses committed in mutual combat ${ }^{50}$; still others allow a combatant to

47 Alabama, Alaska, Arizona, Arkansas, California, Colorado, Connecticut, District of Columbia, Florida, Georgia, Idaho, Illinois, Indiana, Iowa, Kansas, Kentucky, Louisiana, Maine, Maryland, Massachusetts, Michigan, Minnesota, Mississippi, Missouri, Montana, Nevada, New Hampshire, New Mexico, New York, North Carolina, North Dakota, Ohio, Oklahoma, Oregon, Rhode Island, South Carolina, Tennessee, Texas, Utah, Vermont, Virginia, Washington, West Virginia, Wisconsin, Wyoming, and Federal.

48 The MPC $\$ 3.04(2)(\mathrm{b})(\mathrm{i})$; Delaware, Hawaii, Nebraska, New Jersey, Pennsylvania, and South Dakota.

Only Rhode Island could not be confirmed.

50 See, e.g., Hawaii, Nebraska, North Carolina, Pennsylvania, South Dakota, Vermont, Virginia, Washington, West Virginia, and Wisconsin. 
regain the right of self-defense if he withdraws from the encounter. ${ }^{51}$ But none read a full justification into the consent to fight. ${ }^{52}$ Agreement may be made verbally or through actions that clearly indicate consent.

The MPC does not include a section specifically addressing the mutual combat by agreement situation, but it might reach a similar result. Under section 2.11(2), consent can be a defense to assault that causes bodily injury, which means that the use of force by each fighter would not trigger a right of self-defense because it is not defending against "unlawful" force. A right of selfdefense would arise only if an actor was threatened with "serious bodily injury", for which consent is legally ineffective under section 2.11(2).

(h) May an actor ever use force to resist arrest? When police make arrests, they must often use force. That force, without a special exception, might trigger a right to self-defense, at least if the arrest was unlawful. A majority of thirty-six jurisdictions, following the MPC $\$ 3.04(2)(a)(i)$, do not permit the use of force to resist an arrest made by a peace officer, even if the arrest is actually unlawful. ${ }^{53}$ Seven jurisdictions include this limitation in their defense of person's justification ${ }^{54}$; fifteen jurisdictions include this restriction in a separate portion of their criminal codes ${ }^{55}$; and fourteen jurisdictions have this limitation in their case law. ${ }^{56}$

A minority of fifteen jurisdictions, however, differs from the majority by denying the right to self-defense against lawful arrests but allowing it against unlawful arrests. ${ }^{57}$ Yet, it is unclear what level of awareness or belief a person

51 See, e.g., Idaho, Iowa, Michigan, Minnesota, and Oklahoma.

52 Also note that consent as to some combat does not necessarily preclude the right to self-defense if the encounter escalates beyond the sort of combat agreed upon (e.g., one combatant pulls out a gun during a mutually agreed upon fistfight). See Commonwealth v. Barber, 18 Mass. App. Ct. 460 (1984).

53 Alaska, Arizona, Arkansas, California, Colorado, Connecticut, Delaware, District of Columbia, Florida, Hawaii, Idaho, Illinois, Indiana, Iowa, Kansas, Kentucky, Maine, Massachusetts, Minnesota, Missouri, Montana, Nebraska, New Hampshire, New Jersey, New Mexico, New York, North Dakota, Oregon, Pennsylvania, Rhode Island, South Dakota, Texas, Utah, Vermont, Wisconsin, and Wyoming.

54 Arizona, Delaware, Hawaii, Kentucky, Nebraska, New Jersey, and Pennsylvania.

55 Alaska, Arkansas, California, Colorado, Connecticut, Florida, Illinois, Iowa, Kansas, Missouri, Montana, New Hampshire, New York, Oregon, and Rhode Island.

56 District of Columbia, Idaho, Indiana, Maine, Massachusetts, Minnesota, New Mexico, North Dakota, South Dakota, Texas, Utah, Vermont, Wisconsin, and Wyoming.

57 Alabama, Georgia, Louisiana, Maryland, Michigan, Mississippi, Nevada, North Carolina, Ohio, Oklahoma, South Carolina, Tennessee, Virginia, Washington, and West Virginia. The Federal rule may differ by circuit. See U.S. v. Walker, 960 F.2d 409 (5th Cir. 1992). 
must have regarding the lawfulness of his arrest-whether he must know, reasonably believe, or simply believe that the arrest is unlawful.

Importantly, however, while an arrestee normally cannot defend against a police officer's use of force when making an arrest, a majority of at least thirty-one jurisdictions explicitly allow one exception: the arrestee may use defensive force if the officer uses excessive force, whether the arrest itself is lawful or not. ${ }^{58}$

(i) If confronted with unlawful force, does one have a duty to retreat from danger if possible, rather than use defensive force? A majority of thirty-three jurisdictions do not require a party to retreat under the threat of unlawful force, even if they could do so with complete safety. ${ }^{59}$ This is the so-called "stand your ground" rule. In contrast, the MPC and National Commission require retreat if possible, at least before deadly force is used. See, e.g., the MPC $\$$ 3.04(2)(b)(ii); and National Commission's Report $\$$ 607(2)(b). Under the MPC, an individual cannot use deadly defensive force if he is able to retreat to safety or surrender possession of something to which the person attacking asserts a claim of right. Like the majority, however, the MPC does not set a duty to retreat before using non-deadly force. A significant minority of eighteen jurisdictions side with the MPC by recognizing a duty to retreat at least before deadly force may be used: fifteen jurisdictions explicitly require retreat before the use of deadly force ${ }^{60}$; and three require it before the use of any force: Com. v. Toon, 55 Mass. App. Ct. 642 (2002); Com. v. Barbosa, 463 Mass. 116 (2012); Iowa Code $\$ 704.1$; State v. Marin, 776 N.W.2d 111 (Iowa Ct. App. 2009); and State v. Devens, 852 N.W.2d 255, 258 (Minn. 2014). North Carolina recognizes a duty to retreat, but only when threatened with force that does not risk death or serious bodily injury. See N.C. Gen. Stat. \$ 14-51.3; State v. Brown, 117 N.C. App. 239 (1994); and State v. Everett, 163 N.C. App. 95 (2004). It does not require retreat when force threatens such elevated harm.

58 See, e.g., Alaska, Arizona, Arkansas, California, Colorado, Connecticut, Delaware, District of Columbia, Florida, Georgia, Hawaii, Idaho, Illinois, Indiana, Kansas, Kentucky, Louisiana, Maine, Massachusetts, Michigan, Minnesota, Mississippi, Missouri, Nebraska, New Jersey, New Mexico, New York, North Carolina, North Dakota, Oregon, and South Carolina. Nevada requires that a peace officer use both unlawful and excessive force in order for an individual to the have the right of self-defense.

59 Alabama, Alaska, Arizona, California, Colorado, District of Columbia, Florida, Georgia, Idaho, Illinois, Indiana, Kansas, Kentucky, Louisiana, Michigan, Mississippi, Montana, Nevada, New Hampshire, New Mexico, Oklahoma, Oregon, South Carolina, South Dakota, Tennessee, Texas, Utah, Vermont, Virginia, Washington, West Virginia, Wisconsin, and Federal.

60 Arkansas, Connecticut, Delaware, Hawaii, Maine, Maryland, Missouri, Nebraska, New Jersey, New York, North Dakota, Ohio, Pennsylvania, Rhode Island, and Wyoming. 


\subsection{4. \$304. Defense of Property.}

The majority view of the Defense of Property among American jurisdictions might be stated as follows:

Section 304. Defense of Property

(1) The use of force upon or toward the person of another is justifiable when and to the extent [the actor reasonably believes] that such force is necessary:

(a) to prevent the person's unlawful trespass on real property or unlawful interference with personal property in the actor's possession; or

(b) to retake the actor's personal property or to re-enter real property immediately following unlawful dispossession of it.

(2) The use of deadly force is not justified under this Section,

(3) "Possession" means having or exercising dominion or control over property.

A majority of at least forty-five jurisdictions authorize the use of force in defense of both real and personal property under a general "Defense of Property" heading. ${ }^{61}$ For real property, the right to use defensive force is triggered by a need to prevent or terminate trespass on the actor's land. For personal property, the right to use defensive force is triggered by the need to prevent or terminate an unlawful interference with the actor's personal property.

Defense of property formulations differ regarding a number of issues, namely: (a) whether there is a temporal requirement for force to be truly necessary; (b) whether the owner must first request that the unlawful aggressor desist in his activity before resorting to force; (c) whether deadly force is authorized; (d) what other limits, if any, are placed upon the use of force; (e) how to define "possession"; (f) whether an actor may use force to retake or reenter his property; (g) whether a claim of right by the dispossessor should limit the actor's right to use force to resist; and (h) whether an actor may use force to protect against all unlawful acts, or only criminal acts.

(a) Should a temporal requirement as to the necessity of force constrain its use? Most jurisdictions embracing a justification for defense of property require that the force used be necessary. This has a temporal requirement implicit in

61 Alabama, Alaska, Arizona, Arkansas, California, Colorado, Connecticut, Delaware, District of Columbia, Florida, Georgia, Hawaii, Idaho, Illinois, Indiana, Iowa, Kansas, Kentucky, Louisiana, Maine, Michigan, Minnesota, Missouri, Montana, Nebraska, New Hampshire, New Jersey, New Mexico, New York, North Carolina, North Dakota, Ohio, Oklahoma, Oregon, Pennsylvania, Rhode Island, South Dakota, Tennessee, Texas, Utah, Virginia, Washington, West Virginia, Wisconsin, and Wyoming. 
it: the actor cannot use force until the time when it actually becomes "necessary" - that is, he could not effectively defend his property if he waited longer. A majority of thirty-four jurisdictions leave it at that, as does the majority formulation above. ${ }^{62}$

Ten minority jurisdictions, however, add an emphasis to this temporal requirement, with seven of them following the MPC in requiring that force be "immediately necessary". ${ }^{63}$ This emphasizes the temporal necessity for the use of force, perhaps making it even more demanding than it would otherwise be. Compare this with the three jurisdictions that require that the threatened force be "imminent", which focuses on the temporal proximity of the threat, rather than on the timing of the needed defensive force: State v. Walsh, 119 P.3d 645, 652 (Ct. App. Id. 2005); Ind. Code $\$ 35-41-3-2$; and State v. Nelson, 329 N.W.2d 643, 646 (Iowa 1983).

(b) Must the property owner request that the aggressor desist before the owner can resort to force? The majority does not explicitly require such a request, although one might argue that it might, in some circumstances, be implicit in the requirement that the use of force be "necessary". If the threat can be effectively neutralized by such a request, then force is not necessary. Five jurisdictions, however, are not content to leave this unstated and follow both the MPC and the National Commission in making the requirement explicit. ${ }^{64}$

(c) Should deadly force be authorized in defense of property? Many jurisdictions expressly prohibit the use of deadly force in defense of property alone, but do allow it in the defense of premises, habitation, or other similar contexts. ${ }^{65}$ The common rationale for these exceptions is the introduction of danger to persons in addition to the property. Even without the rule, however, in many cases such a threat would presumably trigger the Defense of Persons justification. The MPC and National Commission authorize deadly force-but only by cross-reference to such defense of persons. See the MPC $\$ 3.06(3)(d)$;

62 Alabama, Alaska, Arizona, Arkansas, Colorado, Connecticut, District of Columbia, Florida, Georgia, Illinois, Kansas, Louisiana, Maine, Maryland, Michigan, Minnesota, Mississippi, Missouri, Montana, New Hampshire, New Jersey, New Mexico, New York, North Dakota, Ohio, Oklahoma, Oregon, Rhode Island, South Carolina, South Dakota, Utah, Virginia, Washington, and Wisconsin. For a discussion of the difference between "immediate harm" and "immediately necessary action" as qualifiers upon necessity, see section 305(1) Commentary.

63 The MPC $\$ 3.06(1)$. Delaware, Hawaii, Kentucky, Nebraska, Pennsylvania, Tennessee, and Texas.

64 The MPC $\$ 3.06(3)(a)$; National Commission’s Report $\$ 606$; Delaware, Hawaii, Nebraska, New Jersey, North Dakota, and Pennsylvania.

65 See, e.g., Alaska (authorizes deadly force to protect a vehicle and in prevention of theft or carjacking), Colorado (preventing robberies), Georgia (deadly force allowed to prevent forcible felonies), Illinois (same as Georgia), Indiana (deadly force allowed to prevent forcible felonies and protect one's dwelling, curtilage, or occupied motor vehicle), and Louisiana (deadly force allowed to protect one's dwelling, place of work, or motor vehicle). 
and National Commission's Report $\$ 607(2)$. It is generally understood that Defense of Persons offers authority to use defensive force independent of and in addition to Defense of Property. Therefore, despite the numerous and varied exceptions embraced by several jurisdictions that relate to threats to persons, none have been incorporated into the majority formulation of the defense of property justification.

(d) What other limits, if any, should be placed upon the use of force? Beyond the necessity requirement as a limit on the use of non-deadly force, no other limits find majority support. The MPC, however, adds two additional explicit limitations. First, it addresses the use of a protective device to defend property (the MPC $\$ 3.06(5)$ ). Only six jurisdictions make such explicit reference to the use of devices. ${ }^{66}$ Second, the MPC explicitly addresses the use of confinement and authorizes the use of force to pass a wrongful obstructer. See, e.g., the MPC $\$ 3.06(4)$ and (6). Only a small minority of jurisdictions follows the Code on this issue. ${ }^{67}$ In practice, however, it is likely that the effect of these special limitations is implicit in the normal application of the defense of property, since the requirements of necessity and non-deadly force are likely to generate results similar to the special rules set out by the MPC.

(e) What does "possession" mean? At least thirty jurisdictions explicitly define possession. ${ }^{68}$ Of these jurisdictions, a majority of twenty-one broadly use language that centers on having control or dominion over a tangible thing, without distinguishing between real and personal property. ${ }^{69}$ This approach is reproduced in the majority formulation above. The definition is broad enough to encompass both actual and constructive possession, though only a handful of jurisdictions specifically address both. A notable minority of six jurisdictions embraces only actual, physical control, or dominion. ${ }^{70}$

It is likely the ubiquitous "know it when you see it" quality of possession that explains why more jurisdictions do not bother to define it. Indeed, some

66 Hawaii, Iowa, Nebraska, Pennsylvania, Tennessee, and Texas.

67 See, e.g., Hawaii, Missouri, Nebraska, Pennsylvania, and Washington.

68 Alabama, Alaska, Arizona, Arkansas, California, Colorado, Connecticut, Florida, Indiana, Kansas, Louisiana, Maryland, Massachusetts, Michigan, Missouri, Montana, Nebraska, New York, North Carolina, North Dakota, Ohio, Oklahoma, Oregon, Pennsylvania, Rhode Island, Tennessee, Utah, Virginia, Washington, and Wisconsin.

69 Alaska, Arizona, California, Connecticut, Florida, Kansas, Maryland, Massachusetts, Michigan, Missouri, Montana, New York, North Carolina, North Dakota, Ohio, Oklahoma, Rhode Island, Tennessee, Utah, Virginia, and Wisconsin.

70 Arkansas, Colorado, Indiana, Louisiana, Nebraska, and Washington. Only Pennsylvania follows the MPC by supplying specific examples of possession within the defense of property justification (18 Pa. Cons. Stat. Ann. $\$ 507(c)(1))$. 
jurisdictions' definitions relied upon for the majority formulation appear only in reference to a specific class of crimes (usually involving firearms or drugs) or appear outside their criminal codes altogether. Such definitions, however, are similar to each other regardless of where they are found, and thus are likely to represent the jurisdictions' general conception of possession, including in this context.

(f) May an actor use force to retake or reenter his property of which he was unlawfully dispossessed? A majority of at least twenty-seven jurisdictions authorize the use of force to retake property unlawfully taken by another or to effect reentry upon land from which the actor was unlawfully dispossessed. Twelve allow the use of force to retake or reenter property. ${ }^{71}$ They do not specifically address when such force may be used; however, it seems implied that it should only be allowed soon after the unlawful dispossession. ${ }^{72}$ Four jurisdictions, following the MPC, authorize retaking real or personal property, but only when "immediately necessary" and "in fresh pursuit" following an unlawful dispossession: The MPC $\$ 3.06(1)(b)(i)$; Neb. Rev. Stat. Ann. $\$ 28-$ 1411; 18 Pa. Cons. Stat. Ann. $\$$ 507; and Tenn. Code Ann. $\$ 39-11-614$. Six jurisdictions explicitly authorize the use of offensive force to "retake", "regain", or "re-enter" the actor's property; however, they differ regarding when such force may be used. Three of these jurisdictions require it be used "immediately following" the unlawful taking: Me. Rev. Stat. Ann. tit. 17-A, $\$ 105 ;$ N.H. Rev. Stat. Ann. $\$ 627: 8$; and Tex. Penal Code Ann. $\$ 9.42$ (using the language, "immediately after"). Connecticut requires it to be used within a "reasonable time"; Massachusetts sets no explicit temporal restriction; and Rhode Island is silent on the matter. See, e.g., Conn. Gen. Stat. Ann $\$$ 53a-21; Com. v. Donahue, 148 Mass. 529 (1889); and State v. Holley, 604 A.2d 772 (R.I. 1992). Seventeen jurisdictions authorize the use of force to "terminate" unlawful interference or trespass ${ }^{73}$; however, only five of them interpret this authority to include use of force to repossess property. ${ }^{74}$ Four others explicitly deny that "terminating" interference includes repossession. ${ }^{75}$ Finally, another four jurisdictions explicitly restrict the use of force in protection of property to

71 Arizona, California, Maryland, Michigan, Minnesota, Mississippi, Missouri, Ohio, Oklahoma, South Carolina, Washington, and West Virginia.

72 Allowing the use of force to recapture property at any time would invite the kind of vigilantism expressly condemned by some jurisdictions that oppose such force in the first instance. See, e.g., Yocum v. State, 777 A.2d 782, 784 (Del. 2001).

73 Alabama, Alaska, Arkansas, Florida, Georgia, Illinois, Indiana, Iowa, Kansas, Montana, New Jersey, New York, North Dakota, Oregon, Utah, Wisconsin, and Wyoming.

74 Alabama, Alaska, Georgia, Indiana, and Oregon.

75 Arkansas, Illinois, Iowa, and Wisconsin. 
preventive measures, some going so far as to condemn repossessing property as lawless vigilantism. ${ }^{76}$

Given the popularity of allowing reasonable force to retake or reenter property soon after being dispossessed (twenty-seven jurisdictions in total, versus the eight jurisdictions that explicitly deny such authorization), it is likely that even more jurisdictions than this bare majority would support that position, given the right case.

(g) Should a claim of right by the dispossessor limit the actor's right to use force to resist? A majority of jurisdictions do not support this principle. The MPC limits the use of force in such claim-of-right cases, in an effort to avoid escalation of the conflict into physical injury, arguing that a person acting under a claim of right is more likely to use force to resist the actor (The MPC $\$ 3.06(1)(\mathrm{b})(\mathrm{ii})$ and Commentary). Yet, only a handful of jurisdictions follow the Code in this respect. ${ }^{77}$

(h) May an actor defend against any unlawful aggression, or only against criminal acts? At least twenty-nine jurisdictions permit defense of property against most unlawful aggression, ${ }^{78}$ thus allowing the use of force to defend against aggression that would be only civilly actionable. A minority of at least thirteen jurisdictions require that the actor be defending against criminal force, denying authority to defend against civil wrongs. ${ }^{79}$

The issue of mistake as to a justification is addressed in section 307, though its effect can be seen in the bracketed language in Subsection (1) above.

\subsection{5. §305. Law Enforcement Authority.}

The majority view of the Law Enforcement Authority defense among American jurisdictions might be stated as follows:

Section 305. Law Enforcement Authority.

(1) Use of Force Justifiable to Effectuate an Arrest. The use of force upon or toward the person of another is justifiable when a peace officer, or private actor under the direction of a peace officer, is making or

76 Colorado, Delaware, Idaho, and Vermont.

77 See, e.g., Delaware, Hawaii, Kentucky, Maine, Nebraska, New Jersey, Pennsylvania, Tennessee, and Texas.

78 Alaska, California, District of Columbia, Florida, Georgia, Hawaii, Illinois, Indiana, Kansas, Kentucky, Louisiana, Maine, Maryland, Massachusetts, Minnesota, Missouri, Montana, Nebraska, New Hampshire, New Mexico, North Carolina, North Dakota, Ohio, Oklahoma, Pennsylvania, Tennessee, Texas, Washington, and Wisconsin.

79 Alabama, Arizona, Arkansas, Colorado, Connecticut, Delaware, Idaho, Iowa, New Jersey, New York, Oregon, South Dakota, and Utah. 
assisting in making an arrest and [reasonably believes that] such force is necessary to effectuate the arrest.

(2) Limitations on the Use of Deadly Force. The use of deadly force is not justifiable under this Section unless:

(a) the actor, where feasible, warns the suspect that he or she intends to effectuate an arrest; and

(b) the actor has probable cause to believe:

(i) the suspect poses a threat of serious physical harm to any individual, be it the officer or another; or

(ii) the suspect committed a crime that involved the infliction or threatened infliction of serious physical harm; or

(iii) the suspect is threatening the actor with a weapon.

(3) Use of Force to Prevent Escape from Custody. The use of force authorized in Subsections (1) and (2) can be used to prevent an escape from custody either during or after an arrest.

(4) Use of Force to Prevent Escape from Detention Facility. A peace officer is justified in using force that [he or she reasonably believes] is necessary to prevent the escape of a charged or convicted detainee from a jail, prison, or other such institution. However, a peace officer may not use deadly force unless [he or she reasonably believes] the escapee is in custody for committing a felony.

All jurisdictions agree that a peace officer, and those under the direction of a peace officer, has the authority to use force to make a lawful arrest. The defense protects the reasonable and necessary exercise of that authority. Jurisdictions disagree, however, regarding: (a) what limits to place on such use of force generally; (b) what limits to place on the use of deadly force for such a purpose; and to what extent peace officers' authority to use force extends to preventing escape (c) from custody following an arrest and (d) from a detention facility.

(a) What limits should generally constrain actors' use of force in making an arrest? All jurisdictions require that the force used be necessary to make the arrest. A majority of at least twenty-nine jurisdictions requires that the actor either "believe" 80 or "reasonably believe" 81 that the force used is necessary to effectuate an arrest. Others require the force used in any arrest situation

80 See, e.g., Delaware, Hawaii, Kentucky, Nebraska, and Pennsylvania.

81 See, e.g., Alaska, Alabama, Arkansas, California, Colorado, Connecticut, District of Columbia, Florida, Illinois, Indiana, Iowa, Kansas, Maine, Missouri, New Hampshire, New Jersey, New York, North Carolina, Ohio, Oregon, Tennessee, Texas, Utah, and Wisconsin. 
be objectively reasonable or necessary. ${ }^{82}$ (The issue of mistake as to a justification is taken up and discussed more fully in section 307.)

Additionally, some jurisdictions follow the MPC, $\$ 3.07(2)(a)(i)$, and require that the officer's purpose to affect an arrest be made known to the arrestee before force may be used, see, e.g., Ariz. Stat. Ann. \$ 13-409(2); Del. Code. Ann. $\$ 467(\mathrm{~b})(1)$; and Ken. Rev. Stat. $\$ 503.090(1)(\mathrm{b})$, though a majority of at least thirty-four jurisdictions do not. ${ }^{83}$ Other jurisdictions also follow the MPC, $\$ 3.07(2)(a)$ (ii), by specifically requiring an arrest warrant be valid, or at least that the peace officer believe it to be valid, where an arrest warrant is at issue. See, e.g., Ala. Crim. Code $\$ 13 A-3-27$; Conn. Stat. Ann. \$52a-22; and Del. Code. Ann. $\$ 467$. Some jurisdictions have a related limitation, barring the defense only if the peace officer knows his arrest is unlawful. ${ }^{84}$ Ultimately, many jurisdictions recognize some limitation beyond the "reasonable belief" requirement. None of these, however, commands majority support, so the majority formulation does not include any.

The MPC's section 3.07(4)-(5) includes independent provisions for private assistance in an unlawful arrest and for use of force to prevent suicide, but only a handful of jurisdictions include similar provisions. ${ }^{85}$

(b) What limits should constrain an actor's use of deadly force while effectuating an arrest? Under the common law, peace officers were authorized to use deadly force to effectuate the arrest of any fleeing felon. In Tennessee v. Garner, however, the Supreme Court held that the use of deadly force upon a fleeing arrestee is itself a "seizure" under the Fourth Amendment, and thus subject to constitutional "reasonableness" limitations that did away with the common law rule many jurisdictions followed at the time. Tennessee v. Garner, 105 S.Ct. 1694, 1699 (1985). Prior to Garner, "[m]ost American jurisdictions [... recognized] a general privilege to use [deadly] force to stop a fleeing felon." Ibid. at 1702. To a certain extent, the Garner ruling now controls this legal issue for all jurisdictions.

The Garner limitations are as follows: (1) a peace officer cannot use deadly force to apprehend a suspected misdemeanant (this was always the majority

82 See, e.g., Arizona, Idaho, Louisiana, Maryland, Minnesota, Montana, New Mexico, North Dakota, Oklahoma, Rhode Island, South Dakota, Vermont, Washington, and West Virginia.

83 Alabama, Alaska, Arkansas, California, Colorado, Connecticut, District of Columbia, Florida, Idaho, Illinois, Indiana, Iowa, Kansas, Louisiana, Maine, Maryland, Michigan, Minnesota, Missouri, New Hampshire, New Mexico, New York, Ohio, Oklahoma, Oregon, Pennsylvania, Rhode Island, South Carolina, South Dakota, Utah, Vermont, Virginia, Washington, and Wisconsin.

84 Alabama, Arkansas, Colorado, Connecticut, Maine, Missouri, New Hampshire, New York, North Carolina, and Oregon.

85 See, e.g., Alabama, Delaware, Hawaii, Nebraska, New Jersey, and Pennsylvania. 
rule, even under the common law), and (2) a peace officer cannot use deadly force to effectuate the arrest of a suspected felon unless he warns the arrestee, where feasible, of his intention and has probable cause to believe the arrestee either: (a) poses a threat of serious physical harm, (b) has committed a crime that involved the infliction or threatened infliction of serious physical harm, or (c) threatened the officer with a weapon. The language of Subsection (2) in the majority formulation above mirrors the Supreme Court's ruling (Ibid. at 170102). ("Where the officer has probable cause to believe that the suspect poses a threat of serious physical harm, either to the officer or to others, it is not constitutionally unreasonable to prevent escape by using deadly force. Thus, if the suspect threatens the officer with a weapon or there is probable cause to believe that he has committed a crime involving the infliction or threatened infliction of serious physical harm, deadly force may be used if necessary to prevent escape, and if, where feasible, some warning has been given.")

Consistent with Garner, at least thirty jurisdictions explicitly allow the use of deadly force by peace officers if the arrestee poses a substantial risk of death or serious bodily harm. ${ }^{86}$ Garner does not address the use of deadly force by private actors under the direction of peace officers, but at least thirty jurisdictions allow these private actors to use deadly force in similar, if not identical, circumstances as peace officers themselves. ${ }^{87}$ Therefore, the majority formulation includes such actors within the Garner requirements.

Note that the factors used to assess reasonableness in Garner are not technically an exclusive "test", but rather one example of applying Fourth Amendment reasonableness to seizures through means of deadly force. Garner is cited so frequently for such reasonableness analyses, however, that we find it appropriate to enshrine its specific components as the majority rule. Additionally, Garner merely sets a constitutional "floor" for determining if the use of deadly force is reasonable; there is, however, no majority support for stricter limits than Garner provides.

The MPC does not allow the use of deadly force unless: (1) the arrest is for a felony, (2) the actor is authorized to act, (3) the actor believes the force will not create a substantial risk of injury to innocents, and (4) the actor believes the crime involved the use or threatened use of deadly force or there is a substantial

86 See, e.g., Alabama, Alaska, Arizona, Arkansas, California, Colorado, Delaware, District of Columbia, Florida, Georgia, Hawaii, Illinois, Indiana, Kansas, Maine, Massachusetts, Minnesota, Missouri, Nebraska, Nevada, New Hampshire, New Jersey, New Mexico, New York, Oklahoma, Oregon, Pennsylvania, Tennessee, Texas, and Utah.

87 See, e.g., Alabama, Alaska, Arizona, Colorado, Connecticut, Delaware, Florida, Georgia, Hawaii, Idaho, Illinois, Iowa, Kentucky, Maine, Michigan, Mississippi, Missouri, Nebraska, Nevada, New Hampshire, New Jersey, New Mexico, New York, Oklahoma, Oregon, Pennsylvania, South Dakota, Texas, Utah, and Washington. 
risk the felon will cause death or serious harm (The MPC \$3.07). Garner covers (1), (2), and (4), as discussed above. While (3) is not incompatible with Garner, it does not have majority support, ${ }^{88}$ and thus is not included in the majority formulation.

(c) How much force may a peace officer use to prevent an arrestee's escape? A twenty-nine-jurisdiction majority explicitly includes use of force to prevent an arrestee from escaping within the same provision as use of force to make an arrest. ${ }^{89}$ Only two jurisdictions address arrestee escape in a separate provision; however, the amount of force authorized is the same for both arrest and preventing escape after arrest (Fla. Stat. Ann. \$ 776.07; and Mont. Code Ann. $\$ 45$ 3-106). This makes sense because an arrest is not truly "effectuated" if the arrestee escapes. Thus, one can assume that in other jurisdictions the original authorization to use force to make an arrest would also apply to recovering an arrestee after an escape. In fact, the majority of jurisdictions do not distinguish between these situations, so the majority formulation does not, either. See, e.g., State v. Lawler, 571 N.W.2d 486, 490 (1997) (defining the phrase, "[A]ny force which the person reasonably believes to be necessary to make the arrest", from Iowa Code $\$ 804.10$ to include "prevent[ing] the escape of the arrested person from custody"); Kyle v. City of New Orleans, 353 So.2d 969, 972-73 (1977) (including prevention of escape in an analysis of "reasonable force" in "effect[ing] the arrest or detention" under La. Rev. Stat. Ann. C. Cr. P. Art. 220).

(d) May a peace officer use force to prevent escape from a detention facility? If so, how much force? A majority of at least thirty-five jurisdictions allow deadly force to be used under some circumstances of escape-although jurisdictions vary as to what those circumstances are. ${ }^{90}$ Like the MPC, $\$ 3.07(3)$, at least thirteen jurisdictions allow the use of deadly force under the same conditions as non-deadly force; that is, when it is (reasonably) believed necessary to prevent escape. ${ }^{91}$ However, at least twenty-six other jurisdictions more strictly

88 For examples of jurisdictions that follow the MPC in this regard, see New Jersey, Delaware, Hawaii, Nebraska, and Pennsylvania.

89 Alabama, Alaska, Arizona, Arkansas, California, Colorado, Connecticut, Delaware, Florida, Hawaii, Illinois, Indiana, Kansas, Kentucky, Maine, Minnesota, Missouri, Montana, Nebraska, Nevada, New Hampshire, New Jersey, New York, North Carolina, North Dakota, Oklahoma, Oregon, Pennsylvania, Texas, Utah, and Virginia.

90 Alabama, Alaska, Arizona, Arkansas, Colorado, Connecticut, Delaware, Federal, Florida, Georgia, Hawaii, Idaho, Illinois, Indiana, Iowa, Kentucky, Maine, Michigan, Mississippi, Missouri, Montana, Nebraska, Nevada, New Hampshire, New Jersey, New Mexico, New York, North Carolina, North Dakota, Ohio, Oklahoma, Oregon, Pennsylvania, South Dakota, Texas, Utah, Virginia, Washington, and Wisconsin.

91 Delaware, Florida, Georgia, Hawaii, Illinois, Kentucky, Mississippi, Montana, Nebraska, South Dakota, Texas, Virginia, and Wisconsin. 
limit the use of deadly force to prevent escape. ${ }^{92}$ Of the different limitations imposed by these jurisdictions, twenty-one say that peace officers cannot use deadly force on escapees unless they believe those escapees to be felons (or to have committed specified crimes of similar magnitude). ${ }^{93}$ Additional minority restrictions include requiring peace officers to believe the escapee: threatens life or serious bodily injury, possesses a firearm, or is escaping from a greater than minimum-security correctional institution. See, e.g., Mo. Ann. Stat. $\$ 563.056$ (threatens life or serious bodily injury); Okla. Stat. tit. 21, $\$ 732$ (threatens life or serious bodily injury); Wash. Rev. Code. Ann. \$9A.16.040 (threatens life or serious bodily injury); Alaska Stat. Ann. $\$ 11.81 .410$ (possesses a firearm); and Or. Rev. Stat. Ann. $\$ 161.267$ (escaping from a greater than maximum-security correctional institution). Because over twenty of the twenty-six majority jurisdictions limiting deadly force more strictly than the MPC also specifically limit the use of deadly force to prevent the escape of felons, the majority formulation above has included that limitation as a widely accepted example of the limitations jurisdictions choose to apply.

\subsection{6. \$306. Special Responsibility.}

The majority view of the Special Responsibility defense among American jurisdictions might be stated this way:

Section 306. Special Responsibility.

The use of force upon or toward the person of another is justifiable if:

(1) the actor is a parent, guardian, teacher, or other person similarly entrusted with the care and supervision of a minor, or the guardian of an incompetent person, and:

(a) the force used [is with the purpose to] maintain discipline or promote the minor or incompetent person's welfare, and

(b) the force used is reasonable;

(2) the actor is a warden or other authorized official of a correctional institution, and:

(a) the force used [is with the purpose to] maintain or restore order or discipline, and

92 Alabama, Arizona, Alaska, Arkansas, Colorado, Connecticut, Federal, Idaho, Indiana, Iowa, Maine, Michigan, Missouri, Nevada, New Hampshire, New Jersey, New Mexico, New York, North Carolina, North Dakota, Ohio, Oklahoma, Oregon, Pennsylvania, Utah, and Washington.

93 Alabama, Arizona, Alaska, Arkansas, Colorado, Connecticut, Delaware, Hawaii, Idaho, Michigan, Missouri, Nevada, New Hampshire, New Mexico, New York, North Carolina, North Dakota, Oklahoma, Oregon, Pennsylvania, and Washington. 
(b) [the actor reasonably believes that] such force is necessary;

(3) the actor is charged with the safety of a common carrier of persons, and:

(a) the force used [is with the purpose to] maintain order, and

(b) [the actor reasonably believes that] such force is necessary;

(3) the actor is a doctor or other therapist or a person assisting him at his direction, and the force is used for the purpose of administering a recognized form of treatment which the actor believes to be adapted to promoting the physical or mental health of the patient, and:

(a) the treatment is administered with the consent of the patient or, if the patient is a minor or an incompetent person, with the consent of his parent or guardian or other person legally competent to consent on his behalf, or

(b) the treatment is administered in an emergency when [the actor reasonably believes that] no one competent to consent can be consulted and that a reasonable person, wishing to safeguard the welfare of the patient, would consent.

Every jurisdiction agrees that there are some actors who hold special responsibilities that properly authorize the use of force when needed to promote order or the safety of the persons in their charge. Of course, not all uses of force are authorized by the defense, and the limitations on its use vary depending on the relationship. (a) Parents, teachers, and guardians of both children and incompetent persons tend to be given one kind of authority, whereas (b) prison wardens and authorized officials are given another. More limited authority is given to (c) persons charged with the safety of common carriers and (d) doctors and persons assisting them; though the nature of the authorization for these two categories of actors is completely different.

(a) Parents, teachers, and guardians of minors and incompetent persons: a majority of at least forty-nine jurisdictions recognizes a defense for parents applying force to discipline their children. ${ }^{94}$ All of those jurisdictions have a two-fold requirement for the use of force, comprised both a subjective and an objective component. Subjectively, the defense looks to a parent's state of mind-whether his or her purpose in using force was to maintain discipline or to promote the child's welfare. It also requires, objectively, that the force used be reasonable for that purpose. Thus, even objectively reasonable force or punishment would presumably not be justified if the parent acted with malice or a 
mere desire to hurt the child. Nor would punishment with the acceptable motivation be tolerated if it were objectively unreasonable.

A majority of at least forty jurisdictions additionally recognizes a defense for teachers applying reasonable force to discipline their students. ${ }^{95}$ At least twentyseven jurisdictions apply the same two-fold test regarding the appropriateness of force used by teachers as is used for parents, requiring both proper subjective purpose and objective reasonableness. Of these twenty-seven jurisdictions, twenty-two explicitly treat teachers precisely the same as parents. Of those twenty-two, twelve jurisdictions lump both parents and teachers together by statute, ${ }^{96}$ whereas the other ten consider teachers to be in loco parentis ${ }^{97}$ temporarily in the place of parents when the children are under their care. The five remaining jurisdictions making up the twenty-seven-jurisdiction majority recognize certain actors to be in loco parentis, but it is not explicit as to whether teachers are among them. ${ }^{98}$ Considering the overwhelming majority of jurisdictions that do so, however, it is likely that these latter jurisdictions do intend that teachers be in loco parentis.

A majority of at least thirty-one jurisdictions further confer upon guardians a legal status equivalent to parents for the purpose of this defense, either by lumping them together with parents in the main statute or, like teachers, recognizing them as in loco parentis. ${ }^{99}$

Only nineteen jurisdictions explicitly confer upon guardians of incompetent persons a legal status equivalent to parents for the purpose of this defense. ${ }^{100}$ Other jurisdictions, however, are silent on this subject, and no cases could be found in those jurisdictions contradicting their authority. Given the similar

95 Alabama, Alaska, Arizona, Arkansas, Colorado, Connecticut, Delaware, District of Columbia, Florida, Georgia, Hawaii, Illinois, Indiana, Kansas, Kentucky, Louisiana, Maine, Maryland, Michigan, Minnesota, Mississippi, Missouri, Montana, Nebraska, New Hampshire, New Mexico, New York, North Dakota, Ohio, Oklahoma, Oregon, Pennsylvania, Rhode Island, South Dakota, Tennessee, Texas, Virginia, Washington, Wisconsin, and Wyoming.

96 Alabama, Arizona, Arkansas, Colorado, Delaware, Louisiana, Minnesota, Montana, New York, North Dakota, South Dakota, and Washington.

97 Florida, Illinois, Kansas, Mississippi, New Mexico, Oklahoma, Tennessee, Vermont, Virginia, and Wisconsin.

98 District of Columbia, Georgia, Maryland, Rhode Island, and Wyoming.

99 Alabama, Alaska, Arizona, Arkansas, Colorado, Connecticut, Delaware, District of Columbia, Florida, Georgia, Hawaii, Illinois, Kentucky, Maine, Minnesota, Missouri, Montana, Nebraska, New Hampshire, New Jersey, New York, North Dakota, Oklahoma, Oregon, Pennsylvania, Rhode Island, South Dakota, Texas, Washington, West Virginia, and Wyoming.

100 Alabama, Alaska, Arizona, Arkansas, Colorado, Connecticut, Delaware, Hawaii, Kentucky, Maine, Minnesota, Missouri, Nebraska, New Hampshire, New York, North Dakota, Oregon, Pennsylvania, and Texas. 
situation such people have to teachers and guardians of children, it is likely those silent jurisdictions would support such authority, given the right case. Therefore, guardians of incompetent persons are included with parents in Subsection (1) above.

Like the majority formulation, the MPC treats parents, teachers, and guardians of both children and incompetent persons substantially the same. $C f$. The MPC $\$ 3.08(1)$ with $\$ \$ 3.08(2)-(3)$. The majority formulation deviates from the MPC, however, by applying an objective reasonableness standard to the force used. Section 3.08(1)(a)-(b) of the Code focuses exclusively on the actor's motivation for the use of force and does not demand that the force be objectively reasonable. However, to a similar end, the MPC and the National Commission demand that the force "not be designed to cause or known to create a substantial risk of causing death, serious bodily injury, disfigurement or gross degradation". See the MPC $\$ 3.08(1)(b)$; and National Commission's Report $\$ 605(1)(a)$. The Commission requires any force used to be "reasonable", though it specifies that such force need not be "necessary" in the way that use of force in defense of persons and property must be necessary. See National Commission's Report $\$ 607(1)$.

Notably, a significant minority of at least twenty-two jurisdictions explicitly imposes a necessity requirement upon the use of force by parents, teachers, guardians, and others similarly situated, requiring that the force exerted be "necessary", "reasonably necessary", or "reasonably believed to be necessary". ${ }^{101}$ Other jurisdictions may implicitly consider necessity when determining whether force is reasonable, even though they do not include an explicit necessity requirement. ${ }^{102}$

(b) Prison wardens and authorized correctional officials: at least thirty-two jurisdictions specifically authorize the use of force in correctional settings. ${ }^{103}$ All but two of them have tests with both objective and subjective components that limit this authorization, similar to those governing parents, teachers, and

101 See, e.g., Alabama, Alaska, Arizona, Arkansas, California, Colorado, Connecticut, Indiana, Kentucky, Maine, Missouri, Montana, New Hampshire, New Jersey, New York, Oklahoma, Oregon, Rhode Island, South Dakota, Tennessee, Texas, and Virginia.

102 See, e.g., Delaware, Hawaii, and Nebraska. Cf. N.D. Cent. Code $\$ 12.1-05-05(1)$. ("The force may be used... whether or not it is 'necessary' as required by subsection 1 of section 12.1.05-07.”)

103 Alabama, Alaska, Arizona, Arkansas, California, Colorado, Connecticut, Delaware, Florida, Hawaii, Illinois, Iowa, Kentucky, Maine, Massachusetts, Michigan, Mississippi, Missouri, Nebraska, New Hampshire, New Jersey, New York, Ohio, Oregon, Pennsylvania, South Carolina, South Dakota, Texas, Utah, Vermont, Washington, and Federal. 
guardians. ${ }^{104}$ Regarding the subjective portion of the test, the greatest number of jurisdictions, twenty, require that the actor have the purpose of maintaining order or discipline ${ }^{105}$ _though some of them provide lists of objectives that can be succinctly and accurately summed up that way. Nine other jurisdictions require the actor's purpose be to enforce the lawful rules and/or procedures of the correctional institution. ${ }^{106}$ As those rules and procedures are generally in place to maintain order and discipline, the "maintain order" version of the subjective component is used for the majority formulation. The remaining two jurisdictions allow the use of force for the purpose of performing any legal duty or accomplishing any legitimate law enforcement objective: N.J. Stat. Ann. $\$$ 10A:3-3.2; and Wash. Rev. Code Ann. \$\$ 9a.16.020, 72.09.650.

Regarding the objective portion of the test, of those that have one, the greatest number of jurisdictions, twenty-one, only allow force to be used when and to the extent it is, or is believed or reasonably believed to be, necessary. ${ }^{107}$ Four jurisdictions allow only a reasonable amount of force to be used. ${ }^{108}$ The remaining three jurisdictions allow any amount of force authorized by law: Ala. Code $\$ 13$ A-3-24; Mo. Ann. Stat. $\$$ 563.061; and N.Y. Penal Law $\$ 35.10$. Additionally, according to the U.S. Supreme Court, the use of force in correctional settings is subject to scrutiny under the Eighth Amendment to determine if such force is "cruel and unusual punishment". In Hudson v. McMillian, the Court suggested that inquiry into the necessity of force used might be appropriate when determining whether such force is reasonable, though it did not say such inquiry is required (503 U.S. 1, 5 (1992)). Nevertheless, the Court appeared to embrace the necessity requirement, since the factors the Court considered entered into an ultimate determination whether "unnecessary and wanton infliction of pain" was carried out (Ibid.; emphasis added). Given the close relationship between these concepts, and the great number of jurisdictions that embrace necessity as the basic objective requirement, necessity is also required in the majority formulation.

104 Arizona's test is purely subjective. See Ariz. Rev. Stat. Ann. $\$ 13-403(2)$. Illinois has a purely subjective for use of non-deadly force, but switches to a dual objective-subjective test for deadly force. See 20 Il. Admin. Code $\$ 501.40(a)-(b)$.

105 Alabama, Alaska, Arizona, Arkansas, California, Colorado, Connecticut, Illinois, Massachusetts, Michigan, Mississippi, Missouri, New York, Oregon, South Carolina, South Dakota, Texas, Utah, Vermont, and Federal.

106 Delaware, Florida, Hawaii, Iowa, Kentucky, Maine, Nebraska, Ohio, and Pennsylvania.

107 Alaska, Arkansas, Colorado, Delaware, Florida, Hawaii, Iowa, Kentucky, Maine, Massachusetts, Mississippi, Nebraska, New Jersey, Ohio, Oregon, Pennsylvania, South Carolina, South Dakota, Texas, Vermont, and Washington.

108 California, Connecticut, Michigan, and Utah. 
The MPC only requires that the actor should believe that the force used is necessary (The MPC $\$ 3.08(5)(\mathrm{a})$ ). Although a few jurisdictions agree with the Code in this regard, ${ }^{109}$ most have a simple necessity or reasonableness requirement. The National Commission does not specifically address use of force by wardens.

(c) Persons charged with the safety of common carriers: At least thirty-one jurisdictions, following the MPC, authorize the use of force by persons charged with the safety of common carriers. ${ }^{110}$ Some jurisdictions explicitly grant such authority by statute. See, e.g., 18 Pa. Cons. Stat. Ann. \$ 509(6)-(7). Other jurisdictions' courts have recognized such persons' authority, though the pertinent cases are mostly older ones regarding forcible ejection from railroad cars. See, e.g., White v. Evansville \& T.H. R.R. Co., 133 Ind. 480 (1893). Many jurisdictions' rules on this subject could not be confirmed, so known majority authority only supports the grant of authority to persons responsible for common carriers, not the specific contours of that authority. Among the known rules, however, persons authorized to use force for the safety of common carriers may only use force that is necessary for the purpose of maintaining order in the course of their normal duties.

(d) Physicians and similar actors: At least eighteen jurisdictions follow the MPC and the National Commission by including licensed physicians acting in the course of their regular duties among the actors protected by the special responsibility defense. ${ }^{111}$ Of those, all but two do so using language nearly identical to the MPC. See Ga. Code Ann. $\$ 31-9-3 ;$ N.J. Stat. Ann. $\$ 2 \mathrm{C}: 3-8$. Furthermore, in the jurisdictions that do not give physicians such explicit authorization, no support could be found for denying a defense under relevant circumstances. Given the commonsense nature of acknowledging physicians' authority to exercise at least some physical force in the course of normal treatment, it is highly likely that those silent jurisdictions would support the MPC's position, given the right case. Therefore, a slightly modified version of the Code's authorization is included in the majority formulation.

109 Colorado, Delaware, Hawaii, Kentucky, Nebraska, and Pennsylvania.

110 The MPC $\$ 3.08(6)-(7)$; Alabama, Alaska, Arizona, Arkansas, California, Colorado, Connecticut, Delaware, Florida, Georgia, Hawaii, Illinois, Indiana, Iowa, Kentucky, Maine, Massachusetts, Minnesota, Missouri, Montana, Nebraska, Nevada, New Hampshire, New Jersey, New York, North Carolina, North Dakota, Oklahoma, Oregon, Pennsylvania, and Washington.

111 The MPC $\$ 3.08(4)$; National Commission’s Report $\$ 605(\mathrm{~d})$; Alabama, Alaska, Arizona, Arkansas, Colorado, Connecticut, Delaware, Georgia, Hawaii, Kentucky, Maine, Missouri, Nebraska, New Hampshire, New Jersey, New York, North Dakota, and Pennsylvania. 


\subsection{7. \$307. Mistake as to Justification.}

Every American jurisdiction excuses a person in some instances in which the person reasonably but mistakenly believes his conduct is justified under one of the recognized justification defenses. American jurisdictions vary greatly, however, as to: (a) exactly what mistakes concerning which aspects of a justification will provide a defense; (b) whether culpable mistakes will provide a defense or mitigation; and (c) the legal result when an actor makes a mistake as to the lawfulness of the force being defended against.

Indeed, there is commonly some inconsistency within the defenses of a single jurisdiction regarding these matters. The internal inconsistency arises, in part, because of the approach most commonly used when defining the Mistake as to Justification defense. It is commonly provided not by a discrete general statement of the "mistake-as-to-justification defense", but rather by including within each existing justification defense, the words "believes" or "reasonably believes" immediately before that aspect of the justification defense about which a mistake excuse will be recognized. The MPC popularized this approach.

(a) In determining what mistakes concerning which aspects of a justification will provide a defense, a discussion of the relative characteristics of the two primary forms of the mistake as to justification defense is warranted. If a formulation provides a defense for a person who "reasonably believes his conduct is necessary to protect himself", the actor will get a mistake defense even if he was in error about whether his conduct was actually necessary. Unfortunately, this piecemeal, "embedded" approach leaves some uncertainty as to the scope of the defense. For example, if the formulation provides a defense for a person who "reasonably believes his deadly force is necessary to protect himself from serious bodily injury or death", does the "reasonably believes" apply to both "necessary to protect" and to "serious bodily injury"? That is, can he get a mistake defense if in fact only minor bodily injury was threatened? Or what effect does the "reasonably believes" language have on the use of deadly force if the "deadly force" rules appear in a later or inferior subsection from the one containing such language? Can a reasonable mistake as to the circumstances justifying deadly force provide a defense? Can a reasonable mistake as to the special deadly force rules themselves provide a defense? These uncertainties make it difficult to determine the exact scope of a jurisdiction's mistake as to a justification defense and, therefore, a majority view.

One could argue that a reasonable mistake as to any element of a justification defense ought to exculpate. On the contrary, one might argue-as some havethat mistakes as to certain aspects of a justification defense ought not be recognized (Williams 1961, p. 337; Austin 1920, p. 239). For example, one might want to exclude an actor's mistake as to the law governing what is justified, such as whether an actor had an obligation to retreat before using 
deadly force. A clearer approach than the "embedded" approach would be to use a separate mistake as to a justification provision that applied to all justification defenses and defined the class of justification mistakes that could provide a defense or mitigation.

This is the approach taken by the National Commission, which rejected the MPC's "embedded" approach in favor of one that removed the "believes" language from all justification defenses and provided the mistake as to a justification defense through an excuse provision that reads as follows:

Section 608. Excuse.

(1) Mistake. A person's conduct is excused if he believes that the factual situation is such that his conduct is necessary and appropriate for any of the purposes which would establish a justification... under this Chapter, even though his belief is mistaken, except that, if his belief is negligently or recklessly held, it is not an excuse in a prosecution for an offense for which negligence or recklessness, as the case may be, suffices to establish culpability....

The separate provision approach states a general principle, thus avoiding the linguistic ambiguities that can arise under the "embedded" approach, which depends on the particular placement of "believes" or "reasonably believes" language in a justification defense.

The National Commission's approach also offers several other advantages, which some will see as even more important. First, it more easily accommodates what might be called the more nuanced "sliding scale" approach to mistake, as opposed to the "all or nothing" approach, discussed below. If a person's mistake is completely reasonable, all agree that he ought to gain a complete excuse. However, if he makes an honest mistake but one that a reasonable person would not have made - that is, his mistake was negligent or reckless- then some jurisdictions (and the MPC) have his level of liability track his level of culpability in making that mistake. The provision providing this sliding scale level of liability is easily included within the National Commission's provision above. Thus, if a person kills another honestly believing that he must do so to protect his life, but in fact has made a negligent mistake in coming to this conclusion, ${ }^{112}$ the sliding-scale approach would hold him liable, but only for negligent homicide. Under an "all-or-nothing" approach, he would be denied any defense because his mistake was not "reasonable", and thus he would suffer the liability of a murderer-treated as if he had killed without any thought of self-defense.

112 That is, it never occurred to him that he was not threatened with immediate death, but that possibility would have occurred to the reasonable person. 
Beyond the advantages of promoting increased internal consistency and allowing a more detailed formulation of the defense, a separate provision for mistake as to a justification also provides greater conceptual clarity, which can have practical benefits. As has been detailed elsewhere, (Robinson 1997, chs 6-11), the criminal law performs two distinctive functions: it announces ex ante the criminal law's rules of conduct and provides ex post rules by which a breach of the former rules ought to be adjudicated. The objective justification defenses are part of the rules of conduct. They are addressed to the general public and, therefore, ought to be formulated with that audience in mind to be as clear and objective as their function permits. A defense for a mistake as to justification is not part of the ex ante rules of conduct but rather part of the ex post principles of adjudication. It does not tell citizens ex ante what the law requires of them, but rather tells adjudicators ex post when to punish an offender who has done what the law seeks to forbid. ${ }^{113}$ Given its target audience, a defense for a mistake as to a justification can afford to be more complex and normative in its formulation.

The MPC's approach of embedding the mistake excuse within the objective justification defense-thereby introducing into the rule of conduct elements that ought to relate only to adjudication-obscures the conduct rule. This and other difficulties with commingling objective justifications and the excuse of mistake as to justification have been examined more closely elsewhere. (Robinson 2009, p. 343-53, 361-63) For example, the difficulties of defining the triggering conditions for the use of defensive force are discussed in section 303: all agree that objectively justified attacks ought not to trigger a right to use defensive force, but attacks that are only subjective mistaken beliefs in justification ought to trigger such a right. Thus, the MPC's subjective approach makes it nearly impossible to provide a clear definition of what attacks may be lawfully defended. ${ }^{114}$

Having noted all of this, it is nonetheless the case that the most common approach to the formulation of the mistake as to a justification defense is the "embedded" approach using "reasonably believes" language in justification defenses. A thirty-six-jurisdiction majority, following the MPC, defines all justification defenses subjectively, requiring that the actor "reasonably believes" his conduct to be justified. ${ }^{115}$ Four jurisdictions require only that an actor "believe"

113 Note that the National Commission titles its defense an "Excuse".

114 See text accompanying note 31 .

115 Alabama, Alaska, Arizona, Arkansas, Colorado, Connecticut, District of Columbia, Florida, Georgia, Idaho, Illinois, Indiana, Iowa, Kansas, Louisiana, Maine, Maryland, Massachusetts, Michigan, Missouri, Montana, Nevada, New Hampshire, New Jersey, New Mexico, New York, North Carolina, Oklahoma, Oregon, Pennsylvania, Tennessee, Texas, Utah, Virginia, Washington, and West Virginia. 
his conduct to be justified. ${ }^{116}$ Among modern codifications, only North Dakota, following the National Commission, $\$$ 608(1), defines justification defenses objectively while providing a freestanding mistake as to justification defense (N.D. Cent. Code $\$ 12.01-05-08$ (North Dakota)). For those readers who wish to follow the majority view regarding not only content but also drafting form, the embedded approach is the clear majority view. This is why every justification defense majority formulation in this article includes the "reasonably believes" language.

But for those who are interested in following the majority view on content, but who do not feel bound to use the majority form, we recommend using the separate provision approach of the National Commission. If a jurisdiction takes this "separate provision" approach, it will omit the embedded "reasonably believes" language-which is marked off with brackets in each of the justification defenses in this article. Eliminating the bracketed language would convert the justification formulation to a purely objective formulation-a better ex ante rule of conduct-and would then allow a separate excuse provision-a better principle of adjudication. If one were to adopt the majority view, but were to draft a single provision governing the Mistake as to Justification defense, it might be formulated this way:

Section 307. Mistake as to a Justification Excuse

(1) Mistake. A person's conduct is excused if he reasonably believes that the factual situation is such that his conduct is necessary and appropriate for any of the purposes that would establish a justification defense under this Chapter.

(2) The excuse defense provided in Subsection (1) is unavailable if:

(a) the actor's belief in the unlawfulness of the force or conduct against which he employs protective force or his belief in the lawfulness of an arrest which he endeavors to effect by force is erroneous; and

(b) his error is due to ignorance or mistake as to the provisions of the Code, any other provision of the criminal law or the law governing the legality of an arrest or search.

(b) Will culpable mistakes as to justification provide a defense or mitigation? Moving from format to content, aside from the issue of embedded versus separate mistake defense, the primary disagreement among American jurisdictions concerns whether to take the "all-or-nothing" approach or the "sliding-scale" approach in providing a mistake excuse. A forty-three-jurisdiction majority 
embraces the "all-or-nothing" approach. ${ }^{117}$ Under this majority formulation, only "reasonable" (i.e., non-negligent) mistakes as to justification warrant full exculpation. Any culpable mistakes, regardless of their level of culpability, will incur full liability. Thus, as similarly hypothesized above, a person who kills an attacker honestly believing it was necessary to defend himself against a deadly threat will get a complete defense if his belief was reasonable. But if his belief is honestly held but negligent-that is, it never occurred to him that such force was not necessary, but the reasonable person in his situation would have been aware of a risk that it might not be-then the actor loses his self-defense altogether and is liable for murder. Under the sliding scale approach of the MPC and the National Commission, he would still be criminally liable, but only for negligent homicide.

Twenty-eight jurisdictions have explicitly committed themselves to this "all-or-nothing" view in a statute, ${ }^{118}$ usually embedded in defensive force statutes as discussed above. The other "all-or-nothing" jurisdictions have seminal case law limiting mistake as to justification to a reasonable belief in defensive force situations (defense of property, defense of self, defense of others). ${ }^{119}$

The MPC and National Commission, in contrast, embrace the "sliding scale" approach. See, e.g., the MPC $\$ 3.09(2)$; and National Commission’s Report $\$$ 608 ; see also 11 Del. C. $\$ 470$; and Haw. Rev. Stat. $\$ 703-310$. Under this approach, the defense formulation seems to grant the Mistake as to Justification defense based merely upon a "belief" that the justifying conditions exist. Then a separate provision-section 3.09 of the MPC and section 608 of the National Commission (quoted above)—imposes mitigated liability if the mistake was not reasonable (either reckless or negligent), with the level of liability depending on the level of culpability in the actor's mistake. In case law, this minority view is often labeled as the doctrine of "imperfect self-defense". See, e.g., Lanier v. State, 684 So.2d 93, 97 (Miss. 1996).

117 Alabama, Alaska, Arizona, Arkansas, Colorado, Connecticut, District of Columbia, Florida, Georgia, Idaho, Illinois, Indiana, Iowa, Kansas, Louisiana, Maine, Maryland, Massachusetts, Michigan, Minnesota, Missouri, Montana, Nevada, New Hampshire, New Jersey, New Mexico, New York, North Carolina, Ohio, Oklahoma, Oregon, Rhode Island, South Carolina, South Dakota, Tennessee, Texas, Utah, Vermont, Virginia, Washington, West Virginia, Wisconsin, and Wyoming.

118 See, e.g., Alabama, Arizona, Arkansas, Colorado, Florida, Georgia, Illinois, Indiana, Iowa, Kansas, Louisiana, Maine, Michigan, Minnesota, Missouri, Montana, New Hampshire, New Jersey, New York, Oregon, South Carolina, South Dakota, Tennessee, Texas, Utah, Washington, Wisconsin, and Wyoming.

119 Alaska, Connecticut, District of Columbia, Idaho, Maryland, Massachusetts, Nevada, New Mexico, Ohio, Oklahoma, Rhode Island, Vermont, Virginia, and West Virginia. 
(c) What is the legal result when an actor makes a mistake as to the lawfulness of the force being defended against? The MPC bars a mistake defense when an actor erroneously believes that the force against which he is defending is unlawful and that error is due to ignorance or mistake of the law (The MPC $\$ 3.09(1))$. Nebraska and New Jersey are the only jurisdictions to have statutorily adopted a similar limit on the defense; however, even when left unspoken, this prohibition follows the clear majority view that ignorance or mistake of law is typically no defense to criminal liability. ${ }^{120}$

\subsection{Chapter 4. General Principles of Excuse}

\subsection{1. \$401. Insanity.}

The majority view of the Insanity defense among American jurisdictions might be stated as follows:

Section 401. Insanity.

(1) An actor is not responsible for criminal conduct if at the time of such conduct as a result of mental disease or defect he did not know his conduct was wrong.

(2) As used in Subsection (1), the phrase "mental disease or defect" does not include an abnormality manifested only by repeated criminal or otherwise anti-social conduct.

Insanity defense formulations primarily differ regarding four issues, namely: (a) the extent of cognitive disability required to excuse criminal conduct; (b) whether a defendant's cognitive impairment relates to the ability to understand the morality or the criminality of his conduct; (c) whether and to what extent the defendant's inability to control his physical actions should excuse criminal conduct; and (d) whether to exclude sociopathic behavior from the definition of insanity.

(a) How impaired must a defendant's cognitive abilities be to warrant a defense? Subsection (1) of the majority formulation above reflects the socalled M'Naghten formulation, ${ }^{121}$ which requires absolute inability to tell that one's conduct is wrong. A thirty-four-jurisdiction majority supports either M'Naghten or an even more restrictive position. First, twenty-two

120 For a full discussion of mistake of law, see infra section 406.

121 This formulation is named for the English case in which it was first articulated. M'Naghten's Case, 8 Eng. Rep. 718 (1843) ("[T] o establish a defense on the ground of insanity, it must be clearly proved that, at the time of the committing of the act, the party accused was laboring under such a defect of reason, from disease of the mind, as to not know the nature and quality of the act he was doing; or, if he did know it, that he did not know he was doing what was wrong"). 
jurisdictions expressly embrace M'Naghten language. ${ }^{122}$ Second, five jurisdictions use hybrid language that appears similar to the MPC's "unable to appreciate" standard (discussed below), but operates like M'Naghten. ${ }^{123}$ Third, six jurisdictions have abolished the Insanity defense, obviously the most restrictive position. ${ }^{124}$ Fourth, Missouri requires that an actor meet both the M'Naghten formulation and the MPC's less restrictive cognitive requirement, which makes it a de facto M'Naghten jurisdiction because an actor must meet that more restrictive standard in every case (Mo. Ann. Stat. $\$ 562.086$ ).

The remaining eighteen jurisdictions embrace one of three minority formulations of the cognitive dysfunction requirement. First, sixteen jurisdictions follow the MPC formulation, which requires an actor's cognitive function to be substantially, rather than absolutely, impaired, and that he be unable to "appreciate" the criminality (or wrongfulness) of his conduct. ${ }^{125}$ Second, New York allows an actor to satisfy either the M'Naghten or the MPC formulation, which results, as a practical matter, in nothing more than the MPC's formulation (N.Y. Penal Law $\$ 40.15$ ). Third, New Hampshire follows the Durham "product test", which is even less demanding than the MPC, requiring only that the actor's insanity caused his criminal conduct, without a requirement as to the extent of the cognitive impairment (State v. Fichera, 153 N.H. 588, 593 (2006)).

(b) Precisely what cognitive faculty must be impaired to give rise to the insanity defense? Is it the actor's ability to tell moral right from wrong, or to understand that his actions are criminally prohibited? A majority of thirtyseven jurisdictions discuss cognitive impairment in terms of an actor's ability to "know" or "appreciate" that his actions are wrong. ${ }^{126}$ Subsection (1) of the

122 Arizona, California, Colorado, Florida, Georgia, Iowa, Louisiana, Minnesota, Mississippi, Nebraska, New Jersey, New Mexico, North Carolina, Ohio, Oklahoma, Pennsylvania, South Carolina, South Dakota, Texas, Virginia, Washington, and Wisconsin.

123 Alabama, Alaska, Indiana, Tennessee, and Federal. For instance, Alaska grants the insanity defense when "the defendant was unable, as a result of a mental disease or defect, to appreciate the nature and quality of that conduct" (emphasis added), thus incorporating the MPC's "unable to appreciate" language but not the "substantial capacity" test (discussed below) into the M'Naghten formulation of the cognitive "prong" of the defense (Alaska Stat. Ann. \$12.47.010).

124 Idaho, Kansas, Montana, Nevada, North Dakota, and Utah.

125 Arkansas, Connecticut, Delaware, District of Columbia, Hawaii, Illinois, Kentucky, Maine, Maryland, Massachusetts, Michigan, Oregon, Rhode Island, Vermont, West Virginia, and Wyoming.

126 Alabama, Arizona, California, Colorado, Connecticut, Delaware, District of Columbia, Florida, Georgia, Hawaii, Indiana, Iowa, Louisiana, Maine, Michigan, Minnesota, Mississippi, Missouri, Nebraska, New Jersey, New Mexico, New York, North Carolina, Ohio, Oklahoma, Pennsylvania, Rhode Island, South Carolina, South Dakota, Tennessee, Texas, Virginia, Washington, West Virginia, Wisconsin, Wyoming, and Federal. 
majority formulation therefore reflects this view. Six jurisdictions use the term "criminal" instead of "wrong". ${ }^{127}$ Interestingly, the MPC (and, by reference, Massachusetts, which embraces the MPC's version of the insanity defense wholesale) uses the term "criminality", but parenthetically includes "wrongfulness" as an acceptable alternative (The MPC $\$ 4.01(1)$; and Commonwealth $v$. McHoul, 352 Mass. 544 (1967)).

(c) Should an actor's inability to physically control his actions give rise to an insanity defense? Thirty-five jurisdictions agree that it should not, so Subsection (1) above does not include a "control prong". These thirty-five jurisdictions are made up of twenty-nine that offer an insanity defense for cognitive but not control incapacity ${ }^{128}$ and the six that offer no insanity defense at all. ${ }^{129}$ The remaining jurisdictions embrace control dysfunction as part of the insanity defense by following one of three minority views. First, three jurisdictions use the "irresistible impulse" formulation, which requires absolute impairment of the actor's self-restraint: State v. Hartley, 90 N.M. 488, 490 (1977); State v. Staten, 18 Ohio St.2d 13 (1969); and Herbin v. Commonwealth, 28 Va.App. 173, 181-183 (1998). Second, thirteen jurisdictions use the MPC formulation, ${ }^{130}$ which only requires substantial impairment of the actor's ability to "conform his conduct to the requirements of the law" (The MPC $\$ 4.01(1)$ ). Third, and as previously noted, New Hampshire follows the Durham "product test", which has no requirement regarding the extent of control impairment (State $v$. Fichera, 153 N.H. 588, 593 (2006)).

(d) Ought sociopaths be considered insane for the purpose of excusing criminal conduct? Subsection (2) prohibits a defense for repeated criminal or antisocial conduct because a firm majority of forty jurisdictions, aligned with the MPC, exclude such offenders from the Insanity defense. Thirty-four jurisdictions exclude such behavior explicitly, ${ }^{131}$ whereas the six jurisdictions with no

127 Arkansas, Illinois, Kentucky, Maryland, Oregon, and Vermont.

128 Alabama, Alaska, Arizona, California, Colorado, Delaware, Florida, Georgia, Illinois, Indiana, Iowa, Louisiana, Maine, Minnesota, Mississippi, Missouri, Nebraska, New Jersey, New York, North Carolina, Oklahoma, Pennsylvania, South Carolina, South Dakota, Tennessee, Texas, Washington, Wisconsin, and Federal.

129 See note 124

130 Arkansas, Connecticut, District of Columbia, Hawaii, Kentucky, Maryland, Massachusetts, Michigan, Oregon, Rhode Island, Vermont, West Virginia, and Wyoming.

131 Alabama, Alaska, Arizona, Arkansas, California, Colorado, Connecticut, Delaware, District of Columbia, Florida, Georgia, Hawaii, Illinois, Indiana, Iowa, Kentucky, Maine, Maryland, Missouri, Nebraska, North Carolina, Oregon, Oklahoma, Pennsylvania, Rhode Island, South Carolina, South Dakota, Tennessee, Texas, Vermont, Washington, Wisconsin, Wyoming, and Federal. 
insanity defense exclude such behavior de facto. ${ }^{132}$ Three jurisdictions arguably do not automatically exclude sociopaths: United States v. Gay, 522 F.2d 429, 433 (6th Cir. 1975) (Michigan); State v. Fichera, 153 N.H. 588, 593 (2006); and People v. Santarelli, 49 N.Y.2d 241, 248-49 (1980). The remaining jurisdictions do not appear to have taken a position on the issue.

\subsection{2. \$402. Involuntary Intoxication.}

The majority view of the Involuntary Intoxication defense among American jurisdictions might be stated as follows:

Section 402. Involuntary Intoxication.

(1) Intoxication is a defense if it is involuntary and if by reason of such intoxication the actor at the time of his conduct did not know his conduct was wrong.

(2) Intoxication is "involuntary" if the intoxicating substance was introduced without the actor's knowledge or under circumstances that would afford a defense to a charge of crime.

Involuntary Intoxication defense formulations primarily differ regarding three issues, namely: (a) the extent of cognitive impairment required to excuse criminal conduct; (b) whether and to what extent the defendant's inability to control his conduct due to intoxication should excuse criminal conduct; and (c) how to define "involuntary".

(a) To what degree must intoxication impair a defendant's cognitive function to warrant a defense? Of the forty-six jurisdictions with confirmed views, ${ }^{133}$ thirty-three treat involuntary intoxication as an excuse analogous in form and operation to insanity, as reflected in the majority formulations above and in section $401{ }^{134}$ The thirteen remaining jurisdictions only allow involuntary intoxication to negate the culpability requirement of an offense. ${ }^{135}$

Thirty-three jurisdictions would support the use of the restrictive language of the M'Naghten Insanity defense cognitive prong by requiring either complete loss of the actor's ability to tell moral right from wrong or something even more

132 See note 124.

133 Six jurisdictions have uncertain or not yet established positions on the involuntary intoxication excuse, namely: Nebraska, North Dakota, Oregon, Rhode Island, South Carolina, and West Virginia.

134 Alabama, Alaska, Arizona, Arkansas, California, Colorado, Delaware, District of Columbia, Florida, Georgia, Hawaii, Illinois, Kansas, Kentucky, Maine, Maryland, Massachusetts, Michigan, Minnesota, Missouri, Nevada, New Jersey, New York, North Carolina, Ohio, Oklahoma, Tennessee, Texas, Virginia, Washington, Wisconsin, Wyoming, and Federal.

135 Connecticut, Idaho, Indiana, Iowa, Louisiana, Mississippi, Montana, Nebraska, New Hampshire, New Mexico, South Dakota, Utah, and Vermont. 
restrictive. At least twenty jurisdictions expressly adopt language similar to M'Naghten. ${ }^{136}$ Furthermore, as mentioned in the preceding paragraph, at least thirteen jurisdictions take an even more constrictive view by only allowing involuntary intoxication to negate the culpability element of an offense. ${ }^{137}$ The position adopted in the majority formulation above is based upon the language in the twenty M'Naghten jurisdictions. While the M'Naghten formulation fails to gain majority support, this formulation is presented as the "majority" view because it has the most support of the various formulations in existence and would arguably be supported by those jurisdictions requiring more demanding culpability element negation.

Also supporting the majority formulation above is the fact that twenty-eight jurisdictions use the same cognitive language for Involuntary Intoxication that they use for Insanity, regardless of their positions. ${ }^{138}$ The majority view of Involuntary Intoxication above uses the same language as that of the majority view of Insanity. ${ }^{139}$ This is also consistent with the approach of the MPC, which shapes its Insanity and Involuntary Intoxication defenses similarly, both in language and content.

Fourteen jurisdictions use the MPC's cognitive formulation, ${ }^{140}$ which-like its Insanity defense-requires only substantial impairment, rather than complete loss of the ability to tell moral right from wrong. ${ }^{141}$

(b) Should the fact that intoxication impairs an actor's ability to control his conduct give rise to a defense of involuntary intoxication? A thirty-three-jurisdiction majority agrees that it should not. Twenty of these thirty-three jurisdictions excuse involuntary intoxication solely under a

136 See, e.g., Arizona, Arkansas, California, District of Columbia, Florida, Maryland, Minnesota, Missouri, Nevada, New Jersey, New York, North Carolina, Oklahoma, Pennsylvania, Texas, Virginia, Washington, Wisconsin and Federal. Kansas requires that the actor be "substantially incapable of knowing or understanding the wrongfulness of such person's conduct and of conforming such person's conduct to the requirements of the law" (emphasis added; Kan. Stat. Ann. \$21-5209).

137 See note 135 .

138 Alabama, Alaska, Arizona, Arkansas, California, Florida, Georgia, Hawaii, Illinois, Kansas, Kentucky, Maine, Maryland, Massachusetts, Michigan, Minnesota, Nevada, New Hampshire, New Jersey, North Carolina, Ohio, Oklahoma, Tennessee, Texas, Virginia, Washington, Wisconsin, and Wyoming.

139 See supra section 401.

140 The involuntary intoxication defenses in the MPC and National Commission's Report are identical to the majority view for the purpose of comparison. The MPC $\$ 2.08(4)$; National Commission's Report $\$ 502$.

141 Alabama, Alaska, Delaware, Georgia, Hawaii, Illinois, Kentucky, Maine, Maryland, Massachusetts, Michigan, New Hampshire, Tennessee, and Wyoming. 
cognitive dysfunction theory. ${ }^{142}$ As mentioned above, thirteen more jurisdictions take an even more restrictive view, only allowing involuntary intoxication to negate the culpability of an offense. ${ }^{143}$ Taken together, these thirty-three jurisdictions suggest majority support for the formulation in Subsection (1) above, which does not include a "control prong".

A minority of sixteen jurisdictions recognizes control dysfunction as a defense. Two jurisdictions use the "irresistible impulse" formulation, which requires absolute impairment of the actor's self-restraint. ${ }^{144}$ Fourteen jurisdictions embrace the MPC formulation, ${ }^{145}$ which, as with Insanity, requires only that the actor "[lack] substantial capacity...to conform his conduct to the requirements of law" (The MPC $\$ 2.08(4)$ ).

(c) How should "involuntary" intoxication be defined? Only thirty-nine jurisdictions provide guidance as to what the "involuntary" introduction of an intoxicating substance actually means. ${ }^{146}$ Thirty-six of these jurisdictions agree that an actor's unknowing or innocent ingestion of an intoxicating substance, as in the case where the actor has been drugged, is not voluntary. ${ }^{147}$ These jurisdictions utilize two different defense formulations to reach the same conclusion. First, some jurisdictions specifically find intoxication to be involuntary where the actor was caused to ingest the intoxicating substance against his will by artifice, contrivance, or fraud. See, e.g., State v. Gardner, 870 P.2d 900, 902 n.8 (Utah 1993). Second, some jurisdictions say that intoxication is only

142 Arizona, California, District of Columbia, Florida, Georgia, Illinois, Maine, Minnesota, Missouri, Nevada, New Jersey, New York, North Carolina, Ohio, Oklahoma, Pennsylvania, Texas, Washington, Wisconsin, and Federal.

143 Connecticut, Idaho, Indiana, Iowa, Louisiana, Mississippi, Montana, Nebraska, New Hampshire, New Mexico, South Dakota, Utah, and Vermont.

144 Del. Code Ann. tit. 11, $\$ 422$. Virginia's language is somewhat opaque. It states that intoxication must so unsettle the ability to reason as to prevent the individual from exercising his own free will. Dir. of the Dept. of Corrections v. Jones, 229 Va. 333, 339 (Va. 1985). By using both the language "ability to reason" and "free will" the court appears to awkwardly include both cognitive and control elements.

145 Alabama, Alaska, Arkansas, Colorado, Hawaii, Kansas, Kentucky, Maryland, Massachusetts, Michigan, New Hampshire, Tennessee, and Wyoming.

146 Alabama, Alaska, Arizona, Arkansas, California, Colorado, Delaware, Florida, Georgia, Hawaii, Idaho, Illinois, Indiana, Iowa, Kansas, Kentucky, Maine, Maryland, Massachusetts, Michigan, Minnesota, Missouri, Montana, Nebraska, Nevada, New Hampshire, New Jersey, New York, North Carolina, Ohio, Oklahoma, Pennsylvania, South Dakota, Tennessee, Texas, Utah, Wisconsin, Wyoming, and Federal.

147 Alabama, Alaska, Arkansas, California, Colorado, Delaware, Florida, Georgia, Hawaii, Illinois, Idaho, Indiana, Kansas, Kentucky, Maine, Maryland, Massachusetts, Michigan, Minnesota, Missouri, Montana, Nebraska, Nevada, New Hampshire, New Jersey, New York, North Carolina, Ohio, Oklahoma, Pennsylvania, Tennessee, Texas, Utah, Wisconsin, Wyoming, and Federal. 
voluntary when the actor "knowingly introduced [the intoxicating substance] into his body". See, e.g., Delaware Code $\$ 424(2)$. Under the latter view, a drug introduced to the actor by fraud would necessarily result in involuntary intoxication.

Furthermore, a thirty-three-jurisdiction majority additionally defines "involuntary" in terms of circumstances that provide a defense to criminal conduct. ${ }^{148}$ First, eighteen jurisdictions list independent defenses to criminal liability within which the introduction of an intoxicating substance would be deemed involuntary (such as under force or duress). ${ }^{149}$ Second, fifteen jurisdictions instead define voluntary intoxication. ${ }^{150}$ These jurisdictions state that intoxication is voluntary when it is "caused by a substance that the actor knowingly introduced into his body, and the tendency of which to cause intoxication he knows or ought to know, unless he introduces them under circumstances that would afford a defense to a charge of crime" (e.g., Ala. Code $\$ 13 \mathrm{~A}-3$ $2(\mathrm{e})(2))$. The common denominator between these two positions is the "defense against a charge of crime" provision, which has been adopted in the majority formulation above. Only Arizona and South Dakota utilize the "defense to a charge of crime" definition of involuntary intoxication, but without any language allowing unknowing introduction of the intoxicating substance to provide a defense. See, e.g.,Burrows v. State, 38 Ariz. 99, 115-17 (1931); and Utsler v. State, 84 S.D. 360, 364-65 (1969).

A twenty-jurisdiction minority includes "tendency of a substance" language for circumstances amounting to involuntary intoxication. ${ }^{151}$ Fifteen jurisdictions effectively hold that intoxication is involuntary where the actor either lacks knowledge of the tendencies of the intoxicating substance ${ }^{152}$ or where a

148 Alabama, Alaska, Arizona, Arkansas, California, Colorado, Delaware, Florida, Georgia, Hawaii, Illinois, Indiana, Kansas, Kentucky, Maine, Maryland, Massachusetts, Minnesota, Nebraska, Nevada, New Hampshire, New Jersey, New York, North Carolina, Ohio, Oklahoma, Pennsylvania, South Dakota, Texas, Utah, Wisconsin, and Federal.

149 Alaska, Arizona, Florida, Georgia, Illinois, Kansas, Kentucky, Maine, Maryland, Massachusetts, Nevada, New Hampshire, New York, Ohio, Oklahoma, and Utah.

150 Alabama, Arkansas, California, Colorado, Delaware, Hawaii, Indiana, Nebraska, New Jersey, North Carolina, Pennsylvania, Texas, Wisconsin, Wyoming, and Federal.

151 Alabama, Arkansas, California, Colorado, Delaware, Hawaii, Indiana, Michigan, Minnesota, Missouri, Montana, Nebraska, New Jersey, North Carolina, Pennsylvania, Tennessee, Texas, Wisconsin, Wyoming, and Federal.

152 These jurisdictions actually define voluntary intoxication. One must infer that whatever does not fit that definition is "involuntary". 
traditional defense (like duress) would make such an act involuntary. ${ }^{153}$ This "either/or" formulation is essentially similar to MPC section 2.08. The other five jurisdictions hold that intoxication is involuntary only when the defendant lacks knowledge of the intoxicating tendency of the substance. ${ }^{154}$

\subsection{3. §403. Immaturity.}

A majority of jurisdictions provide an Immaturity defense, which might be summarized as follows:

Section 403. Immaturity.

(1) A person may be prosecuted as an adult if he is:

(a) 18 years old or older,

(b) 15 years old or older and is charged with [specified offenses], or

(c) 14 years old or older and the court determines after a hearing that he should be transferred to a criminal court for prosecution as an adult.

(2) In determining whether a person should be transferred to a criminal court for prosecution as an adult under Subsection (1)(c), the court shall consider the following factors:

(a) the nature and seriousness of the alleged offense,

(b) whether there is probable cause to believe that the person in question committed the alleged offense,

(c) the person's prior history and record in the juvenile or criminal system,

(d) the person's age and physical and mental maturity,

(e) the facilities available to serve the person's needs, and

(f) his amenability to treatment and the prospect of rehabilitation in the juvenile system.

Only twenty-three jurisdictions specifically address infancy or immaturity within their criminal codes. ${ }^{155}$ Other jurisdictions' immaturity statutes are scattered among various juvenile codes and other public laws. Cf. Utah Code

153 Alabama, Arkansas, California, Colorado, Delaware, Hawaii, Indiana, Nebraska, New Jersey, North Carolina, Pennsylvania, Texas, Wisconsin, Wyoming, and Federal. These jurisdictions are also counted among the majority for their traditional defense position.

154 Michigan, Minnesota, Missouri, Montana, and Tennessee.

155 Alabama, Arizona, California, Colorado, Florida, Georgia, Hawaii, Idaho, Illinois, Louisiana, Maine, Minnesota, Nevada, New Hampshire, New Jersey, New York, North Dakota, Oklahoma, Oregon, South Dakota, Texas, Utah, and Washington. 
Ann. $\$ 76-2-301$, with Del. Code Ann. tit. X, $\$ 1010$. The defense codifications vary greatly, both in form and content. Generally, however, immaturity defenses differ along four issues, namely: (a) the absolute age of maturity; (b) whether to try juveniles above a particular age as adults for specified offenses; (c) whether a court has the discretion to try a juvenile as an adult, and if so, what factors ought to be considered; and (d) the cut-off age below which a court lacks authority to try a juvenile as an adult.

(a) How old must a person be to be prosecuted as an adult in every case? Forty-six jurisdictions agree that persons who are eighteen years of age or older are subject to prosecution as an adult for any offense. ${ }^{156}$ Five minority jurisdictions set the age of majority at seventeen, ${ }^{157}$ and Nebraska alone sets it at nineteen (Neb. Rev. St. \$43-245).

(b) Should youths of a certain age, but below the age of maturity, be tried as adults for certain specified, serious offenses? A twenty-seven-jurisdiction majority agrees that they should. In twenty-four jurisdictions, a person below the age of eighteen may be charged automatically as an adult for certain specified serious offenses. ${ }^{158}$ Although the phrasing of these statutes varies, the resulting authority is the same in each formulation. ${ }^{159}$ (While these twenty-four jurisdictions do not themselves make up the twenty-seven needed for a majority view among the fifty-two jurisdictions, three additional jurisdictions set the default age of majority for criminal prosecution at seventeen, rather than eighteen, years of age. ${ }^{160}$ This necessarily includes adult treatment for any offense specified by another jurisdiction, thus creating of twenty-seven-jurisdiction majority view on this issue.) To determine the age at which this automatic

156 This includes all jurisdictions except Massachusetts, Michigan, Missouri, Nebraska, South Carolina, and Wisconsin.

157 Massachusetts, Michigan, Missouri, South Carolina, and Wisconsin.

158 Alabama, Arizona, Arkansas, Colorado, Connecticut, Delaware, District of Columbia, Georgia, Illinois, Indiana, Kansas, Maryland, Mississippi, Nevada, New York, North Carolina, Oklahoma, Oregon, Pennsylvania, Rhode Island, South Carolina, South Dakota, Tennessee, and Federal.

159 For example, Alabama and Arizona specifically provide for automatic treatment of juveniles as adults for listed offenses: Ala. Code $\$ 12-15-204$; and Ariz. Rev. Stat. Ann. $\$ 13-501$. South Carolina changes its definition of "child" for certain crimes to reflect a lower age (S.C. Code Ann. $\$ 63-19-20)$. Georgia, alternatively, grants exclusive jurisdiction to the superior court rather than the juvenile court for specific crimes (Ga. Code Ann. \$15-11-28). Maryland and Massachusetts both deny the juvenile court any jurisdiction over certain criminal offenders above a specified age. Md. Code Courts and Judicial Proceedings $\$ 3-8$ A-03; Mass. Gen. Laws Ann. ch. 119, $\$ 74$. Kansas creates a rebuttable presumption of adulthood for certain offenses (Kan. Stat. Ann. \$ 38-2347). Pennsylvania requires that juveniles who are alleged to have committed certain crimes be tried in juvenile courts "under the criminal law and procedure", unless they are transferred to an adult court (42 Pa. Cons. Stat. Ann. \$6355).

160 Massachusetts, Michigan, and Wisconsin. 
treatment is available for the majority formulation, each jurisdiction's relevant age was averaged: first, within each jurisdiction that has different ages assigned to different offenses; and second, combining those internal averages with all other jurisdictions, resulting in an age rounded to fifteen. ${ }^{161}$

The offenses for which adult prosecution is authorized are quite diverse, however, such that no majority rule can be formed on this point. It is common for jurisdictions to mention: "felonies"; violent crimes such as rape, assault, or robbery; and crimes involving weapons.

A minority of jurisdictions do not provide for automatic adult criminal treatment of an actor below the age of majority for any reason. The MPC seems to agree with this approach by generally providing that the adult criminal court has no jurisdiction over a sixteen- or seventeen-year old actor. The MPC does not list any specific offenses for which a juvenile actor may be automatically charged as an adult. See the MPC $\$ 4.10$.

(c) Does a court, aside from automatic treatment as an adult for specified offenses, have discretion to transfer a juvenile below the age of majority (eighteen in the majority formulation above) to criminal court? The majorityat least thirty-five jurisdictions-allows court discretion in the transfer of persons from juvenile to criminal court, but requires a hearing to determine whether transfer should be allowed. ${ }^{162}$ In at least twenty-eight of these jurisdictions, specific factors or court findings are listed that must be considered during such hearings. ${ }^{163}$ The factors contained in the majority formulation above are examples of those mentioned most often, though many jurisdictions leave the determination and weight of relevant factors to judges. See, e.g., Ark. Code Ann. \$9-27-318(g)(10); and Colo. Rev. Stat. Ann. \$ 19$2-518(4)(c)$.

Significantly, nineteen of the thirty-five majority jurisdictions have specific offense requirements that must be met before a transfer hearing can be held to determine whether a juvenile of a certain age should be prosecuted as an

161 The exact average is 14.75 years. Including the three jurisdictions that set the age of majority at 17, the average is 15.06 years.

162 See, e.g., Alabama, Alaska, Arizona, Arkansas, Colorado, Connecticut, Delaware, District of Columbia, Florida, Idaho, Illinois, Iowa, Kansas, Kentucky, Louisiana, Maine, Maryland, Minnesota, Missouri, Montana, New Hampshire, New Jersey, New Mexico, North Dakota, Ohio, Pennsylvania, Rhode Island, South Dakota, Tennessee, Texas, Vermont, Virginia, Washington, West Virginia, and Wyoming.

163 See, e.g., Alabama, Alaska, Arkansas, Colorado, Connecticut, Delaware, District of Columbia, Florida, Idaho, Illinois, Iowa, Kentucky, Maryland, Minnesota, Missouri, Montana, New Hampshire, New Mexico, North Dakota, Ohio, Pennsylvania, Rhode Island, South Dakota, Tennessee, Texas, Vermont, Virginia, and Washington. 
adult. $^{164}$ This minority view, if incorporated into (1)(c) of the majority formulation above, would read:

(1) ... if he is:

(c) 14 years old or older and charged with [specific offenses] and the court determines after a hearing that he should be transferred to a criminal court for prosecution as an adult.

In congruence with the majority, both the MPC and National Commission allow for the discretionary transfer of a juvenile actor to adult criminal court, though with far less operational specificity. The MPC allows for transfer without specifying factors to consider, and the National Commission allows for the prosecution of an actor under the age of eighteen to "promote justice" (The MPC $\$ 4.10$; and National Commission’s Report $\$$ 501).

(d) Below what age does a court lack discretion to transfer a juvenile to criminal court? Fourteen years-the age in (1)(c) of the majority formulation above-is the average of every age at which jurisdictions allow transfer to a criminal court, not including the ages at which adult prosecution is required or automatic. For example, Hawaii allows for transfer under different circumstances at fourteen and sixteen (Haw. Rev. Stat. $\$ 571.22$ ). Thus, fifteen is the age used to calculate the average. Alabama only allows for transfer to adult proceedings at age fourteen, so this age was used in the averaging (Ala. Code $\$$ 12-15-203). The average for all jurisdictions was approximately fourteen years. $^{165}$

Under the majority formulation, persons below fourteen years of age fall exclusively under the jurisdiction of the juvenile court system and cannot be criminally prosecuted or convicted for any offense. Jurisdictions either imply such a cut-off by providing for transfer above a certain age, but not below, see, e.g., Tex. Family Code Ann. $\$ 54.02$, or explicitly prohibiting the criminal prosecution of juveniles below a certain age. See, e.g., Utah Code Ann. $\$ 76-2-301$. In either case, the result is the same for the purpose of forming a majority view. Both the MPC and the National Commission have the same restriction on adult prosecution of a juvenile, but they specify higher ages - sixteen and fifteen, respectively_below which prosecution is prohibited. See, e.g., the MPC $\$ 4.10$; and National Commission’s Report $\$ 501$.

164 Arkansas, Colorado, Connecticut, District of Columbia, Idaho, Illinois, Kentucky, Louisiana, Maryland, Minnesota, Missouri, Montana, New Hampshire, North Dakota, Tennessee, Texas, Vermont, Virginia, and West Virginia.

165 The exact average is 14.025 years. 


\subsection{4. \$404. Duress.}

The majority view of the Duress defense among American jurisdictions might be stated as follows:

Section 404. Duress.

In a prosecution for an offense other than murder, it is a defense that the actor engaged in the proscribed conduct because he was coerced to do so by what he reasonably believed was an unlawful threat of imminent death or severe bodily injury to himself or another. This defense is not available if the actor culpably placed himself in a situation where duress was foreseeable.

At least fifty of the fifty-two jurisdictions recognize some type of Duress defense. ${ }^{166}$ Their formulations differ, however, regarding a variety of issues, most significantly whether: (a) to allow a defense for any offense upon coercion by any "unlawful force", or to require that the actor be coerced by a particularly serious threat; (b) the actor must have a "reasonable belief" that his actions were required under the circumstances; (c) the anticipated threat or harm must be "imminent"; (d) the defense should be unavailable for specific offenses; (e) the defense ought to be available when the threat is to a third party, rather than the actor himself; and (f) an actor can claim duress when responsible for putting himself in the situation that led to his coercion.

(a) Should the Duress defense be available only upon coercion by a very serious threat? A twenty-nine-jurisdiction majority takes this demanding approach, championed by the National Commission. ${ }^{167}$ Only three of these jurisdictions, however-Indiana, North Dakota, and Texas-actually reflect the full National Commission approach of applying different standards of the defense availability to acts amounting to felonies (requiring threats of "serious bodily injury") and acts amounting to non-felonies (requiring threats of "use of force”). See, e.g., Ind. Code $\$$ 35-41-3-8; N.D. Cent. Code $\$$ 12.1-05-10; Tex. Penal Code Ann. $\$ 8.05$; and National Commission’s Report $\$ 610$. Most of the majority jurisdictions, and thus the majority formulation as well, require the more serious threat before offering a defense to any offense, even a non-felony.

166 Alabama, Alaska, Arizona, Arkansas, California, Colorado, Delaware, District of Columbia, Florida, Georgia, Hawaii, Idaho, Illinois, Indiana, Iowa, Kansas, Kentucky, Louisiana, Maine, Maryland, Massachusetts, Michigan, Minnesota, Mississippi, Missouri, Montana, Nebraska, Nevada, New Hampshire, New Jersey, New Mexico, New York, North Carolina, North Dakota, Ohio, Oklahoma, Oregon, Pennsylvania, Rhode Island, South Dakota, Tennessee, Texas, Utah, Vermont, Virginia, Washington, West Virginia, Wisconsin, Wyoming, and Federal.

167 Alabama, California, District of Columbia, Georgia, Illinois, Indiana, Kansas, Louisiana, Maine, Maryland, Massachusetts, Minnesota, Mississippi, Montana, Nevada, New Hampshire, New Mexico, North Carolina, North Dakota, Ohio, Oklahoma, Rhode Island, Texas, Vermont, Washington, West Virginia, Wisconsin, Wyoming, and Federal. 
The remaining minority jurisdictions take one of two approaches to the issue. First, thirteen adopt a more lenient formulation in which a duress defense is available when an actor is subject simply to "unlawful force". ${ }^{168}$ Some of these jurisdictions appear to agree with the MPC's approach, which-although similarly lenient when compared to the majority view-shifts the issue from the nature of the threat to an objective assessment of the strength of the coerced actor's resolve, thus requiring that a "person of reasonable firmness" would not have been able to resist (The MPC $\$ 2.09(1)$ ). Second, nine minority jurisdictions require that the crime committed be less severe than the harm threatened to coerce the actor into committing that crime. ${ }^{169}$ Essentially, these latter jurisdictions treat duress like a lesser evils defense. That is, they define duress in a way that makes it a justification (the actor did the right thing and avoided a greater evil) rather than an excuse (the actor did the wrong thing but is judged blameless nonetheless). In some jurisdictions, this "lesser harm" test is implied; other jurisdictions overtly require it. Cf. Ariz. Rev. Stat. Ann. \$13-412 (allowing the duress defense when an actor is subjected to "a threat or use of immediate physical force against his person or the person of another which resulted or could result in serious physical injury". Simultaneously, it asserts, "the defense provided by subsection A is unavailable for offenses involving homicide or serious physical injury". Thus, an actor threatened with serious physical injury may not commit a crime in response to that threat which results in the serious physical injury of another. In other words, the actor may not perform an "equal evil" under duress.) with Tugmon v. State, 896 P.2d 342, 345-46 (Ibid. 1995) and State v. Heinemann, 920 A.2d 278 (Conn. 2007).

(b) To receive the Duress defense, must an actor "reasonably believe" that he or someone else will be harmed unless he carries out a given crime? At least twenty-seven jurisdictions agree that he must. ${ }^{170}$ Jurisdictions formulate the requirement in one of two ways, requiring either a "reasonable belief" in or "well-grounded apprehension" of the threatened harm. Both formulations apply an objective standard to determine whether a duress claim applies in a given situation, making them similar enough to jointly form a majority. The majority formulation adopts the "reasonably believes" language because,

168 Alaska, Arkansas, Colorado, Delaware, Hawaii, Kentucky, Missouri, New Jersey, New York, Oregon, Pennsylvania, South Dakota, and Utah.

169 Arizona, Connecticut, Florida, Idaho, Iowa, Michigan, South Carolina, Tennessee, and Virginia.

170 See, e.g., Arizona, Arkansas, California, District of Columbia, Georgia, Illinois, Iowa, Kansas, Louisiana, Maryland, Michigan, Minnesota, Mississippi, Montana, Nevada, North Carolina, Oklahoma, Rhode Island, South Carolina, Tennessee, Vermont, Virginia, Washington, West Virginia, Wisconsin, Wyoming, and Federal. 
of the two, it is used most often. None of the remaining jurisdictions require that an actor's belief necessarily be reasonable.

(c) Must the threatened harm be "imminent?" At least thirty-nine jurisdictions require that the harm threatened upon the actor not be too far removed in time from the unlawful act performed in response. Of those thirty-nine, a twenty-six-jurisdiction majority specifically uses the term "imminent", either alone or in conjunction with other terms. ${ }^{171}$ Therefore, the majority formulation's temporal requirement takes this form. Thirteen more jurisdictions use terms like "immediate" and "instant" to describe the threat's proximity in time, ${ }^{172}$ but in practice these terms are interchangeable with "imminent". A few jurisdictions use more than one term, which underscores such interchangeability. ${ }^{173}$ The remaining jurisdictions do not explicitly require a temporal relationship between the criminal conduct and the unlawful threat that coerces it, theoretically allowing broader use of the Duress defense.

(d) Should the Duress defense be available in prosecutions for all offenses? Thirty-two jurisdictions exclude the use of duress as a defense for certain, specified offenses. ${ }^{174}$ Although exclusions range from "intentionally or recklessly caus[ing] physical injury" to intentional homicide, the only offense that commands majority exclusion is murder. See, e.g., Iowa Code $\$ 704.10$ ("other than... intentionally or recklessly caus[ing] physical injury"); and Ky. Rev. Stat. Ann. $\$ 501.090$ ("other than an intentional homicide”). Twenty-nine jurisdictions exclude murder, ${ }^{175}$ usually under a larger umbrella such as homicide generally or "offenses punishable by death". See, e.g., Cal. Penal Code $\$ 26$. Wisconsin and New Jersey do not allow a full duress defense for homicide or murder, but instead allow mitigation from first- to second-degree intentional

171 Alabama, Connecticut, Florida, Georgia, Illinois, Indiana, Iowa, Kansas, Maine, Maryland, Michigan, Mississippi, Missouri, Montana, New Hampshire, New York, North Carolina, North Dakota, Oklahoma, South Carolina, Tennessee, Texas, Utah, West Virginia, Wisconsin, and Wyoming.

172 Arizona, District of Columbia, Idaho, Louisiana, Massachusetts, Minnesota, Nebraska, New Mexico, Rhode Island, Vermont, Virginia, and Washington.

173 Florida, Maryland, Massachusetts, Michigan, Mississippi, South Carolina, Tennessee, West Virginia, and Wyoming.

174 Alabama, Arizona, California, Colorado, Florida, Georgia, Illinois, Indiana, Iowa, Kansas, Kentucky, Louisiana, Maine, Maryland, Massachusetts, Michigan, Mississippi, Missouri, Montana, Nebraska, Nevada, New Jersey, New Mexico, North Carolina, Ohio, Oregon, South Carolina, Virginia, Washington, West Virginia, Wisconsin, and Wyoming.

175 Alabama, Arizona, California, Colorado, Florida, Georgia, Illinois, Indiana, Kansas, Kentucky, Louisiana, Maine, Maryland, Massachusetts, Michigan, Mississippi, Missouri, Montana, Nebraska, Nevada, New Mexico, North Carolina, Ohio, Oregon, South Carolina, Virginia, Washington, West Virginia, and Wyoming. 
homicide, or from murder to manslaughter. See, e.g., Wis. Stat. Ann. $\$ 939.46$ ("except that if the prosecution is for first-degree intentional homicide, the degree of the crime is reduced to 2nd-degree intentional homicide"); and N.J. Stat. Ann. $\$ 2$ C:2-9 ("In a prosecution for murder, the defense is only available to reduce the degree of the crime to manslaughter."). The remaining jurisdictions, like the MPC, do not specifically preclude duress as a defense to any particular crime, although, as a practical matter, its terms will be more difficult to satisfy in increasingly serious cases.

(e) Should the Duress defense be available if a third person, rather than the actor himself, is the one under threat? At least twenty-seven jurisdictions embrace a duress defense for third person threats of some sort. At least twenty-four jurisdictions allow a duress defense if the threat is made toward any third person. ${ }^{176}$ Three more jurisdictions make the same concession, but only if that third person is a spouse, child, or other family member: 720 Ill. Comp. Stat. Ann. 5/7-11; Kan. Stat. Ann. \$21-5206; and Okla. Stat. tit. 21, \$ 156. Since the greatest number of jurisdictions within the majority supports a defense for any third person, that version is adopted in the majority formulation.

(f) Should an actor receive a duress defense if he placed himself in the position leading to his coercion? A majority of at least twenty-seven jurisdictions follow the MPC and National Commission by barring a Duress defense if the actor, with some specified level of culpability, placed himself in a situation in which duress was "probable" or "foreseeable" (these terms being used interchangeably). ${ }^{177}$ These jurisdictions disagree, however, about the specific culpability requirement for the actor putting himself in that position. Some jurisdictions require intent or recklessness, while others will deny use of the defense if the actor's behavior was negligent, particularly where negligence is sufficient culpability for the crime itself. See, e.g., Colo. Rev. Stat. Ann. $\$ 18-1-708$ (requiring intent or recklessness); Wash. Rev. Code Ann. \$9a.16.060 (requiring intent or recklessness); Ala. Code $\$ 13 \mathrm{~A}-3-30$ (allowing negligence to prohibit the defense when negligence is sufficient culpability for the crime itself); and Me. Rev. Stat. Ann. tit. 17-A, $\$ 103-A$ (allowing the same). The majority formulation reflects the need for some level of culpability while maintaining this ambiguity concerning the specific requirement.

176 See, e.g., Alabama, Alaska, Arizona, Arkansas, Colorado, Connecticut, Delaware, Hawaii, Indiana, Kentucky, Maine, Missouri, New Jersey, New York, North Dakota, Oregon, Pennsylvania, South Dakota, Tennessee, Texas, Utah, Virginia, Washington, and Wisconsin.

177 See, e.g., Alabama, Alaska, Arizona, Arkansas, Colorado, Connecticut, Delaware, Florida, Hawaii, Idaho, Indiana, Kansas, Kentucky, Maine, Michigan, Mississippi, Missouri, New Jersey, New York, North Dakota, Oregon, Pennsylvania, Tennessee, Texas, Utah, Washington, West Virginia, and Federal. 


\subsection{5. §405. Involuntary Act or Omission.}

The majority view of the Involuntary Act defense among American jurisdictions might be stated as follows:

Section 405. Involuntary Act or Omission.

(1) In any prosecution, it is a defense that the defendant's conduct constituting the offense was involuntary or, in the case of liability for an omission, that the defendant was not physically capable of performing the conduct required by the offense.

(2) An act is involuntary if it is not the product of the defendant's conscious effort or determination.

Arguably, a voluntary act is the most fundamental requirement of criminal liability. See the MPC $\$ 2.01$, Commentary on Subsection (1). The Involuntary Act or Omission defense is therefore largely ubiquitous. There are, however, key areas of difference among American jurisdictions that must be addressed in constructing this portion of the ACC, namely: (a) the broad formulation of the defense and whether to include omissions along with acts; (b) the definitions of "involuntary" or "voluntary" acts or omissions; and (c) whether specific dysfunctions giving rise to this defense are listed in the provision.

(a) American jurisdictions broadly agree that an involuntary act should receive a defense to liability. At least forty-two jurisdictions either require a voluntary act as an element of every offense or specify a defense for involuntary acts. ${ }^{178}$ Additionally, the majority formulation recognizes liability for an omission only when the actor failed to perform an act of which he is "physically capable". Only fifteen jurisdictions explicitly include this language in their formulations ${ }^{179}$; however, no jurisdiction rejects this requirement, and it may well be implicit in the requirement of voluntariness. ${ }^{180}$

178 See, e.g., Alabama, Alaska, Arizona, Arkansas, California, Colorado, Connecticut, Delaware, District of Columbia, Georgia, Hawaii, Idaho, Illinois, Indiana, Iowa, Kansas, Kentucky, Louisiana, Maine, Maryland, Massachusetts, Michigan, Minnesota, Missouri, Montana, Nebraska, New Hampshire, New Jersey, New York, Nevada, North Carolina, Ohio, Oklahoma, Oregon, Pennsylvania, Tennessee, Texas, Utah, Virginia, Vermont, Washington, and Wisconsin.

179 Alabama, Alaska, Arizona, Colorado, Delaware, Hawaii, Illinois, Kentucky, Missouri, Montana, New Hampshire, New Jersey, New York, Ohio, and Pennsylvania.

180 Unlike the majority formulation, the National Commission does not require any sort of "voluntariness" (National Commission's Report $\$ 301(1)$ ). Only North Dakota follows the National Commission formulation, requiring only an "act" in violation of the law (N.D. Cent. Code $\$$ 12.1-02-01(1)). 
(b) Many jurisdictions provide the defense but fail to define what constitutes involuntary conduct, or a "voluntary" act. ${ }^{181}$ The majority formulation above follows the most common definition among those jurisdictions that do define either "involuntary" or "voluntary" (in which case, "involuntary" is inferred to be the negative of it). ${ }^{182}$ The MPC goes further to explicitly include "habitual" (though unconscious) acts to be "voluntary"; however, only a few jurisdictions follow its lead. See, e.g., the MPC \$2.01(1)(d); Del. Code Ann. tit. 11, \$243; and Haw. Rev. Stat. $\$ 702-201$. Most do not address the issue.

(c) Some jurisdictions follow the MPC in listing specific dysfunctions that are not to be considered voluntary acts. ${ }^{183}$ These lists of involuntary actions may not be exhaustive or exclusive, but they paint a general picture of what might constitute an involuntary act. These lists commonly are capped with a catch-all provision, with language similar to that in Subsection (2) of the majority formulation above. See, e.g., Mont. Code Ann. \$ 45-2-101(33) (“An 'involuntary act' means an act that is ... a bodily movement that otherwise is not a product of the effort or determination of the actor, either conscious or habitual").

\subsection{6. \$406. Reliance Upon Official Misstatement of Law.}

The majority view of the Reliance Upon Official Misstatement of Law defense among American jurisdictions might be stated as follows:

Section 406. Reliance Upon Official Misstatement of Law.

A belief that conduct does not legally constitute an offense is a defense to a prosecution for that offense based upon such conduct when the actor reasonably relies upon an official statement of law, afterward determined to be invalid or erroneous, contained in:

(a) a statute or other enactment;

(b) a judicial decision, opinion or judgment;

(c) an administrative order; or

(d) an official interpretation by the public officer or body charged by law with responsibility for the interpretation, administration or enforcement of the law defining the offense.

As a general rule, ignorance or mistake of the law is no defense unless it negates a required offense element. That is, there is typically no general excuse

181 See, e.g., Arkansas, California, Connecticut, Idaho, Illinois, Oklahoma, Pennsylvania, Utah, and Vermont.

182 See, e.g., Alabama, Alaska, Arizona, Colorado, Delaware, Hawaii, Kentucky, Maine, Missouri, Nebraska, New Jersey, New York, Oregon, Tennessee, Texas, and Washington.

183 The MPC $\$ 2.01(2)$. See, e.g., Indiana, Maine, Montana, Ohio, Texas, and Wyoming. 
for even a reasonable mistake of law. Only one state, New Jersey, provides such a general excuse:

c. A belief that conduct does not legally constitute an offense is a defense to a prosecution for that offense based upon such conduct when:

$[\ldots]$

(3) The actor ... diligently pursues all means available to ascertain the meaning and application of the offense to his conduct and honestly and in good faith concludes his conduct is not an offense in circumstances in which a law-abiding and prudent person would also so conclude.

N.J. Stat. Ann. \$2C:2-4(c).

However, a majority of American jurisdictions recognize an excuse for someone who reasonably relies upon an official misstatement of law. The arguments in support of such a rule are not just the blamelessness of the actor, but alsoand perhaps more importantly-estoppel against a government that has brought about the offense by its own erroneous advice.

A majority of thirty-six jurisdictions, following the MPC, $\$ 2.04(3)(\mathrm{b})$, recognize a reasonable reliance upon mistake of law defense. ${ }^{184}$ A minority of jurisdictions closely follow the MPC by explicitly requiring that the official misstatement of law be "afterward determined to be invalid or erroneous". ${ }^{185}$ We believe this is implicit even when not explicitly stated. Thus, it has been included in the majority formulation. After all, if the official statement of law is not actually erroneous, then the actor has not actually committed an offense, and therefore needs no defense. The majority formulation, therefore, tracks MPC $\$ 2.04(3)(b)$.

Although commonly recognizing a defense for reliance upon official misstatement of law, jurisdictions disagree on several issues, namely: (a) what sources of official misstatement are recognized as giving rise to a defense; (b) whether to expressly require that the actor have relied upon the misstatement in good faith; and (c) whether to provide a defense where the mistake arises not from an official misstatement but because the law has not been published or otherwise publicly made known.

184 Alabama, Alaska, Arkansas, Colorado, Connecticut, Delaware, District of Columbia, Florida, Hawaii, Idaho, Illinois, Indiana, Kansas, Kentucky, Louisiana, Maine, Massachusetts, Michigan, Minnesota, Mississippi, Missouri, Montana, New Hampshire, New Jersey, New Mexico, New York, North Carolina, North Dakota, Pennsylvania, Rhode Island, Texas, Utah, Virginia, Washington, Wisconsin, and Federal.

185 The MPC $\$ 2.04(3)(b)$. See, e.g., Arkansas, Hawaii, Illinois, Indiana, Kansas, Kentucky, Maine, Missouri, Montana, and New Jersey. 
(a) What legal sources have such authority that their misstatement of law gives rise to a defense to criminal liability? Most jurisdictions have, either explicitly in their various codes or generally in their case law, adopted some combination of the four official sources of misstatements recognized in the MPC. At least twenty-two jurisdictions allow reliance upon statutes ${ }^{186}$; twenty-nine allow reliance upon judicial decisions ${ }^{187}$; twenty-three allow reliance upon administrative orders ${ }^{188}$; and twenty-six allow reliance upon official interpretations of law by those legally charged with this duty. ${ }^{189}$ Fifteen of the eighteen jurisdictions providing for this defense by statute follow the MPC and allow reliance on all four of these sources. ${ }^{190}$ Four additional common law jurisdictions support all four sources of authority. ${ }^{191}$

It is likely that these tabulations understate the support for reliance upon statements from these sources. In the remaining common law jurisdictions that have failed to address the various sources of authority, it is likely the only reason these four sources have not been explicitly recognized is that relevant cases debating their merits have not come up in their court systems. For this reason, we have relied on the simple majority statutory support and significant minority common law support for all four sources of authority in including them in our majority formulation.

(b) Must the actor have relied upon the misstatement of law in "good faith?" Only twelve jurisdictions, following the National Commission $\$ 609$, explicitly require that the defendant's belief that the conduct does not constitute a crime

186 The MPC $\$ 2.04(3)(\mathrm{b})(\mathrm{i})$; Alabama, Alaska, Arkansas, Colorado, Connecticut, Delaware, District of Columbia, Hawaii, Illinois, Kansas, Kentucky, Louisiana, Maine, Missouri, Montana, New Hampshire, New Jersey, New York, North Carolina, North Dakota, Rhode Island, and Pennsylvania.

187 The MPC \$2.04(3)(b)(ii); Alabama, Alaska, Arkansas, Colorado, Connecticut, Delaware, District of Columbia, Florida, Hawaii, Idaho, Illinois, Indiana, Kansas, Kentucky, Louisiana, Maine, Michigan, Minnesota, Missouri, Mississippi, Montana, New Hampshire, New Jersey, New Mexico, New York, North Dakota, Rhode Island, Pennsylvania, Texas, Utah, and Federal.

188 The MPC $\$ 2.04(3)(\mathrm{b})(\mathrm{iii})$; Alaska, Arkansas, Colorado, Connecticut, Delaware, District of Columbia, Hawaii, Illinois, Kansas, Kentucky, Louisiana, Maine, Minnesota, Missouri, Montana, New Hampshire, New Jersey, New York, North Carolina, North Dakota, Rhode Island, Pennsylvania, Texas, Utah, and Federal.

189 The MPC $\$ 2.04(3)(\mathrm{b})(\mathrm{iv}) ;$ Alaska, Arkansas, Colorado, Connecticut, Delaware, District of Columbia, Hawaii, Idaho, Illinois, Kansas, Kentucky, Louisiana, Maine, Massachusetts, Minnesota, Missouri, Montana, New Hampshire, New Jersey, New York, North Dakota, Rhode Island, Pennsylvania, Texas, Utah, Virginia, and Wisconsin.

190 Arkansas, Colorado, Connecticut, Hawaii, Illinois, Kansas, Kentucky, Maine, Missouri, Montana, New Hampshire, New Jersey, New York, North Dakota, and Pennsylvania.

191 Alaska, Delaware, District of Columbia, and Rhode Island. 
be in good faith. ${ }^{192}$ Only two jurisdictions have codified this: N.J. Stat. Ann. $\$ 2$ C:2-4(C); and N.D. Cent. Code $\$ 12.1-05-09$. Alabama references the need for good faith in the commentary for Ala. Code $\$ 13 \mathrm{~A}-2-6$. But the lack of codification probably exists because a "good faith" requirement is implicit in the defense. A "good faith" belief in this instance is a belief that the actor truly holds-an honest belief. Such a requirement is inherent in the statutory requirement that a "belief that conduct does not legally constitute an offense is a defense", as appears in the majority formulation. It is also inherent in the requirement that the actor's reliance upon the official statement of law be "reasonable". Since neither the MPC nor the majority of jurisdictions thought it necessary to include redundant "good faith" language, the majority formulation does not include it, either.

(c) Should an actor have a defense where his mistake arises not from relying upon an official misstatement, but rather because the law has not been published or otherwise made publicly known? The MPC explicitly recognizes such a basis for defense; however, only two jurisdictions appear to follow the MPC in recognizing such a defense: The MPC $\$ 2.04(3)(a) ;$ Me. Rev. Stat. Ann. tit. 17-A $\$ 36$; and N.J. Stat. Ann. $\$ 2$ C:2-4. Four others specifically allowing the defense with regard to administrative regulations or orders, but not statutes. ${ }^{193} \mathrm{~A}$ majority of jurisdictions simply do not address the issue, failing to account for it in either their statutes or case law. ${ }^{194}$ The Pennsylvania Legislature arguably explicitly declined to adopt such a defense. ${ }^{195}$ On the contrary, such a defense may be constitutionally required by notions of due process. See State v. Berberian,

192 Delaware, District of Columbia, Florida, Minnesota, Missouri, New Jersey, North Dakota, Pennsylvania, Virginia, Washington, Wisconsin, and Federal.

193 Illinois, Kansas, Missouri, and Montana.

194 See, e.g., Alabama, Alaska, Arkansas, California, Colorado, Connecticut, Delaware, District of Columbia, Florida, Hawaii, Idaho, Indiana, Iowa, Kentucky, Louisiana, Massachusetts, Minnesota, Mississippi, Nebraska, Nevada, New Hampshire, New Mexico, New York, North Carolina, North Dakota, Ohio, Oklahoma, Oregon, Tennessee, Texas, Utah, and Vermont.

195 In Com. v. Kratsas, 564 Pa. 36, 52 (2001), the court explained, "Some state legislatures, following the example in Section 2.04(3)(b) of the MPC, have enacted statutes providing for a limited defense based upon a mistake of law in a manner that parallels the reliance doctrine, affording an elemental structure and the status of an affirmative defense. In such jurisdictions, it is clear that, even if the circumstances involving an official misrepresentation are not sufficient to require dismissal of the prosecution on due process grounds, the defendant would generally be permitted to present them to the jury in the context of the affirmative defense. However, the availability of a reliance defense on such terms (independent of constitutional due process principles and constraints) is not so clear in Pennsylvania-although the General Assembly adopted many provisions of the MPC in enacting the comprehensive Crimes Code, it declined to adopt Section 2.04(3)(b) or to effectuate any substantial equivalent. Indeed, official commentary reflects the legislative intent that ' $\mathrm{g}$ ] enerally speaking, ignorance or mistake of law is no defense.' 18 Pa.C.S. $\$ 304$ (official comment)” (emphasis added). 
427 A.2d 1298, 1301 (R.I. 1981); and Miller v. Commonwealth, 492 S.E.2d 482, 487 (Va. 1997).

\subsection{Chapter 5. Other Bars to Liability}

\subsection{1. §501. All Defenses Defined by Statute.}

The majority view among American jurisdictions is that all offenses must be defined by statute. It might be codified as follows:

Section 501. All Offenses Defined by Statute.

No conduct constitutes an offense unless it is a crime or violation under this Code or other statute.

By requiring that all offenses be defined by statute, the provision above provides a defense for any person whose conduct does not satisfy the elements of a codified offense. A thirty-four jurisdiction majority supports this requirement in barring judicial creation of offenses. Legislatures in thirty-two jurisdictions have explicitly abolished all common law offenses, recognizing only those crimes that have been or will be enacted by legislation. ${ }^{196}$ Arizona has further abolished all common law affirmative defenses (Ariz. Rev. Stat. Ann. $\$ 13-103)$. Federal courts have affirmed that there is, technically speaking, no federal criminal common law-though some scholars insist that there is at least some such body of law in practice. ${ }^{197}$

An eighteen-jurisdiction minority recognizes common law offenses to the extent that they have not been explicitly superseded by statute. ${ }^{198}$ These states maintain "reception" statutes, which codify the incorporation of common law offenses without defining them. Some of these reception statutes do not specifically refer to criminal offenses, but simply incorporate the common law in its entirety, so long as it is not inconsistent with U.S. or state law. See, e.g., Ark. Code Ann. $\$ 1-2-119$. This incorporation necessarily includes the criminal common law, unless abolished or repealed elsewhere.

196 Alabama, Alaska, California, Colorado, Connecticut, Delaware, Georgia, Hawaii, Idaho, Illinois, Indiana, Iowa, Kansas, Kentucky, Louisiana, Maine, Minnesota, Missouri, Montana, Nebraska, Nevada, New Hampshire, New Jersey, Oklahoma, Oregon, Pennsylvania, South Dakota, Tennessee, Texas, Utah, Wisconsin, and Wyoming.

197 Cf., Liparota v. United States, 471 U.S. 419, 424 (1985) ("The definition of the elements of a criminal offense is entrusted to the legislature, particularly in the case of federal crimes, which are solely creatures of statute.") and Central Bank of Denver, N.A. v. First Interstate Bank of Denver, N.A., 511 U.S. 164, 184 (1994) (“There is no federal common law of crimes ....") with Ben Rosenberg. 2002. The Growth of Federal Criminal Common Law. 29 Am. J. Crim. L. 193 (discussing the practical existence of a Federal criminal common law).

198 Arkansas, District of Columbia, Florida, Maryland, Massachusetts, Michigan, Mississippi, New Mexico, New York, North Carolina, North Dakota, Ohio, Rhode Island, South Carolina, Vermont, Virginia, Washington, and West Virginia. 


\subsection{2. \$502. Statute of Limitations.}

The majority view of the Statute of Limitations among American jurisdictions might be stated as follows:

Section 502. Statute of Limitations.

(1) The prosecution of murder [and other specified serious felonies] may be commenced at any time.

(2) The prosecution of a felony is barred unless commenced within 6 years of the commission of the offense.

(3) The prosecution of any other offense is barred unless commenced within 2 years of the commission of the offense.

(4) The period of limitation is extended for any period during which the defendant is continuously absent from the State or has no reasonably ascertainable place of abode or work within the State.

Nearly every jurisdiction recognizes a defense under a statute of limitations. ${ }^{199}$ Jurisdictions disagree, however, about several of the specific demands of the defense, including: (a) whether to suspend the statute of limitations for serious offenses other than murder; (b) the period of limitation that should be set for most felonies; (c) the period of limitation for other offenses; (d) under what conditions the limitation period can be extended, and for how long; and (e) whether to alter the limitation rules under special circumstances.

(a) Should the statute of limitations be suspended for especially egregious crimes? An overwhelming majority of at least forty-four jurisdictions, following the MPC, $\$ 1.06(1)$, and National Commission, $\$ 701(3)$, have no statute of limitation for murder. ${ }^{200}$ These jurisdictions either specifically exempt murder or exempt a category of crime that necessarily includes murder, such as capital offenses.

Additionally, at least thirty-seven jurisdictions additionally have no limitation period for one or more crimes other than murder. ${ }^{201}$ As to what other

199 Alabama, Alaska, Arizona, Arkansas, California, Colorado, Connecticut, Delaware, District of Columbia, Federal, Florida, Georgia, Hawaii, Idaho, Illinois, Indiana, Iowa, Kansas, Kentucky, Louisiana, Maine, Maryland, Massachusetts, Michigan, Minnesota, Mississippi, Missouri, Montana, Nebraska, Nevada, New Hampshire, New Jersey, New Mexico, New York, North Carolina, North Dakota, Ohio, Oklahoma, Oregon, Pennsylvania, Rhode Island, South Dakota, Tennessee, Texas, Utah, Vermont, Virginia, Washington, West Virginia, and Wisconsin.

200 Alabama, Alaska, Arizona, Arkansas, California, Colorado, Connecticut, Delaware, District of Columbia, Florida, Georgia, Hawaii, Idaho, Illinois, Indiana, Iowa, Kansas, Kentucky, Louisiana, Maine, Massachusetts, Michigan, Minnesota, Mississippi, Missouri, Montana, Nebraska, Nevada, New Hampshire, New Mexico, New Jersey, New York, North Dakota, Ohio, Oregon, Pennsylvania, Rhode Island, South Dakota, Tennessee, Texas, Vermont, Washington, Wisconsin, and Federal.

201 Alabama, Alaska, Arizona, Arkansas, California, Colorado, Connecticut, Delaware, Florida, Hawaii, Idaho, Illinois, Indiana, Kansas, Kentucky, Louisiana, Maine, Massachusetts, Michigan, Minnesota, 
serious felonies should have this exemption, these jurisdictions disagree. The bracketed text in the majority formulation ("and other specified serious felonies") is included to acknowledge this situation. The most common offenses additionally exempted include: sexual abuse of a minor, ${ }^{202}$ sexual assault generally, ${ }^{203}$ arson, ${ }^{204}$ child pornography, ${ }^{205}$ human trafficking, ${ }^{206}$ forgery, ${ }^{207}$ terrorism, ${ }^{208}$ rape ${ }^{209}$ kidnapping, ${ }^{210}$ and drug trafficking. See, e.g., Ala. Code $\$ 15-3-1$; and R.I. Gen. Laws Ann. $\$ 12-12-17$. The MPC does not provide for exemption of offenses other than murder. See the MPC $\$ 1.06(1)$.

(b) What should be the limitation period for felonies? The majority formulation above imposes a six-year limitation period for felonies. This represents the average limitation period for felonies (other than those exempt, such as murder, as discussed above) of all American jurisdictions. (The average is actually 6.15 years, rounded down to 6-all jurisdictions express the limitation period in whole years.) However, this average is not quite as simple a measure as one might like.

Some jurisdictions break felonies into two or more subclasses, each with a different limitation period. ${ }^{211}$ The MPC, for example, recognizes two felony classes distinguished by degree, with limitation periods of six and three years. The MPC $\$ 1.06(2)(a)-(b)$. However, most jurisdictions-at least twentyeight-treat felonies generally as a single class, ${ }^{212}$ though many list several exceptions to the general category. See, e.g., Ariz. Code $\$ 13-107$. For example, the

Mississippi, Missouri, Montana, Nebraska, Nevada, New Jersey, New Mexico, New York, Oregon, Pennsylvania, Rhode Island, South Dakota, Tennessee, Texas, Vermont, Washington, and Federal.

202 See, e.g., Alabama, Alaska, Arkansas, Colorado, Idaho, Maine, Mississippi, Nebraska, New York, Rhode Island, Texas, and Vermont.

203 See, e.g., Alaska, Arizona, Arkansas, Nebraska, Rhode Island, Texas, and Vermont.

204 See, e.g., Alabama, Illinois, Mississippi, Nebraska, Rhode Island, Vermont, and Washington.

205 See, e.g., Alaska, Arizona, Arkansas, Illinois, and Mississippi.

206 See, e.g., Alaska, Arizona, Mississippi, Texas, and Vermont.

207 See, e.g., Alabama, Colorado, Illinois, Mississippi, and Nebraska.

208 See, e.g., Idaho, Kansas, Michigan, and Nevada.

209 See, e.g., Idaho, New York, and Rhode Island.

210 See, e.g., Alaska, Colorado, Mississippi, and Vermont.

211 See, e.g., Florida, Georgia, Hawaii, Iowa, Kansas, Louisiana, Massachusetts, Michigan, Minnesota, Mississippi, Nevada, New Jersey, New Mexico, Oklahoma, and Tennessee.

212 Arizona, Alabama, Alaska, Colorado, Connecticut, Delaware, District of Columbia, Idaho, Illinois, Indiana, Kentucky, Maine, Missouri, Montana, Nebraska, New Hampshire, New York, North Dakota, Ohio, Oregon, Pennsylvania, Rhode Island, South Dakota, Texas, Utah, Vermont, Washington, and Wisconsin. 
National Commission sets a general limit of five years for felonies, but separates out a small group of treason- and corruption-related felonies for a ten-year limit (National Commission’s Report $\$ 701(2)(\mathrm{a})-(\mathrm{b}),(4))$. (Jurisdictions do not consistently exclude the same crimes, however, so these exceptions are ignored for the purpose of the majority rule.) Among the jurisdictions that break felonies into two or more classes, the average of those different classifications within the jurisdiction was used to compute an average for that jurisdiction and it was this average that was used for the jurisdiction in the averaging done to reach the figure in the majority formulation.

(c) What should be the limitation period for lesser crimes than felonies? Nearly every jurisdiction describes one or more categories of crimes that are less serious than felonies-for example, misdemeanors and/or petty offensesand assigns a shorter limitation period to these grades of offenses. ${ }^{213}$ A majority of these jurisdictions have a single statute of limitations for all such subfelonies. A minority of these jurisdictions provides a different limitation period for their different sub-felony classes, but there is little agreement as to the grading distinctions between them.

For the purposes of the majority calculation for sub-felony limitation period, where a jurisdiction had more than one sub-felony limitation period, the subfelony periods were averaged to give a figure for that jurisdiction. This was used in averaging all jurisdictions' sub-felony limitation periods to reach an overall average of 2.27 years, rounded down to 2 years for the majority formulation limit for sub-felonies. ${ }^{214}$ (As with felonies, the MPC diverges from the majority formulation by dividing sub-felony crimes into misdemeanors and petty misdemeanors, with limitation periods of three years and six months, respectively (The MPC $\$ 1.06(2)(\mathrm{c})-(\mathrm{d}))$. The National Commission aligns with the majority view in treating all sub-felony crimes as a single class, with a three-year limitation period (National Commission’s Report $\$ 701(2)(\mathrm{c})$ ).

(d) Under what circumstances, and for how long, can the limitation period be extended? Commonly referred to as "tolling", jurisdictions take many different approaches to this question. The only circumstance commanding a majority of jurisdictions is tolling the limitation period where the accused is a

213 See, e.g., Alabama, Arizona, Arkansas, Colorado, Delaware, Florida, Georgia, Hawaii, Idaho, Illinois, Indiana, Iowa, Kansas, Louisiana, Maine, Maryland, Missouri, Montana, Nebraska, Nevada, New Hampshire, New Mexico, New York, North Carolina, North Dakota, Ohio, Oregon, Pennsylvania, Rhode Island, South Dakota, Tennessee, Texas, Utah, Vermont, Virginia, Washington, and Wisconsin.

214 Though some jurisdictions express their sub-felony limits in months, rather than years, most do not, and 2.27 is close enough to two that rounding down is appropriate. 
"fugitive from justice". Thirty jurisdictions follow this rule. ${ }^{215}$ Some jurisdictions explicitly require the accused to be outside its borders, while others toll in any case where the accused is somehow evading prosecution. See, e.g., N.Y. Penal Law $\$ 30.10(4)(a)(i)$ (requiring the accused to be outside its borders to toll the limitations period); and Ind. Code $\$ 35-41-4-2(\mathrm{~h})(1)-(2)$ (allowing tolling where the accused is evading prosecution).

The shared concept is to toll the limitation period when the accused is unavailable for prosecution, but there is significant disagreement regarding how this provision should function. With this level of disagreement, no single wording could accurately describe the approach used by a majority of jurisdictions. Instead, the majority formulation is stated narrowly. This ensures that the described conduct will toll the statute of limitations in a majority of jurisdictions, even if other related conduct would also be sufficient in many.

Jurisdictions also disagree about the maximum number of years the tolling mechanism can add to the limitation period. At least twenty-eight jurisdictions allow the clock to toll indefinitely, at least when the defendant is not located within the state. ${ }^{216}$ Some jurisdictions limit this period to a certain number of years. See, e.g., Ark. Code Ann. \$ 5-1-109; and Fla. Stat. Ann. \$ 775.14.

In contrast, MPC section 1.06(3) tolls in specific cases-where fraud or breach of fiduciary duty is a material element, or for misconduct by anyone holding public office-for a maximum of three years. Only a handful of states follow the MPC by addressing these specific tolling instances. See, e.g., Ind. Code $\$ 31-4-2(\mathrm{~h})(3)$; and Iowa Code Ann. $\$ \$ 802.5,802.6$. Section 1.06(4) of the MPC describes when the limitation period actually begins, and section 1.06(5) defines what it means for prosecution to commence. Both of these more technical sections were left out of the majority formulation due to the lack of similar provisions in the majority of jurisdictions. On the contrary, many jurisdictions, if not most, may reach similar results through uncodified rules or common practice.

Finally, section 1.06(6)(b) of the MPC includes another tolling circumstance in addition to the "fugitive from justice" rule: for any time when the accused is being prosecuted for the same conduct. Only thirteen jurisdictions follow the

215 Arizona, Arkansas, Colorado, Connecticut, Delaware, District of Columbia, Florida, Hawaii, Idaho, Indiana, Iowa, Kansas, Maine, Massachusetts, Michigan, Minnesota, Mississippi, Missouri, Nebraska, New Hampshire, New Jersey, New York, North Dakota, Ohio, Pennsylvania, South Dakota, Virginia, Washington, Wisconsin, and Federal.

216 See, e.g., Arizona, Connecticut, Delaware, District of Columbia, Idaho, Indiana, Iowa, Kansas, Massachusetts, Michigan, Minnesota, Mississippi, Nebraska, New Hampshire, New Jersey, North Dakota, Ohio, Pennsylvania, South Dakota, Virginia, Washington, and Wisconsin. 
MPC in codifying this condition, ${ }^{217}$ but presumably it is the standard practice. Any other rule would bar retrial after reversal on appeal if the limitation period had ended in the meantime, which it commonly does.

(e) Should the basic limitation rules change under special circumstances? There is no majority support for any particular special circumstance, but two are common enough to warrant mention. First, fifteen jurisdictions modify their basic rules for crimes against minors. ${ }^{218}$ The exact modifications vary greatly, however, so these jurisdictions can only be loosely considered one group. The largest group provides that there is no statute of limitation for "sexual abuse of a minor", as mentioned in (a) above. ${ }^{219}$ Second, at least thirteen jurisdictions alter their statute of limitations when DNA evidence later surfaces linking the accused to the crime. ${ }^{220}$ Some jurisdictions limit their DNA rule to sexual crimes, whereas others allow DNA evidence to prolong the limitation period for any offense. See, e.g., Iowa Code $\$ 802$ (limiting DNA rule to sexual crimes); and Ark. Code Ann. $\$ 5-1-109$ (allowing DNA evidence to prolong the limitations period for any defense).

\subsection{3. §503. Entrapment.}

The majority view of the Entrapment defense among American jurisdictions might be stated as follows:

Section 503. Entrapment.

A person has a defense to an offense if:

(1) he was induced to commit it by a public law enforcement official, or a person acting in cooperation with such an official, for the purpose of obtaining evidence of the commission of the offense; however,

(2) the defense is unavailable if the person was predisposed to commit the offense and the public law enforcement official, or agent of such, merely afforded the person an opportunity to commit the offense.

All fifty-two jurisdictions recognize an entrapment defense by statute or case law in one form or another, typically when a person commits an offense because

217 Arkansas, Colorado, Delaware, Hawaii, Kansas, Maine, Missouri, New Hampshire, New Jersey, New York, Ohio, Pennsylvania, and Wisconsin.

218 Alabama, Alaska, Arkansas, Colorado, District of Columbia, Hawaii, Idaho, Illinois, Indiana, Kansas, Maine, Massachusetts, Mississippi, Nebraska, New York, North Dakota, Oklahoma, Oregon, Rhode Island, Pennsylvania, Texas, Vermont, and Federal.

219 See, e.g., Alabama, Alaska, Arkansas, Colorado, Idaho, Maine, Mississippi, Nebraska, New York, Rhode Island, Texas, and Vermont.

220 See, e.g., Arkansas, Delaware, Florida, Hawaii, Indiana, Iowa, Minnesota, Oklahoma, Oregon, Pennsylvania, Utah, Washington, and Federal. 
a law enforcement officer or his agent improperly provided the opportunity to do so to gain evidence for its prosecution. ${ }^{221}$ Jurisdictions differ greatly, however, both on the broad policies justifying such a defense as well as on the specific language used to give these policies content.

The most fundamental split between jurisdictions is over the proper focus of the defense. Should an entrapment defense be based purely on an assessment of the propriety of the police conduct in response to which the person committed the offense, without regard for the actor's own inclination toward committing that offense? Under this approach (called an "objective" or "police misconduct" formulation), even a career criminal can get the defense if the police acts improperly. This approach ignores what effect the entrapping conduct had or did not have on the defendant; it only cares about the propriety of what the police did. Or, alternatively, should the defense be limited to cases where police induce persons who are not already predisposed to commit the offense? Under this approach (called the "subjective" or "predisposition" formulation), a person predisposed to commit the offense cannot invoke the Entrapment defense.

Note that even the latter, subjective formulation is not an excuse defense. That is, the Entrapment defense is available even though the person was not induced to commit the offense by such pressure as would entitle the defendant to a duress excuse. Rather, the actor has simply been presented with a temptation that he has chosen to act on. The underlying rationale for the defense is not the actor's blamelessness, but rather objection to police overreaching by creating improper temptations, then prosecuting persons who give in to them. The basis for the defense is rooted in principles of limitation on governmental intrusion in private lives and in notions of collateral estoppel. (That is why this defense is included in Chapter 5 of the code, among the nonexculpatory defenses.) The nonexculpatory rationale is more obvious in the objective formulation, in which even career criminals looking for the opportunity to commit the offense can get the defense if the police overreach. The subjective formulation is different only in that it is formulated to limit the price we are willing to pay to rein in police overreach: we are not willing to let predisposed offenders go free. Notice, for example, that even under the subjective formulation an actor committing an offense induced by a private party has no defense

221 Alabama, Alaska, Arizona, Arkansas, California, Colorado, Connecticut, Delaware, District of Columbia, Florida, Georgia, Hawaii, Idaho, Illinois, Indiana, Iowa, Kansas, Kentucky, Louisiana, Maine, Maryland, Massachusetts, Michigan, Minnesota, Mississippi, Missouri, Montana, Nebraska, Nevada, New Hampshire, New Jersey, New Mexico, New York, North Carolina, North Dakota, Ohio, Oklahoma, Oregon, Pennsylvania, Rhode Island, South Carolina, South Dakota, Tennessee, Texas, Utah, Vermont, Virginia, Washington, West Virginia, Wisconsin, Wyoming, and Federal. 
whatever, even if the inducing conduct is identical to that which would give an entrapment defense if performed by the police.

The question of (a) whether to take the subjective or objective approach to entrapment is the most significant disagreement among American jurisdictions. Beyond that, however, there are disagreements about a variety of other issues, such as: (b) how to define "predisposition"; (c) who can commit an improper entrapment; (d) whether to explicitly require that law enforcement's inducement be for the purpose of prosecution; (e) what behavior on the part of law enforcement constitutes an improper entrapment; and (f) whether there should be an exception to the defense for violent crimes.

(a) Which approach to entrapment predominates—subjective or objective? A majority of thirty-one jurisdictions take the subjective, predisposition approach. ${ }^{222}$ A minority uses the objective formulation, following the MPC and National Commission: The MPC $\$ 2.13(1)$; and National Commission’s Report $\$ 702(2)$. The majority of jurisdictions use different language to capture the importance of the actor's inward preparedness to commit a crime, but all require some sort of inducement or persuasion by law enforcement toward a person who would not normally behave as they did.

Thirty-one jurisdictions include additional statements intended to clarify the relevant standard that do not change its basic meaning. Twenty-nine use language noting that merely affording an opportunity for offense commission does not establish entrapment. ${ }^{223}$ Other jurisdictions provide that the criminal design must originate with the entrapper, who "implants" it in the mind of the defendant. ${ }^{224}$ Some jurisdictions include both of these types of provisions. ${ }^{225}$ Since a majority embraces some clarifying statement, the most common "merely affording an opportunity" language is incorporated in the ACC formulation above.

(b) What does it mean for an actor to be "predisposed" toward criminal conduct? This question is crucial because the predisposition requirement is at the heart of the subjective formulation. See State v. Vallejos, 123 N.M. 739, 741

222 Alabama, Arizona, Connecticut, Delaware, Florida, Georgia, Idaho, Illinois, Indiana, Kentucky, Louisiana, Maine, Maryland, Massachusetts, Minnesota, Mississippi, Missouri, Nebraska, Nevada, North Carolina, Ohio, Oregon, Rhode Island, South Carolina, South Dakota, Tennessee, Virginia, Washington, West Virginia, Wisconsin, and Wyoming.

223 Arkansas, Colorado, Idaho, Illinois, Indiana, Iowa, Kentucky, Louisiana, Maryland, Michigan, Minnesota, Mississippi, Montana, Nebraska, New Hampshire, New York, North Carolina, North Dakota, Ohio, Oklahoma, Oregon, South Carolina, Texas, Utah, Virginia, Washington, West Virginia, Wisconsin, and Wyoming.

224 See, e.g., Georgia, Massachusetts, North Carolina, Washington, West Virginia, and Wisconsin.

225 See, e.g., Idaho, Indiana, Maryland, and Minnesota. 
(1997) ("the focal issue is 'the intent or predisposition of the defendant to commit the crime" "). Its key feature is that it considers only the accused and not whether the inducement would have encouraged the average person. Though jurisdictions explain this requirement in a variety of ways, the only significant difference between the approaches is the level of generality used to describe what the accused was predisposed to do. Some jurisdictions describe it broadly - that is, that the accused cannot have been predisposed to engage in "conduct of the sort induced". See, e.g., Colo. Rev. Stat. Ann. \$ 18-1-709. This language immediately presents the problem of deciding precisely what conduct is of that "sort". Consider a person who was predisposed to sell marijuana but was not predisposed to sell prescription drugs until the idea of selling prescription drugs was introduced to him by a police officer. In this scenario, the broader "conduct of the sort induced" might (or might not, depending on how it is applied) prevent the accused from claiming the defense, whereas a more narrow requirement that the accused be predisposed to commit the specific criminal conduct that was committed might be more likely to entitle him to a defense. No more than a few jurisdictions use any particular version of this generality aspect, so broad language has been adopted in the majority formulation. This way, the majority jurisdictions would all agree to at least this limited an application of the Entrapment defense.

(c) Who can commit an improper entrapment? A thirty-five-jurisdiction majority explicitly indicates that the person committing the entrapment must be acting as an agent for, or working with, law enforcement. ${ }^{226}$ Jurisdictions use a variety of terms to describe this class. Some refer to "the police or their agents", ${ }^{227}$ whereas others refer to "a public law enforcement official or a person acting in cooperation with such an official". See, e.g., People v. Watson, 22 Cal.4th 220, 223 (2000); and Alaska Stat. Ann. \$ 11.81.450.

(d) Must law enforcement act with a particular kind of purpose to commit entrapment? A bare majority-twenty-seven jurisdictions-requires that the entrapping behavior be done with the purpose of using the criminal justice system against the actor in some way. ${ }^{228}$ Jurisdictions use slightly different

226 Alabama, Alaska, Arizona, Arkansas, California, Colorado, Connecticut, Delaware, Florida, Georgia, Hawaii, Idaho, Illinois, Indiana, Kansas, Kentucky, Louisiana, Maine, Michigan, Missouri, Montana, Nebraska, New Hampshire, New Jersey, New Mexico, New York, North Carolina, Oregon, Pennsylvania, Rhode Island, Tennessee, Texas, Utah, Vermont, and Washington.

227 See, e.g., People v. Watson, 22 Cal.4th 220, 223 (2000).

228 Alaska, Colorado, Connecticut, Florida, Georgia, Hawaii, Idaho, Illinois, Kansas, Kentucky, Louisiana, Michigan, Mississippi, Missouri, Montana, Nebraska, New Hampshire, New Jersey, New York, North Dakota, Ohio, Oregon, Pennsylvania, South Dakota, Utah, Vermont, and Wisconsin. 
language to describe this requirement. For example, some jurisdictions require officers to act "in order to obtain evidence of the commission of an offense". See, e.g., Alaska Stat. Ann. $\$ 11.81 .450$. Others require that the entrapping conduct be done for the "mere purpose of instituting criminal proceedings". See, e.g., State v. Nelsen, 228 N.W.2d 143, 146 (S.D. 1975).

(e) What behavior must law enforcement perform to commit an improper entrapment? Thirty jurisdictions describe the basic "entrapping" behavior as an "inducement", 229 or use additional terms generally illustrating the same concept, rather than recognizing specific qualifying behavior. For example, Alabama holds that "[e]ntrapment occurs when State officers or persons under their control, incite, induce, lure, or instigate a person into committing a criminal offense, which that person would not have otherwise committed, and had no intention of committing" (Johnson v. State, 285 So.2d 723, 724 (Ala. 1973)).

MPC section 2.13(1)(a), allowing an entrapment defense when the actor's conduct was based on false representations by law enforcement, is not included in the majority formulation because only a small minority of jurisdictions adopt this rule. See, e.g., U.S. v. Schafer, 625 F.3d 629, 637 (2010); Haw. Rev. Stat. $\$ 702-237$; and N.J. Stat. Ann. \$2C:2-12; 18 Pa. Cons. Stat. Ann. \$313. This is analogous in some ways to the defense of Reliance Upon Official Misstatement of Law-outlined in section 406 above. In both instances, a government official is telling the defendant that the conduct at issue is not a crime, then the criminal justice system seeks to prosecute him for it. But under section 406, the actor must reasonably rely upon this misstatement. The entrapment defense's foundation, in contrast, is not the actor's blamelessness, therefore, the MPC's objective entrapment defense is available even if the offender never believed the undercover agent's claim of the lawfulness of the conduct since such attempts to mislead are improper and the defense exists to deter such conduct.

(f) Should the Entrapment defense be available for violent offenses? Only a handful of jurisdictions follow the MPC in providing such an exception, ${ }^{230}$ but this is likely because few jurisdictions have had occasion to adjudicate cases where police entrapped someone into committing a violent offense. No jurisdiction explicitly embraces an entrapment defense for violent offenses, except perhaps South Dakota. See State v. Huber, 356 N.W.2d 468 (S.D. 1984). But

229 Alabama, Arizona, Arkansas, Colorado, Florida, Georgia, Hawaii, Idaho, Iowa, Kansas, Kentucky, Maine, Maryland, Massachusetts, Michigan, Minnesota, Mississippi, Missouri, Montana, Nebraska, New Jersey, North Carolina, North Dakota, Oklahoma, Pennsylvania, Rhode Island, South Dakota, Texas, Vermont, and Washington.

230 The MPC $\$ 2.13(3)$. See, e.g., Delaware, Hawaii, Kentucky, Missouri, New Jersey, Pennsylvania, and Utah. 
without authority, we do not include this limitation in the majority formulation.

One last issue deserves discussion. Subsequent to the enactment of many of the state entrapment statutes, the U.S. Supreme Court recognized a due processbased defense apart from an entrapment defense, for especially egregious forms of police inducement. In United States $v$. Russell, a case involving a drug manufacturing conviction despite an entrapment instruction, Justice Rehnquist alluded to this due-process defense in his "some day" dicta, saying, "[W]e may some day be presented with a situation in which the conduct of law enforcement agents is so outrageous that due process principles would absolutely bar the government from invoking judicial processes to obtain a conviction" (411 U.S. 423, 431-32 (1973)). He went on to clarify that the case before the Court did not meet this description. While Rehnquist later attempted to repudiate his earlier dicta in a subsequent case, a plurality of justices in that same case suggested that the defense would be cognizable under the Fourth and Fourteenth Amendments (Hampton v. U.S., 425 U.S. 484, 490 (1976)). Lower courts have overwhelmingly accepted this "outrageous government conduct" defense as a valid exercise of substantive due process. See, e.g., U.S. v. Twigg, 588 F.2d 373 (3d. Cir. 1978); and U.S. v. Bogart, 783 F.3d 1428 (9th Cir. 1986); but see U.S. v. Tucker, 28 F.3d 1420 (6th Cir. 1994) (refusing to accept an "outrageous government conduct" defense with regard to substantive due process).

State v. Lively provides one example (921 P.2d 1035 (Wash. 1996)). Lively was charged and convicted of delivering cocaine. At trial, the court rejected the entrapment defense, as she was not induced to commit a crime that she would not otherwise have committed. On appeal, the Supreme Court of Washington reversed, holding that although Lively failed to prove an entrapment defense, the government's conduct of soliciting Lively in her vulnerable and emotional state was so outrageous as to violate due process.

Because the due process defense and the objective entrapment formulation both focus on the nature of the police misconduct, independent of the offender's predisposition, the two defenses are easily confused and are somewhat redundant. In State v. Knight, for example, the West Virginia Supreme Court incorporated a consideration of unconscionable police conduct into the state's entrapment defense (230 S.E.2d 732, 736-37 (W.Va. 1976)). Shortly thereafter, however, the court overruled itself, putting forth that there should be a separate and distinct defense, other than entrapment, for a criminal defendant subjected to police or government agent misconduct (State v. Houston, 475 S.E.2d 307, 318-19 (W. Va. 1996)). If the Constitution in fact already bars liability for conduct induced by improper police entrapment, it is worth considering whether a separate entrapment defense remains necessary in the particular form it now takes. 


\section{DOCTRINAL CORRELATION ANALYSIS: UNCOVERING RELATIONSHIPS AMONG JURISDICTIONS AND DEFENSES}

Is there a way to use the findings reported in the preceding section to uncover previously unexplored patterns and correlations pertaining to criminal law defenses? As suggested in the introduction to this article, Doctrinal Correlation Analysis (DCA) is a versatile framework that can examine a broad spectrum of correlations, ranging from general patterns across the surveyed defenses to relationships between specific doctrines.

The DCA framework, developed and employed by one of the authors' in a previous work, contains two main analytical components. The first is the internal aspect, which looks into correlations between the criminal law doctrines among the various jurisdictions. The second is the external aspect, which examines correlations between these doctrines and variables outside the realm of criminal law, such as demographic qualities and certain statistical data on crime rates in the various jurisdictions. (Robinson 2014).

The specific criminal law doctrines surveyed in the preceding section serve as the basis for both the internal and external aspect of the DCA. Importantly, however, DCA can be conducted on various levels of generality pertaining to such doctrines, ranging from correlations between two or more issues on which jurisdictions disagree within a particular defense, through comparison of similar issues in distinct defenses (such as the nature of the required cognitive dysfunction in the insanity and the involuntary intoxication defenses) between jurisdictions. Moreover, the surveyed criminal law doctrines can serve as the building blocks for constructing complex, multifactorial variables such as jurisdictions' "strictness" in granting criminal law defenses, and DCA can be conducted, in turn, on these constructed variables, in order to analyze even broader patterns related to jurisdictions' approaches to specific defenses or classes of defenses. ${ }^{231}$

In what follows, we will illustrate the usefulness of DCA by suggesting preliminary answers to certain important questions, such as: "What is the relationship between jurisdictions' views on different contested issues within a particular defense?"; "Are jurisdictions consistently strict or lenient in granting criminal law defenses?"; and "Do states' characteristics—such as violent crime rate, racial composition, or population size-bear on the former questions, and to what extent?" 
Before delving into the analysis, however, a methodological note and an important caveat regarding the purpose of this section are in order. Aside from the findings reported in the previous section, this section relies on certain statistical data related to the aforementioned characteristics of jurisdictions-specifically, crime rates and demographic qualities. We obtained this data from the U.S. Census website and additional reliable sources. ${ }^{232}$ Nevertheless, since the figures were obtained from different data sets representing different data collection methodologies, their approximation of the "real world" is not uniform-which, naturally, affects our findings. Moreover, as a general matter, a temporal misalliance exists between the (relatively) contemporary statistical data we collected on jurisdictions and these jurisdictions' positions on criminal law defenses. For example, our findings in the previous section represent the present view of each jurisdiction on an issue-such as the duty to retreat in Defense of Persons - which is appropriate to compare to a jurisdictions' present or recent violent crime rates, but it is also true that some jurisdictions may have initially adopted their views on this issue in the early 1970s.

This brings us to the aforementioned caveat. Naturally, more sophisticated methods might more fully substantiate our data, enhance their temporal alignment, and improve the quality of the findings presented below. These, however, are not necessary for the purposes of this section. Our analysis below is not intended to guide legislative reform, and it is neither comprehensive nor conclusive on any of the issues we address. Rather, its main purpose is to illustrate the kinds of correlations that can be explored and the kinds of patterns that can be uncovered using DCA. Although we suggest preliminary answers to the questions raised above, our goal in this section is not to provide such answers, but rather to set an agenda for further research.

To illustrate the possibilities of DCA, we will first present several correlations pertaining to two specific issues on which jurisdictions disagree within Defense of Persons and the correlations between them. We will then explore the broader patterns related to all of the issues on which jurisdictions disagree within Defense of Persons. Our caveat notwithstanding, and as demonstrated below, DCA yields intriguing, and at times counter-intuitive, findings.

232 Specifically, for each jurisdiction we obtained and used the following "statistical" parameters: (1) population size; (2) racial composition of the population; (3) the quotient between urban and rural population; (4) violent crime rate; and (5) gun ownership rate. Citations to each appear in notes to the analysis below. 


\subsection{Correlations Between Jurisdictions' Disagreement: Duty to Retreat and Resisting}

\section{Unlawful Arrest}

\subsubsection{General Patterns}

What is the relationship between a jurisdiction's view on the duty to retreat prior to the use of force and its view on the right to use force to resist unlawful arrest? One might assume that a jurisdiction is likely to exhibit some consistency with regard to its view on these two contested Defense of Persons issues. That is one might expect that a jurisdiction's choice to impose a duty to retreat would correlate with a choice to bar resistance to unlawful arrest, and vice versa.

To explore this question, we relied on our findings in section 303 above. For each jurisdiction, we coded whether, for the purposes of granting a Defense of Persons justification, it imposes a duty to retreat from unlawful aggression before using deadly force and whether it recognizes a right to resist unlawful arrest. Table 1 below details our findings.

As expected, the majority of jurisdictions are consistent in their approaches to both issues (as can be observed in the upper-left and lower-right cells of Table 1, marked in light gray). ${ }^{233}$ Moreover, consider the upper-right cell, representing the only three jurisdictions allowing resistance to unlawful arrest while imposing a duty to retreat. This cell reveals a significant asymmetry within the jurisdictions with inconsistent approaches to both issues and highlights an interesting relationship between them. By knowing that a jurisdiction recognizes a right to resist unlawful arrest, we have at least 80 percent certainty that it also imposes no duty to retreat. ${ }^{234}$ Similarly, by knowing that a jurisdiction imposes a duty to retreat, we have at least 84 percent certainty that it does not recognize the right to resist unlawful arrest. ${ }^{235}$

\subsubsection{Specific Patterns and Correlations}

Although the discussion above focuses on patterns pertaining to U.S. jurisdictions in general, we were also interested in what DCA could reveal about the specific jurisdictions adopting a particular approach to the duty to retreat and right to resist unlawful arrest. We suspected that jurisdictions' approaches to these issues might correlate with some of what one might call their "statistical" characteristics, such as rates of gun ownership, racial composition, and the quotient between urban and rural populations.

As we suspected, some correlation exists between a jurisdiction's imposition of a duty to retreat and characteristics such as its percentages of urban population

233 We suspected that whether a jurisdiction tends to adopt a strict or lenient approach to Defense of

Persons might mediate such correlation. We explore the strictness-leniency continuum in Section 3.2.1.

234 Thirteen out of sixteen jurisdictions adopt such an approach.

235 Sixteen out of nineteen jurisdictions adopt such an approach. 
Table 1. Right to Resist Unlawful Arrest vs Duty to Retreat

\begin{tabular}{|c|c|c|}
\hline & No Duty to Retreat & Duty to Retreat \\
\hline $\begin{array}{l}\text { Right to Resist Unlawful } \\
\text { Arrest }^{\mathrm{a}}\end{array}$ & $\begin{array}{l}\text { AL, GA, LA, MI, MS, } \\
\text { NV, OK, SC, TN, VA, } \\
\text { WA, WV, FED }\end{array}$ & $\mathrm{MD}, \mathrm{NC}, \mathrm{OH}$ \\
\hline $\begin{array}{l}\text { No Right to Resist } \\
\text { Unlawful Arrest }\end{array}$ & $\begin{array}{l}\text { AK, AZ, CA, CO, DC, FL, } \\
\text { ID, IL, IN, KS, KY, MT, } \\
\text { NH, NM, OR, SD, TX, } \\
\text { VT, UT, WI }\end{array}$ & $\begin{array}{l}\text { AR, CT, DE, HI, IA, ME, } \\
\text { MA, MN, MO, NE, NJ, } \\
\text { NY, ND, PA, RI, WY }\end{array}$ \\
\hline
\end{tabular}

a. The Federal jurisdiction imposes no uniform duty to resist unlawful arrest; the situation in the Federal jurisdiction may vary by circuit. See U.S. v. Walker, 960 F.2d 409 (5th Cir. 1992). Therefore, it appears in both cells pertaining to such right (representing Federal jurisdiction's view not to impose a duty to retreat).

and gun ownership. For instance, among the nineteen jurisdictions imposing a duty to retreat, ${ }^{236}$ eight are those in which the urban population is below the U.S. average (74.1 percent), ${ }^{237}$ and eight are jurisdictions in which the gun ownership rate is above the U.S. average (36.99 percent). ${ }^{238}$ At this point, however, it is important to note that not every correlation is meaningful. In fact, correlations with gun ownership rate (other than in the present example) consistently yielded weaker findings than correlations with other characteristics we examined.

For assessing our findings we used the following simple method exemplified by the current case: since in twenty-nine among the fifty-two U.S. jurisdictions the gun ownership rate is above average, a corresponding proportion (29/52) of such jurisdictions can be expected to exist in any random group of jurisdictions as a matter of chance. Consequently, in a group of the nineteen jurisdictions imposing a duty to retreat, we might expect some to be also jurisdictions in which the gun ownership rate is above average. Specifically, we might expect 10.6 such jurisdictions $\left((29 / 52)^{\star} 19=10.6\right)$. Nevertheless, we observe only eight

236 Arkansas, Connecticut, Delaware, Hawaii, Iowa, Maine, Maryland, Massachusetts, Minnesota, Missouri, Nebraska, New Jersey, New York, North Carolina, North Dakota, Ohio, Pennsylvania, Rhode Island, and Wyoming.

237 Arkansas, Iowa, Maine, Minnesota, Nebraska, North Carolina, North Dakota, and Wyoming. See U.S. Census Bureau, 2010 Decennial Census: Urban Areas. http://factfinder2.census.gov/faces/tableservices/jsf/pages/productview.xhtml?pid=DEC_10_113_P2\&prodType=table (last visited August 15, 2014).

238 Arkansas, Iowa, Maine, Minnesota, Missouri, North Carolina, North Dakota, and Wyoming. See Gun Ownership by State, The Washington Post (May 30, 2006). http://www.washingtonpost.com/ wp-srv/health/interactives/guns/ownership.html. 
jurisdictions with both characteristics. Thus, the expected number of jurisdictions is different from the observed by 2.6 jurisdiction, representing approximately 25 percent difference from "chance" findings $(2.6 / 10.6=\sim 25 \%) .{ }^{239}$ Note that all findings presented in the text from this point on are different from "chance" findings by more than approximately 15 percent.

A more intriguing correlation, however, exists between the right to resist unlawful arrest and the racial composition of a jurisdiction's population. Using the U.S. Census data and website, we divided U.S. jurisdictions into four groups according to the percentage of their total population that is Black or African American. ${ }^{240}$ We found that among the fifteen jurisdictions adopting the right to resist unlawful arrest, ${ }^{241}$ only two are those in which the Black or African American population is $0.5-5.1$ percent (first group) of the total, ${ }^{242}$ and only three are those in which it makes up 5.8-12.2 percent (second group). ${ }^{243}$ The remaining ten jurisdictions have Black or African American percentages of their total populations that are higher than 13.5 percent (third and fourth groups). Viewed a different way, these data reveal that among the seventeen jurisdictions with Black or African American population percentages higher than 13.5 percent, ${ }^{244}$ ten adopt the right to resist unlawful arrest. ${ }^{245}$ See Figure 1 for a graphic representation of this data.

239 Due to specific nature of our data on criminal law doctrines, it is uncertain whether using standard methods for statistical analysis such as Analysis of Variance, which, inter alia, rely on certain assumptions that might not hold for such data, is appropriate. Admittedly, the alternative method of assessment we use is somewhat crude and may be improved upon by using more sophisticated statistical analyses. Nevertheless, we believe this method is suitable for our present purposes, which are not to reveal statistically significant findings, but rather to exemplify DCA's potential and outline interesting paths for future research.

240 We created this division using the U.S. Census data on "Race", which included data on "Black or African American" population, and the U.S. Census website map creating tool, employing the "natural breaks" classing method which "identifies groupings that naturally exist in the data". See U.S. Census Bureau, ACS Demographic and Housing Estimates 2008-2012. http://factfinder2. census.gov/faces/tableservices/jsf/pages/productview.xhtml?pid=ACS_12_5YR_DP05\&prodType= table and http://factfinder.census.gov/help/en/changing_data_classes_help.htm.

241 As mentioned in note a to Table 1 above, with regard to the right to resist unlawful arrest, the situation in the federal jurisdiction may vary by circuit. Thus, for the purpose of the current analysis, the federal jurisdiction is excluded.

242 Washington and West Virginia.

243 Ohio, Oklahoma, and Nevada.

244 Alabama, Arkansas, Delaware, District of Columbia, Florida, Georgia, Illinois, Louisiana, Maryland, Michigan, Mississippi, New Jersey, New York, North Carolina, South Carolina, Tennessee, and Virginia.

245 Alabama, Georgia, Louisiana, Maryland, Michigan, Mississippi, North Carolina, South Carolina, Tennessee, and Virginia. 
Figure 1. Black or African American Representation vs Right to Resist Unlawful Arrest.

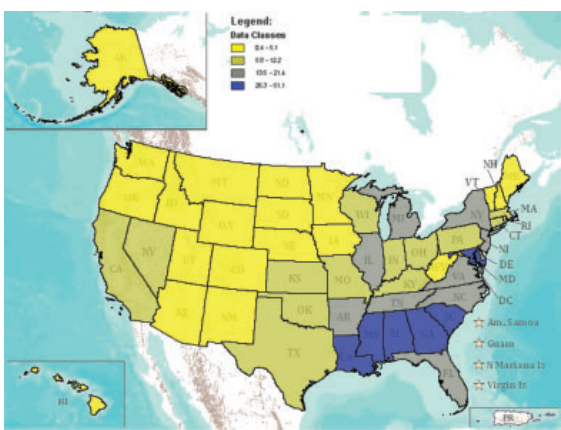

Black or African American Representation

Source (Map and Data): U.S. Census Bureau, 2008-2012 American Community Survey

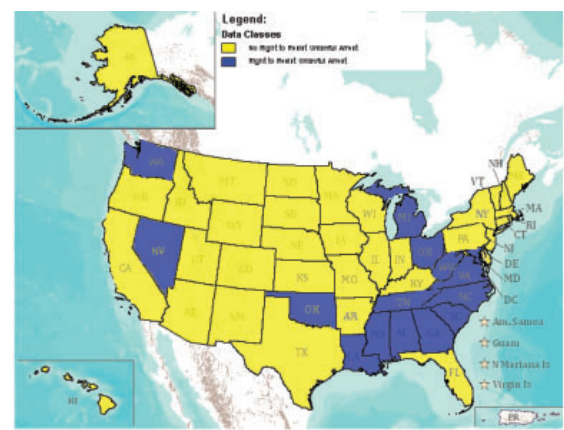

Right to Resist Unlawful Arrest

Source (Map): U.S. Census Bureau; (Data): Section 2.1.3. (h) supra.

In addition, among the fifteen jurisdictions adopting the right to resist unlawful arrest, all but Nevada are in the lower three quartiles ${ }^{246}$ of the urban population percentage. ${ }^{247}$ Viewing the data another way, observe that among the sixteen most urban jurisdictions (in which the urban populations consists of 84.7-100 percent of the total populations), only Nevada allows an actor to resist unlawful arrest. In addition, among the fifteen jurisdictions adopting the right to resist unlawful arrest, ten have gun ownership percentages above the U.S. average (36.99 percent). ${ }^{248}$

The discussion above involves correlations of jurisdictions' characteristics with the right to resist unlawful arrest and the duty to retreat as separate doctrines. However, the interactions between the right to resist unlawful arrest and the duty to retreat (represented by the cells of Table 1 above), when compared to jurisdictions' crime and demographic characteristics, also yield several interesting findings.

First, some correlation exists between jurisdictions allowing resistance to unlawful arrest while imposing no duty to retreat (upper-left cell of Table 1 above) and their respective percentages of gun ownership. Specifically, all of the

246 Seven of these (Georgia, Maryland, Michigan, Nevada, Ohio, Virginia, and Washington) still have urban populations above the U.S. average (74.1 percent).

247 We used U.S. Census data for the urban/rural division (see, http://factfinder2.census.gov/faces/tableservices/jsf/pages/productview.xhtml?pid=DEC_10_113_P2\&prodType=table). The percentage of urban population in U.S. jurisdictions runs the gamut from 38.66 percent (Maine) to 100 percent (District of Columbia). Therefore, we divided the jurisdictions to four groups with equal intervals (of 15.35 percent) between them.

248 Oklahoma, Louisiana, Mississippi, Alabama, Georgia, South Carolina, North Carolina, Tennessee, West Virginia, and Michigan. 
thirteen jurisdictions adopting such an approach are in the third (33.4-44.4 percent) and fourth (47.7-59.7 percent) quartiles of gun ownership rate in the population. $^{249}$

Second, and perhaps more intriguing, is the correlation between jurisdictions allowing no right to resist unlawful arrest while imposing a duty to retreat (lower right cell of Table 1) and the percentage of their total populations that are white. ${ }^{250}$ Here, as before, we divided U.S. jurisdictions into four groups according to the white population percentage in each. Among the sixteen jurisdictions allowing no right to resist unlawful arrest while imposing a duty to retreat, twelve have white population percentages in the upper two groups: seven are in the third group (76.5-86 percent), ${ }^{251}$ and five are in the fourth (87.2-95.3 percent)..$^{252}$

What do the specific correlations examined in this part tell us? Though we are not in a position to offer any definitive conclusions, our findings suggest several hypotheses and promising directions of further exploration.

For instance, it appears that a more urban population suggests a more restrictive view in permitting resistance to unlawful arrest. ${ }^{253}$ One might speculate that the reasons underlying this phenomenon are an increased danger to bystanders from the use of force in densely populated urban environment, or alternatively better training of law enforcement officials along with timely accessibility to legal institutions in urban settings (whether real or perceived), which might be seen as decreasing the burdens associated with unlawful arrests.

According to the former hypothesis, however, one might also expect a correlation between an increase in urban population and the imposition of a duty to retreat, while our findings, if anything, imply the opposite. ${ }^{254}$ Conversely, the latter hypothesis appears to be more plausible due to its differential import on the duty to retreat and the right to resist unlawful arrest.

249 See Gun Ownership by State, The Washington Post (May 30, 2006), http://www.washingtonpost. com/wp-srv/health/interactives/guns/ownership.html. Additionally, in eight of such jurisdictions the percentage of the Black or African American population is higher than 13.5 percent. Nevertheless, this finding is fully accounted for by the right to resist unlawful arrest and does not appear to result from an interaction between such right and a duty to retreat. See text accompanying notes $240-245$.

250 For this division, we divided the U.S. census data using the "natural breaks" classing method. See supra note 240 , for a more detailed explanation.

251 Arkansas, Connecticut, Massachusetts, Minnesota, Missouri, Pennsylvania, and Rhode Island. See U.S. Census Bureau, ACS Demographic and Housing Estimates 2008-2012. http://factfinder2.census. gov/faces/tableservices/jsf/pages/productview.xhtml?pid=ACS_12_5YR_DP05\&prodType=table.

252 Iowa, Maine, Nebraska, North Dakota, and Wyoming. See ibid.

253 See text accompanying notes 246 and 247.

254 See text accompanying notes 237 . 
Another, and perhaps more intriguing finding, is the correlation between a jurisdiction's racial composition and its view on the issues under consideration. Recall that a majority of jurisdictions with a relatively high percentage of Black or AfricanAmerican population adopt the right to resist unlawful arrest ${ }^{255}$ and two-thirds of the jurisdictions adopting such a right are those with a relatively high percentage of Black or African American population. ${ }^{256}$ It may be that the reasons underlying this phenomenon are a combination of an increased (real or perceived) amount of improper law enforcement practices (due to racial profiling or similar methods) in these jurisdictions, along with a greater Black or African American populations' political influence and public sensitivity to such practices. These, in turn, increase the chances for an appropriate case to spark public attention to the issue and impact criminal legislation. (Robinson 2014, pp. 15, 19).

Interestingly, this hypothesis is also partially substantiated by a contrasting finding: three-fourths of the jurisdictions allowing no right to resist unlawful arrest (while also imposing a duty to retreat) are those with a relatively high white population percentage. These are jurisdictions in which the chances for an appropriate case to catch public attention and impact legislation are naturally reduced. ${ }^{257}$

The discussion above does not exhaust the inferences that may be drawn from our findings in this section. Neither is it conclusive for the particular phenomena discussed. Which are the precise reasons underlying these phenomena? The purpose of this discussion is not to answer this question. It is rather to illustrate the potential of DCA as a method enabling researchers to uncover these phenomena in the first place, form the appropriate questions, and evaluate hypotheses in light of the findings. Such potential will be further elucidated in the next section.

\subsection{Correlations Between Jurisdictions' Disagreement: Defense of Persons}

\subsubsection{General Patterns and the Strictness-Leniency Continuum}

So far, we have explored several correlations between two specific issues on which jurisdictions disagree within Defense of Persons. Such an examination can indeed reveal interesting correlations; however, it is somewhat limited by the specific issues under consideration. Moreover, it is unclear whether jurisdictions' views on these specific issues are consistent with their views to other

255 See text accompanying notes 244 and 245 .

256 See text accompanying, and immediately following note 243.

257 See text accompanying notes $250-252$. 
Defense of Persons issues or happen to represent an issue-specific idiosyncrasy. Can broader patterns be uncovered?

Yes. Relying on the comprehensive research into each Defense of Persons issue on which jurisdictions disagree (reported at length in section 303), we can explore, for instance, whether jurisdictions are consistently strict or lenient in their approach to all contested issues within the Defense of Persons justification that yield to such analysis. ${ }^{258}$ To do so, we determined which among the various views on each contested issue in Defense of Persons represented the strict, lenient, or intermediate (if applicable) approach to that particular issue. ${ }^{259}$ We then placed each jurisdiction in its appropriate place on the strictnessleniency continuum, as shown in Table 2 below.

The first broad pattern, revealed by the table below, is that, with regard to Defense of Persons, the ACC leans strongly toward the strict side of the strictness-leniency continuum. Among the seven issues analyzed, the lenient approach gains majority only once. Conversely, the strict approach gains majority in five issues, ${ }^{260}$ and is also adopted by a significantly larger number of jurisdictions than the lenient approach in the remaining issue (in which the intermediate approach gains majority).

Of course, the revealed skew toward strictness is relative rather than absolute, as it only pertains to positions that were in fact adopted by the various jurisdictions under examination. Thus, for instance, our present findings do not support a statement that U.S. jurisdictions are fundamentally "strict" or skewed toward strictness as compared to foreign jurisdictions. The main point, however, is that among the available plausible options (i.e., options adopted by some domestic jurisdictions), U.S. jurisdictions consistently adopt the stricter ones. $^{261}$

258 Among the nine issues discussed in section 303, issue (a), "What constitutes the 'unlawful force' that triggers a right to use defensive force?" does not lend itself to the strictness-leniency analysis in this section due to both the lack of explicit statutory definitions referring to this issue and apparent general agreement on this point. Thus, it is excluded from the analysis—as is issue (g), "What legal effect does mutual combat have upon the right of self-defense?" The reason for this second exclusion is that at least fifty-one jurisdictions take a strict position of not recognizing a right to regain the defense. Although the differences between jurisdictions' approaches on this issue are interesting and merit presentation, we exclude it from the present analysis to avoid tilting the result toward the strict end of the strictness-leniency continuum.

259 The division into strict, intermediate, or lenient pertains to the approaches jurisdictions take within each issue under consideration. We make no claims as to the relative strictness of the positions between the issues under consideration.

260 The strict view gains a majority for issue (d) by adding the strict and intermediate-strict approaches together.

261 The authors are grateful to an anonymous reviewer for pointing out that our presentation of this issue in a previous draft required clarification. 
Table 2. The Strictness-Leniency Continuum

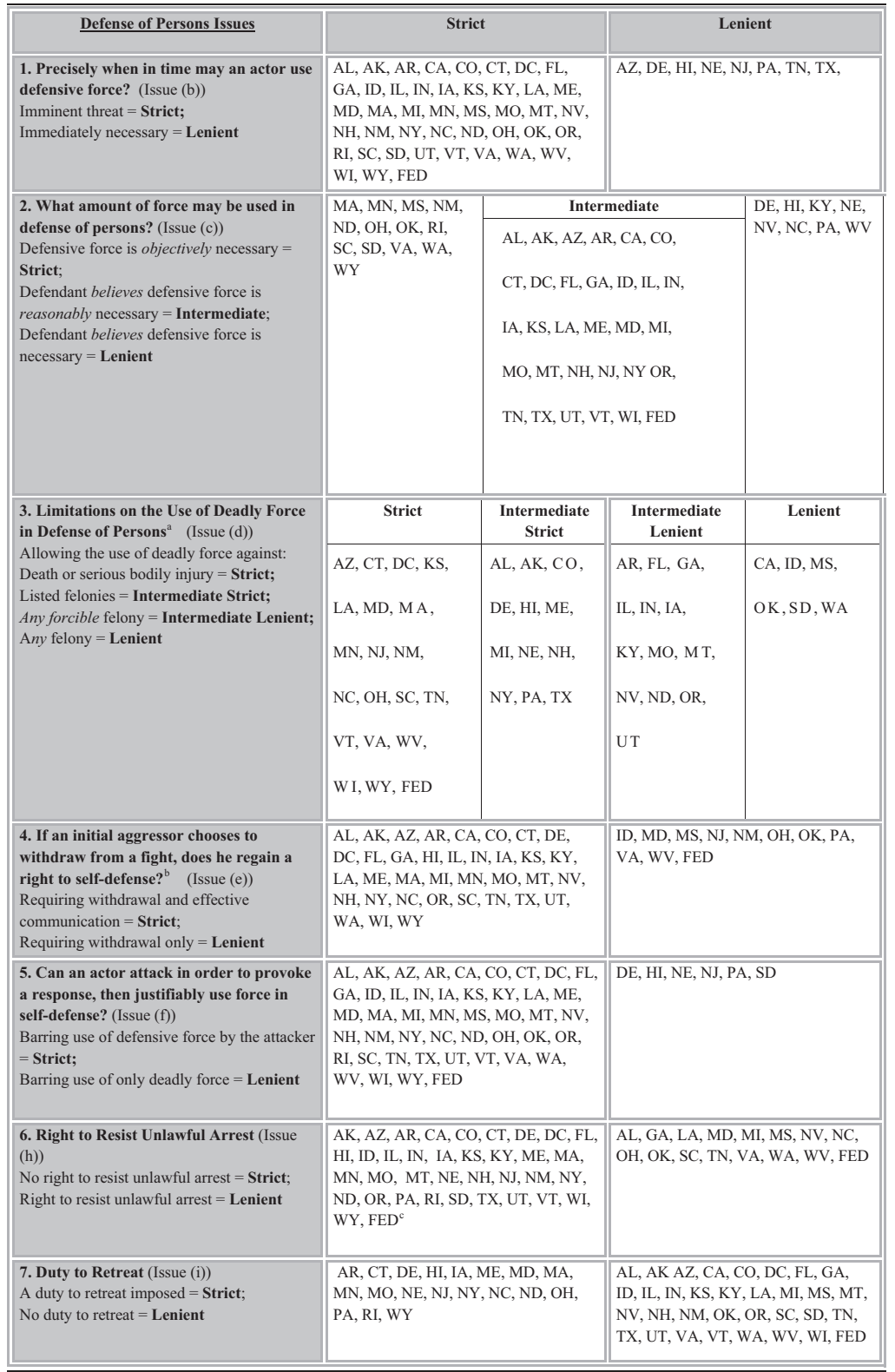

a. As noted in section 303 above, Rhode Island takes a unique position on this issue, adopting a "totality of the circumstances" test. Thus, Rhode Island is excluded from the analysis.

b. As noted in section 303 above, the state of the law in Nebraska, Rhode Island, South Dakota, and Vermont on this issue could not be confirmed. Thus, these jurisdictions are excluded from the present analysis. North Dakota is also excluded because, as noted in note 45 , it uses the slightly different standard of "indication", rather than the majority's "effective communication" of withdrawal.

c. See note a to Table 1. 
Such strictness of the ACC is reflected in the text of the majority formulation we presented at the beginning of section $303 .{ }^{262}$ Nevertheless, the text of the formulation cannot reveal the underlying pattern pertaining to the strictnessleniency continuum, which is easily uncovered by the analysis above.

Significantly, we had little reason to posit the skew toward strictness ex ante. In light of the important interests at play in cases when Defense of Persons applies and the many debates and various opinions that exist on each issue (reflected not only in scholarly disputes, but in the actual legislation of many jurisdictions), we could have expected a more mixed, and perhaps even an opposite, result.

We do not claim that the skew toward strictness in Defense of Persons among U.S. jurisdictions is a result of a deliberate decision-making process with the conscious goal to be strict on such issues. We are only pointing out the state of affairs as they exist. This finding, in turn, opens interesting routes for further exploration of the strictness-leniency continuum regarding other defenses. For instance, in light of the skew toward strictness on Defense of Persons, researchers may hypothesize that jurisdictions' approaches to other justification, excuse, and nonexculpatory defenses should be even stricter. The data we collected on jurisdictions' approaches to such defenses and further analysis similar to the one presented in Table 2 above will allow researchers to explore such questions and uncover broad patterns related to the consistency (or lack thereof) in jurisdictions' approaches to criminal law defenses.

\subsubsection{Specific Patterns and Correlations}

Aside from the intriguing "tendency to strictness" pattern on Defense of Persons, the strictness-leniency division presented in Table 2 above allows us to conduct a more sophisticated examination of both the correlations between jurisdictions' general tendencies and their particular views on specific Defense of Persons issues, as well as broader patterns and correlations with their statistical characteristics, such as crime rates and demographic makeups. Although similar in form to the analysis conducted above on the correlations between the duty to retreat and the right to resist unlawful arrest, the exploration below is much more general in its nature since it applies to all pertinent Defense of Persons issues.

262 Note, however, that some discrepancies exist. For example, the majority formulation pertaining to the limitations on the use of deadly force in defense of persons (allowing an actor to use deadly force against threats of death, serious bodily injury, rape, and kidnapping) is constructed by using the common denominators of several approaches that vary greatly on the strictness-leniency continuum. In contrast, the present analysis refers to each of these approaches separately, enabling us to explore their correlations to other issues directly. 
To conduct this examination, we divided the jurisdictions according to their location on the strictness-leniency continuum, creating four groups. Two of the groups are broad and cover the whole continuum. The first broad group consists of thirty-one "lenient" jurisdictions ${ }^{263}$ positioned on the lower end of that continuum (i.e., jurisdictions that are strict on only 3-4 issues). ${ }^{264}$ The second broad group consists of the remaining twenty-one "strict" jurisdictions (i.e., jurisdictions that are strict on 5-7 issues). ${ }^{265}$ The last two groups are more narrowly tailored and cover the extreme ends of the continuum. The first narrow group includes the sixteen "most lenient" jurisdictions (i.e., jurisdictions which are lenient on 3-4 issues). ${ }^{266}$ The second narrow group includes the six "strictest" jurisdictions ${ }^{267}$ (i.e., jurisdictions which are strict on 6-7 issues). ${ }^{268}$

These groups allow us to reexamine and refine our findings above regarding specific Defense of Persons issues. For example, recall that jurisdictions' approaches to the duty to retreat issue is somewhat anomalous: among the seven contested issues in Defense of Persons, it is the only issue for which the lenient approach gains majority. Does this mean that findings related to the duty to retreat are idiosyncratic and have little bearing on broader questions related to Defense of Persons? Close examination of the correlations between jurisdictions' positions on the duty to retreat and their positions on the strictness-leniency continuum suggests the opposite.

In fact, a jurisdiction's view on the duty to retreat is a good proxy for its location on the strictness-leniency continuum. We found that among the nineteen jurisdictions imposing such a duty (the strict position for this

263 Alabama, Arizona, California, Delaware, Florida, Georgia, Hawaii, Idaho, Illinois, Indiana, Kentucky, Louisiana, Maryland, Michigan, Mississippi, Montana, Nebraska, Nevada, New Jersey, Oklahoma, Oregon, Pennsylvania, South Dakota, Tennessee, Texas, Utah, Vermont, Virginia, Washington, West Virginia, and Federal.

264 For the purpose of this analysis, we counted the number of times a jurisdiction took the strict or lenient position on the issues considered. If a jurisdiction took the intermediate position on issue (c), this position was not included in the count for that jurisdiction, even though it might have affected the classification of that jurisdiction into one of the groups. Conversely, if a jurisdiction took the intermediate-lenient or intermediate-strict position on issue (d), we counted this position as lenient or strict, respectively. See supra Table 2.

265 Alaska, Arkansas, Colorado, Connecticut, District of Columbia, Iowa, Kansas, Maine, Massachusetts, Minnesota, Missouri, New Hampshire, New Mexico, New York, North Carolina, North Dakota, Ohio, Rhode Island, South Carolina, Wisconsin, and Wyoming.

266 Delaware, Georgia, Hawaii, Idaho, Kentucky, Mississippi, Nebraska, Nevada, New Jersey, Oklahoma, Pennsylvania, South Dakota, Tennessee, Virginia, Washington, and West Virginia.

267 Connecticut, Maine, Massachusetts, Minnesota, New York, and Wyoming.

268 For convenience, below we refer to the four groups as the "lenient", "strict", "most lenient", and "strictest" jurisdictions. 
issue), ${ }^{269}$ thirteen are also strict jurisdictions, ${ }^{270}$ including all six of the strictest. ${ }^{271}$ Similarly, among the thirty-three jurisdictions not imposing such a duty (the lenient position for this issue), ${ }^{272}$ twenty-five ${ }^{273}$ are also lenient jurisdictions. ${ }^{274}$ In short, knowing a jurisdiction's position on the duty to retreat enables us to better predict the position it is likely to take on other Defense of Persons issues.

Moreover, although these four groups are, in a sense, a purely artificial construct (created by us according only to jurisdictions' positions on contested Defense of Persons issues), several interesting connections nevertheless exist between them and the real world. We explored various correlations between these groups and certain statistical characteristics of jurisdictions and discovered several intriguing findings.

First, a regional geographic pattern is apparent. ${ }^{275}$ Five of six New England jurisdictions are strict jurisdictions, ${ }^{276}$ including three of the strictest jurisdictions. ${ }^{277}$ Conversely, Southern jurisdictions are predominantly lenient. Among the seventeen Southern jurisdictions, ${ }^{278}$ only four are strict. ${ }^{279}$ The remaining

269 See text accompanying note 60 or Table 1.

270 Arkansas, Connecticut, Iowa, North Carolina, Ohio, Maine, Massachusetts, Minnesota, Missouri, New York, North Dakota, Rhode Island, and Wyoming.

271 Alaska, Connecticut, Maine, New York, Massachusetts, Minnesota, and Wyoming.

272 See supra note 59 or Table 1.

273 Alabama, Arizona, California, Florida, Georgia, Illinois, Indiana, Idaho, Kentucky, Louisiana, Michigan, Mississippi, Montana, Nevada, Oklahoma, Oregon, South Dakota, Tennessee, Texas, Utah, Vermont, Virginia, Washington, West Virginia, and Federal.

274 Naturally, the position a jurisdiction takes, on the duty to retreat, may influence its categorization within one of the four groups and account for a portion of the correlation. Such influence, however, is probably modest, since jurisdictions' classification into groups is also influenced by six other issues, and since those groups were deliberately structured to prevent a single issue from having a decisive effect on a jurisdiction's classification.

275 The division into regions conforms with the division used by the Uniform Crime Report of the FBI. See Table 4, Crime in the United States by Region, Geographic Division, and State, 2011-2012 http://www.fbi.gov/about-us/cjis/ucr/crime-in-the-u.s/2012/crime-in-the-u.s.-2012/tables/4table datadecoverviewpdf/table_4_crime_in_the_united_states_by_region_geographic_division_and_ state_2011-2012.xls\#overview.

276 Connecticut, Maine, Massachusetts, New Hampshire, Rhode Island, and Vermont.

277 Connecticut, Maine and Massachusetts.

278 Alabama, Arkansas, Delaware, District of Columbia, Florida, Georgia, Kentucky, Louisiana, Maryland, Mississippi, North Carolina, Oklahoma, South Carolina, Tennessee, Texas, Virginia, and West Virginia.

279 Arkansas, District of Columbia, North Carolina, and South Carolina. 
thirteen are lenient jurisdictions, including eight of the most lenient jurisdictions. $^{280}$

Second, a correlation exists between jurisdictions' strictness and their violent crime rates. Using data from the FBI's Uniform Crime Report, ${ }^{281}$ we divided all U.S. jurisdictions between those in which the violent crime rate is either above or below the U.S. national average. ${ }^{282}$ We found that, of the twenty-nine jurisdictions in which the violent crime rate is below average, ${ }^{283}$ twelve are among the sixteen most lenient. ${ }^{284}$

280 Delaware, Georgia, Kentucky, Mississippi, Oklahoma, Tennessee, Virginia, and West Virginia.

281 See, Table 5, Crime in the United States by State, 2012. http://www.fbi.gov/about-us/cjis/ucr/crimein-the-u.s/2012/crime-in-the-u.s.-2012/tables/5tabledatadecpdf/table_5_crime_in_the_united_ states_by_state_2012.xls. Of note, UCR data are subject to various criticisms (see, e.g., Nathan James \& Logan Rishard Council. 2008. How Crime in the United States is Measured, 56, Cong. Research Serv., RL3430917-21. https://www.fas.org/sgp/crs/misc/RL34309.pdf; Kimberly A. Lonsway \& Joanne Archambault. 2012. The "Justice Gap" for Sexual Assault Cases: Future Directions for Research and Reform. 18 Violence Against Women 145, 149; Corey Rayburn Yung. 2014. How to Lie with Rape Statistics: America's Hidden Rape Crisis. 99 Iowa L. Rev. 1197, 1206-1207), with the possible exclusion of homicide rate, which appears to be the most accurate UCR data (see, e.g., ibid How to Lie at 1225-1226). Nevertheless, "Despite the shortcomings of the system, the UCR remains the dominant source of information about crime levels and rates in the United States. The media uncritically reports the statistics from the program without noting the limitations of the data... The UCR data often serves as the basis for crime and social policy in America.... Policymakers also regularly use the UCR data to evaluate the efficacy of criminal justice programs. As a result, the annual FBI reports become the definitive proxy for evaluating crime control." (ibid, How to Lie at 1207-1208, (internal quotations and references omitted, emphasis not in the original). See also ibid, at 1200; ibid, How Crime in the United States is Measured at 1-2; ibid, The "Justice Gap" at 149). In other words, the criticisms of the UCR notwithstanding, UCR data, as is (rather than the real, but unknown crime rate) influences criminal justice policy. Therefore, and since data on offences such as forcible rape, robbery, and aggravated assault (which are included, along with homicide, in the UCR's violent crime rate data, see, Crime in the United States 2012, Violent Crime http://www.fbi.gov/about-us/cjis/ucr/crime-in-the-u.s/2012/ crime-in-the-u.s.-2012/violent-crime/violent-crime), are likely to influence criminal justice policies related to the Defense of Persons, we elected to conduct our analysis on the "violent crime" data set, rather than rely solely on the much narrower criteria of homicide rate. We are grateful to an anonymous commentator for noting that such choice requires clarification.

282 Since there are compatibility problems with the reported data for some jurisdictions (specifically, District of Columbia and Minnesota), rather than calculating the average violent crime rate from the jurisdictions' data, we used FBI's estimate for such a rate. See, Table 1, Crime in the United States by volume and rate per 100,000 inhabitants, 1993-2012. http://www.fbi.gov/about-us/cjis/ ucr/crime-in-the-u.s/2012/crime-in-the-u.s.-2012/tables/1tabledatadecoverviewpdf/table_1_ crime_in_the_united_states_by_volume_and_rate_per_100000_inhabitants_1993-2012.xls.

283 Connecticut, Colorado, Georgia, Hawaii, Idaho, Indiana, Iowa, Kansas, Kentucky, Maine, Mississippi, Montana, Nebraska, New Hampshire, New Jersey, North Carolina, North Dakota, Ohio, Oregon, Pennsylvania, Rhode Island, South Dakota, Utah, Vermont, Virginia, Washington, West Virginia, Wisconsin, and Wyoming.

284 Georgia, Hawaii, Idaho, Kentucky, Mississippi, Nebraska, New Jersey, Pennsylvania, South Dakota, Virginia, Washington, and West Virginia. 
Third, a correlation exists between jurisdictions' strictness and population size. Using the U.S. Census data, we divided all U.S. jurisdictions into five groups according to their population size. ${ }^{285} \mathrm{We}$ discovered that among the sixteen jurisdictions in which the population is below 2,055,287 (the first group), ${ }^{286}$ eight are strict jurisdictions. ${ }^{287}$

Fourth, a correlation exists between jurisdictions' strictness and the racial composition of their populations. As mentioned above, we divided U.S. jurisdictions into four groups according to the percentage of their total population that is Black or African American. We found that among the twenty jurisdictions in which the Black or African American population is 0.5-5.1 percent of the total (the first group), ${ }^{288}$ a mere nine are strict jurisdictions (which is not very different from chance distribution); ${ }^{289}$ however, those include three of the strictest jurisdictions. ${ }^{290}$ The reverse correlation also exists, though to a lesser extent. Among the seventeen jurisdictions in which the Black or African American population makes up more than 13.5 percent of the total population (the third and fourth groups), ${ }^{291}$ six are among the most lenient jurisdictions. $^{292}$

What insights can be derived from these findings? Here, as in Section 3.1.2, we cannot offer definitive answers. Our present findings, however, allow us to suggest some interesting conjectures, reexamine the correlations found in previous sections, discover broader patterns and detect promising paths for further examination.

Consider, for instance, that ex ante, one might have expected jurisdictions with a relatively high violent crime rate to be lenient. The reasoning is that in a

285 For the division, we employed the U.S. census data and the "natural breaks" classification method. See supra note 240, for a more detailed explanation.

286 See U.S. Census Bureau, Total Population 2008--2012. , available at http://factfinder2.census.gov/ faces/tableservices/jsf/pages/productview.xhtml?pid=ACS_12_5YR_B01003\&prodType=table (last visited Sept.ember 2, 2014).

287 Alaska, District of Columbia, Maine, New Hampshire, New Mexico, North Dakota, Rhode Island, and Wyoming.

288 Alaska, Arizona, Colorado, Hawaii, Idaho, Iowa, Maine, Minnesota, Montana, Nebraska, New Hampshire, New Mexico, North Dakota, Oregon, South Dakota, Utah, Vermont, Washington, West Virginia, and Wyoming.

289 Alaska, Colorado, Iowa, Maine, Minnesota, New Hampshire, New Mexico, North Dakota, and Wyoming.

290 Maine, Minnesota, and Wyoming.

291 See U.S. Census Bureau, ACS Demographic and Housing Estimates 2008-2012. http://factfinder2. census.gov/faces/tableservices/jsf/pages/productview.xhtml?pid=ACS_12_5YR_DP05\&prodType= table (last visited September 2, 2014).

292 Delaware, Georgia, Mississippi, New Jersey, Tennessee, and Virginia. 
high-crime environment, jurisdictions may be likely to support individuals' right to defend themselves and others. Nevertheless, we observed no such correlation. On the contrary, we found that the jurisdictions in which the crime rate is relatively low are relatively lenient. This finding may imply a starkly different causal story, suggesting that a jurisdiction's leniency in granting the defense of persons may have an impact on the violent crime rate, helping to reduce it. Naturally, we do not claim proving the existence of such a causal connection. Our data on correlations cannot support a claim on causation. We do suggest, however, that the possibility of such causal connection is interesting, and may merit further examination.

Recall also the finding that more than two-thirds of the jurisdictions allowing no right to resist unlawful arrest while also imposing a duty to retreat (represented by the lower right cell of Table 1) are those with a relatively high white population percentage. ${ }^{293}$ Currently, we can clearly see that such a correlation represents the strict position on both issues, suggesting that it might be fruitful to explore its relationship with our present findings on other groups of jurisdictions with a tendency to strictness, such as New England jurisdictions, jurisdictions with relatively small populations or those in which the Black or African Americans population percentage is relatively low.

Similarly, our present findings allow us to notice that the correlation we found between the Black or African American population percentage in a jurisdiction and its tendency to adopt the right to resist unlawful arrest ${ }^{294}$ may be part of a broader pattern. Such correlation, as we are now in a position to see, is consistent with (and might represent a private case of) such jurisdictions' general tendency for lenience. ${ }^{295}$

The important takeaway from this discussion is, once again, not any particular conjecture. ${ }^{296}$ It is the larger point: DCA enables one to engage in these kinds of analyses, which may reveal new and previously unexplored specific connections and broad patterns between jurisdictions' characteristics and their approaches to criminal law. Clearly, applying these analyses to all of the data

293 See text accompanying notes 250-252.

294 See text accompanying notes 241-245.

295 See text accompanying notes 291 and 292.

296 In fact, a change in a jurisdiction's position on one or more issues may result in a re-categorization of that jurisdiction (e.g., from strict to lenient, or from merely "strict" to one of the "strictest" jurisdictions) and consequently change the sizes of these categories themselves. This, in turn, is likely to influence many of the calculations by either strengthening or weakening the findings above. Since changes in jurisdictions' positions involve dynamic processes and are likely to occur, the strength of some of the findings above might fluctuate. Nevertheless, as will be further elaborated in the main text, the larger point of the analysis does not hang on any particular finding. 
presented in Section 2 would be a major undertaking beyond the scope of the present article. We can, however, suggest some additional interesting directions of further exploration that can be pursued relying on such data.

For example, it may be of interest to researchers to compare jurisdictions' positions on similar issues in distinct defenses. For instance, they can examine the differences in the nature of the cognitive dysfunction requirement between the Insanity and Involuntary Intoxication defenses, ${ }^{297}$ or in the weight assigned to one's culpability in creating a situation in which the Lesser Evils justification or Duress excuse arise. ${ }^{298}$ Moreover, broader patterns may be unearthed by expanding the strictness-leniency continuum we used for Defense of Persons issues to all justification defenses, or even to all defenses. This may allow examining whether jurisdictions are consistently strict or lenient between specific defenses or classes of defenses. Notably, the data in our article and its methodology provide fertile ground for such and other intriguing investigations.

\section{CONCLUSION}

What is the American rule on each general defense? This article's most direct and immediate contribution is in providing detailed answers to this question on each contested issue concerning each justification, excuse, and nonexculpatory defense. The majority formulations, and their comparisons with significant minority positions, the MPC, and the National Commission, provide legislatures, drafting commissions, judges, lawyers, and scholars with valuable and formerly unavailable information. That information, rather than the frequently wrong common wisdom, can presently be used to improve the quality of criminal legislation, legal arguments, and judicial opinions.

Moreover, as mentioned in the introduction, the existing ACCs' influence on codification in other countries can be significantly improved. Despite such codes' accessibility and comprehensiveness, their practical appeal is significantly reduced by the seemingly insurmountable obstacles-especially for foreigners-to determining the American rule. By removing uncertainty, this article enhances the attractiveness of using ACCs in developing and reforming criminal legislation abroad.

The article's goals, however, extend beyond these immediate contributions. It serves as the cornerstone for a broader project: drafting a comprehensive ACC reflecting the majority position on all major topics of substantive criminal law 
among U.S. jurisdictions. Although drafting such a code (or parts thereof) is indeed a major research undertaking, this article demonstrates (contrary to the skepticism expressed by some before its initiation) that such an endeavor can be accomplished and exemplifies what the results of such a project might look like. This may embolden others to embark on similar efforts and draft additional portions of the ACC, such as its general principles of liability, inchoate crimes, or specific offense chapters.

In addition, as illustrated in the article's last section, by using DCA, the findings pertaining to a jurisdiction's approaches to various criminal law issues can be leveraged to uncover and explore previously unexamined correlations and patterns. The added value of that section is not in its particular insights but rather in demonstrating how such analysis can be done, and providing the tools for further research in a similar vein. For instance, the strictness-leniency continuum we used for assessing correlations related to defense of persons can be utilized to assess jurisdictions' positions on issues such as complicity, attempts, or criminal homicide. Studying whether jurisdictions take strict or lenient positions on these issues may help disentangle the rhetoric of being "tough on crime" from the actual state of legislation and assist in implementing consistent policies in this regard.

Similarly, criminal law scholars can use additional metrics, such as deviations of jurisdictions' approaches to particular issues from the MPC or National Commission, to evaluate the impact (or lack thereof) of those model codes. Social scientists can use additional demographic variables, such as religious affiliation, income disparity, or political inclinations, to account for those jurisdictions' positions on subjects pertaining to criminal law or other issues.

Importantly, although our comprehensive analysis of the general defenses provides clear and well-defined answers on the American rule, our DCA mainly raises additional questions. Both, however, are essential for achieving key purposes of the article: eliciting interest in the ACC drafting project and helping to set an agenda for further research employing DCA. It is our hope that by exemplifying how such drafting can be done, and how interesting the discovered patterns and correlations can be, this article will help entice criminal law scholars and social scientists to engage in this new and fascinating research field.

It is the authors' sincere hope that the reader can now appreciate the immense value a completed ACC would have, both at home and abroad. Legislators and criminal law reformers could survey the complete landscape of positions on every issue of American criminal law, enabling them to advocate with confidence knowing where their jurisdictions stand among all others. Furthermore, criminal law reformers abroad looking to the USA for guidance would know, for the first time, exactly what we collectively have to offer. We 
therefore invite other criminal law researchers to pick up where we have left off and furnish the remaining parts of the ACC, both general principles and specific offenses. We also invite social scientists to fully mine the data provided for useful patterns and relationships. We hope that this article is the beginning of a larger project that has the potential to revolutionize global understanding of American criminal law.

\section{REFERENCES}

Austin, John. 1920. Austin on Jurisprudence: Student's Edition, 13th edn, 239. London: John Murray.

Garner, Brian A (ed.) 2006. Black's Law Dictionary: Third Pocket Edition, 3rd edn, 569. Eagen, Mn: Thomson West Publishers.

Robinson, Paul H. 1982. Criminal Law Defenses: A Systematic Analysis. Colum.

L. Rev. 82, 199-291. Columbia University Law Review, New York, NY. . 1997. Structure and Function in Criminal Law. Oxford: Clarendon Press.

—. 2009. Objective Versus Subjective Justification: A Case Study in Function and Form in Constructing a System of Criminal Law Theory. In Robinson, Garvey, \& Ferzan (eds.), Criminal Law Conversations, pp. 343-53; 361-63. Oxford: New York.

- 2014. Murder Mitigation in the Fifty-Two American Jurisdictions: A Case Study in Doctrinal Interrelation Analysis 47, 19-40; Texas Tech Law Review, Lubbock, TX.

Williams, Glanville. 1961. Criminal Law: The General Part, 2d edn, 337. Published by Stevens and Sons, London. 


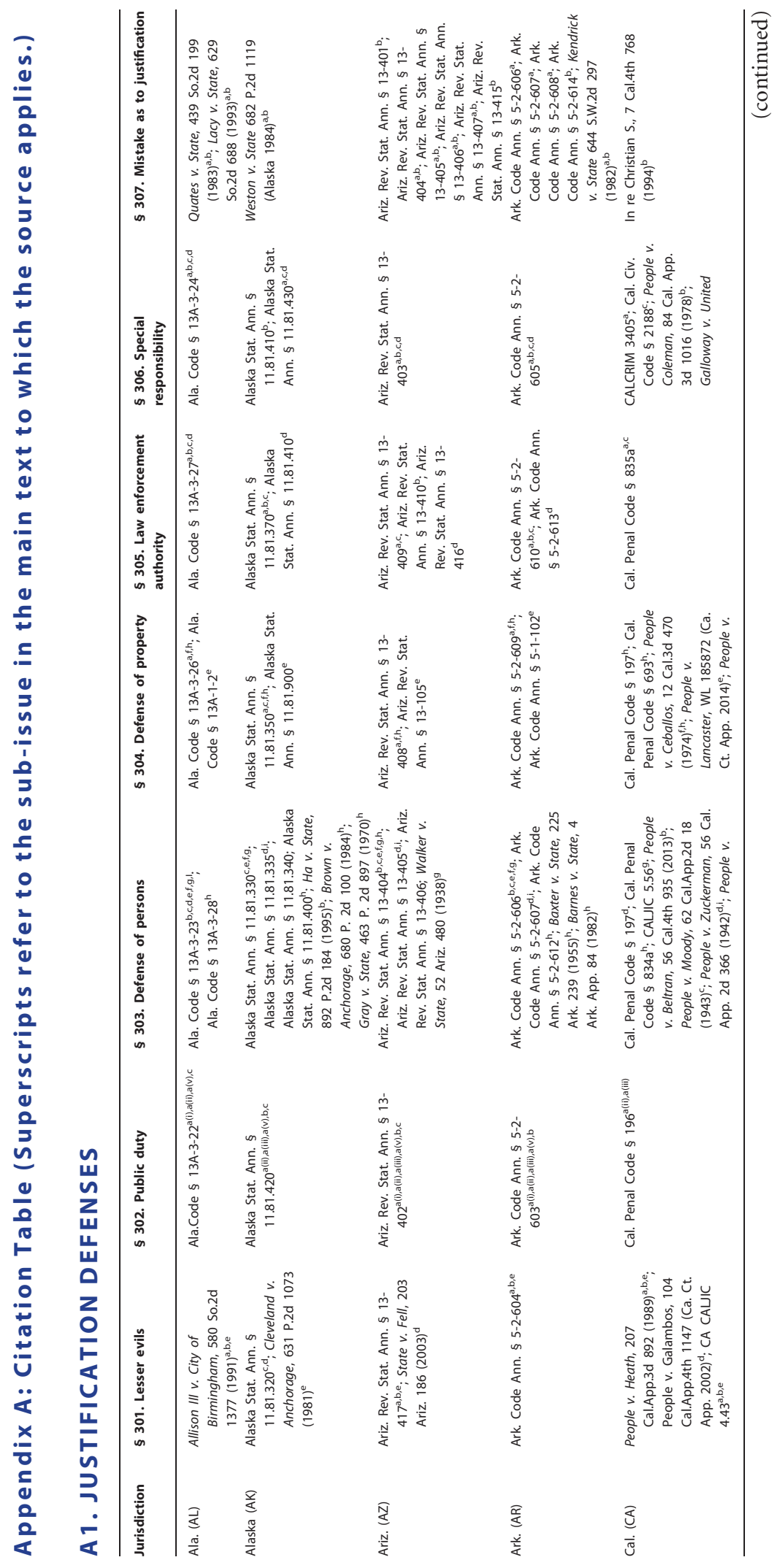

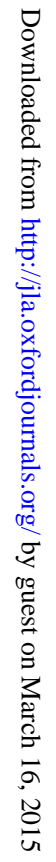




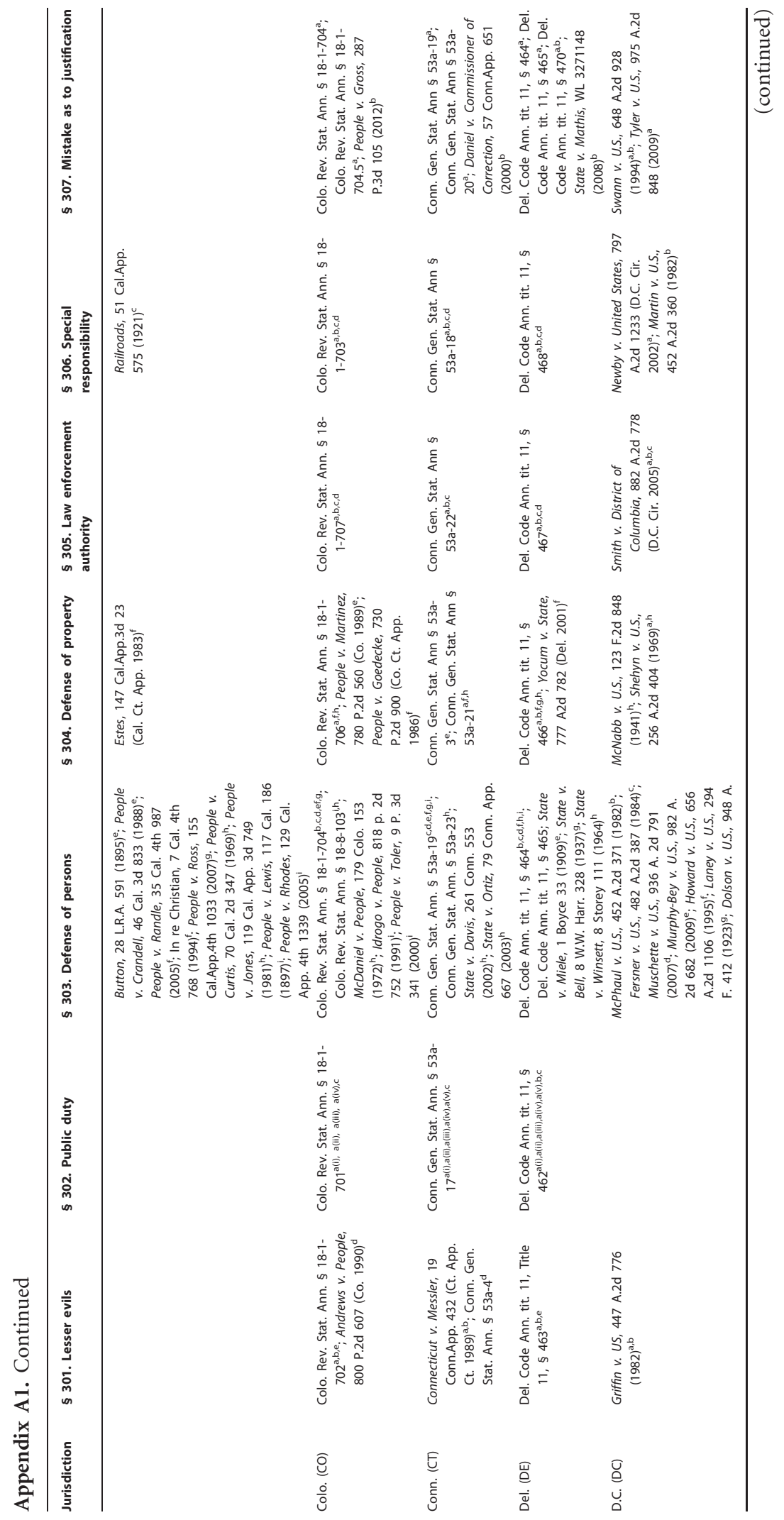

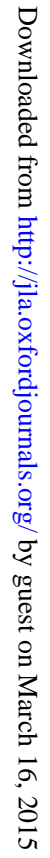




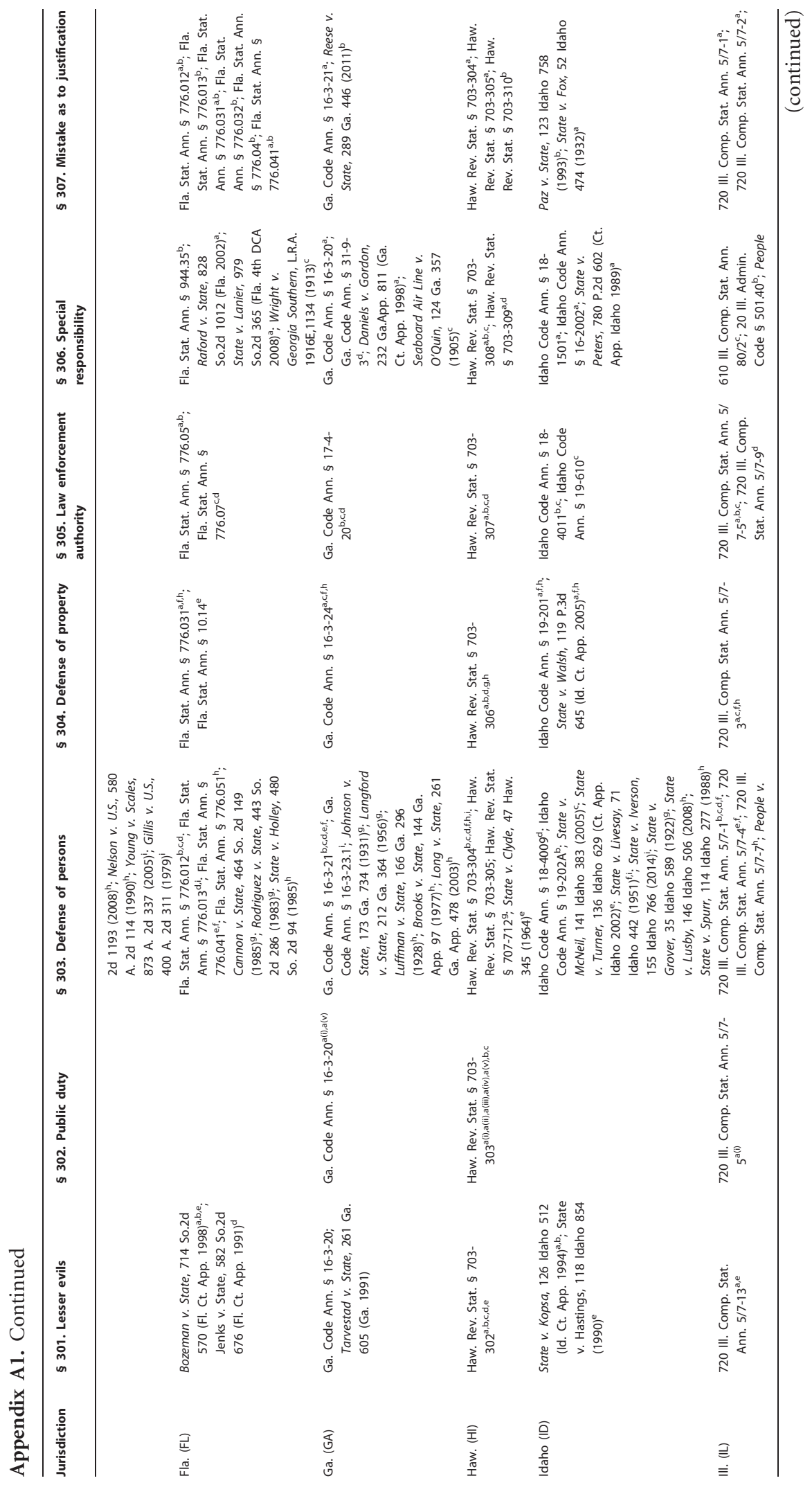

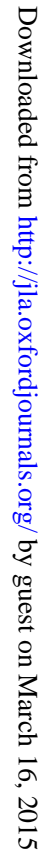




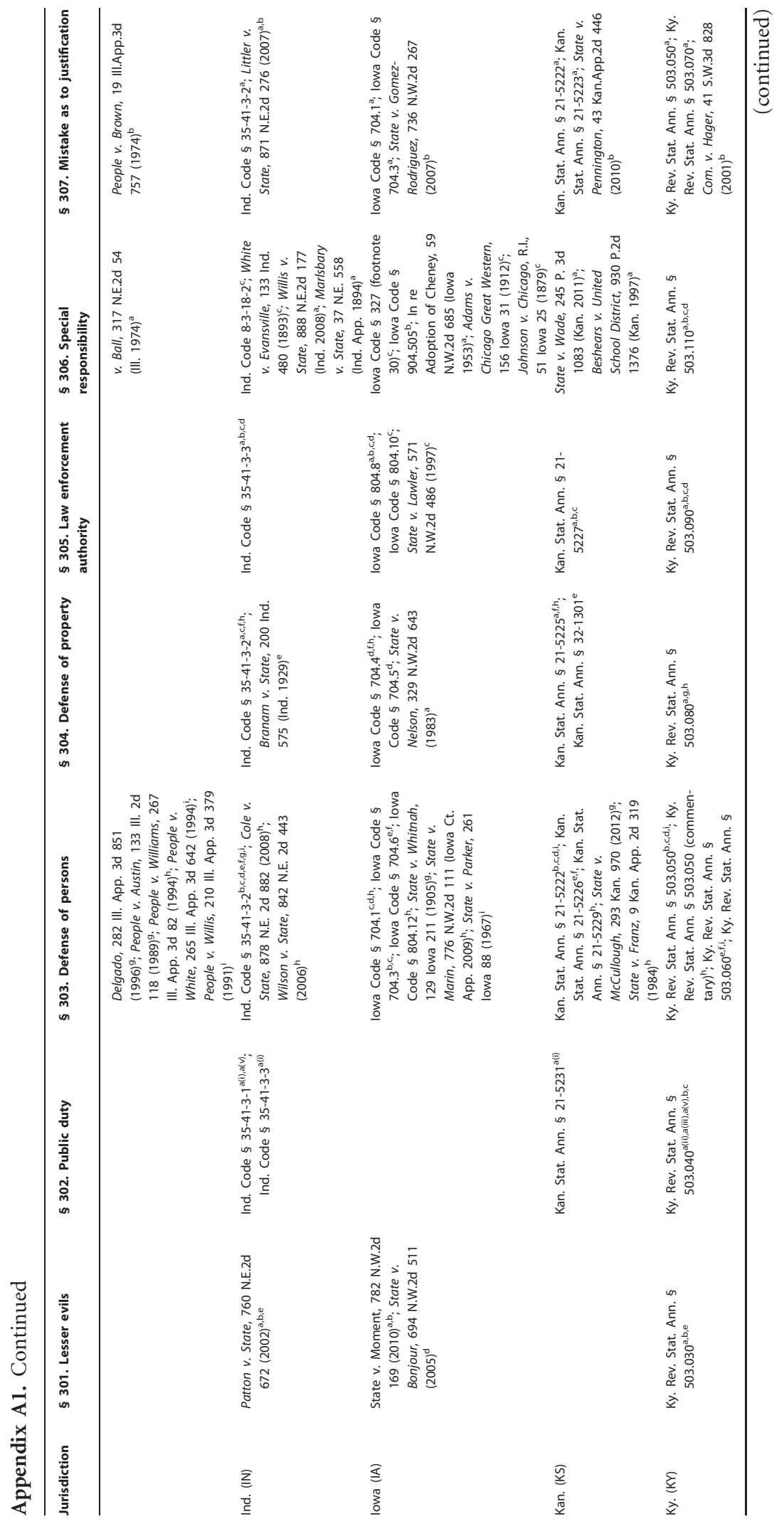

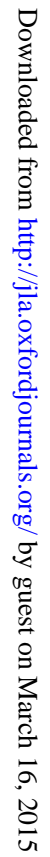




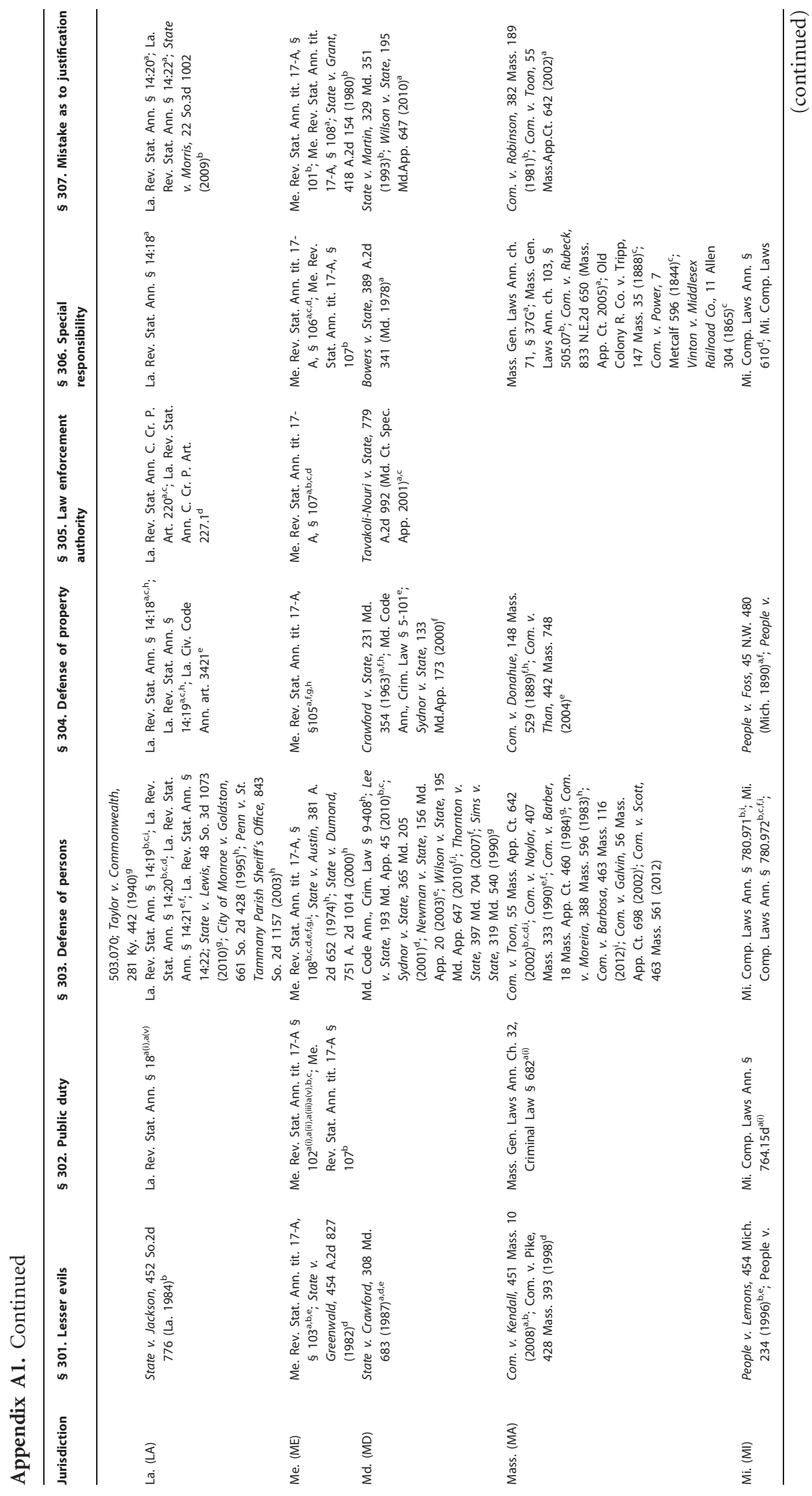

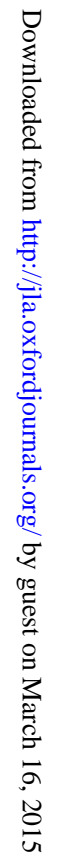




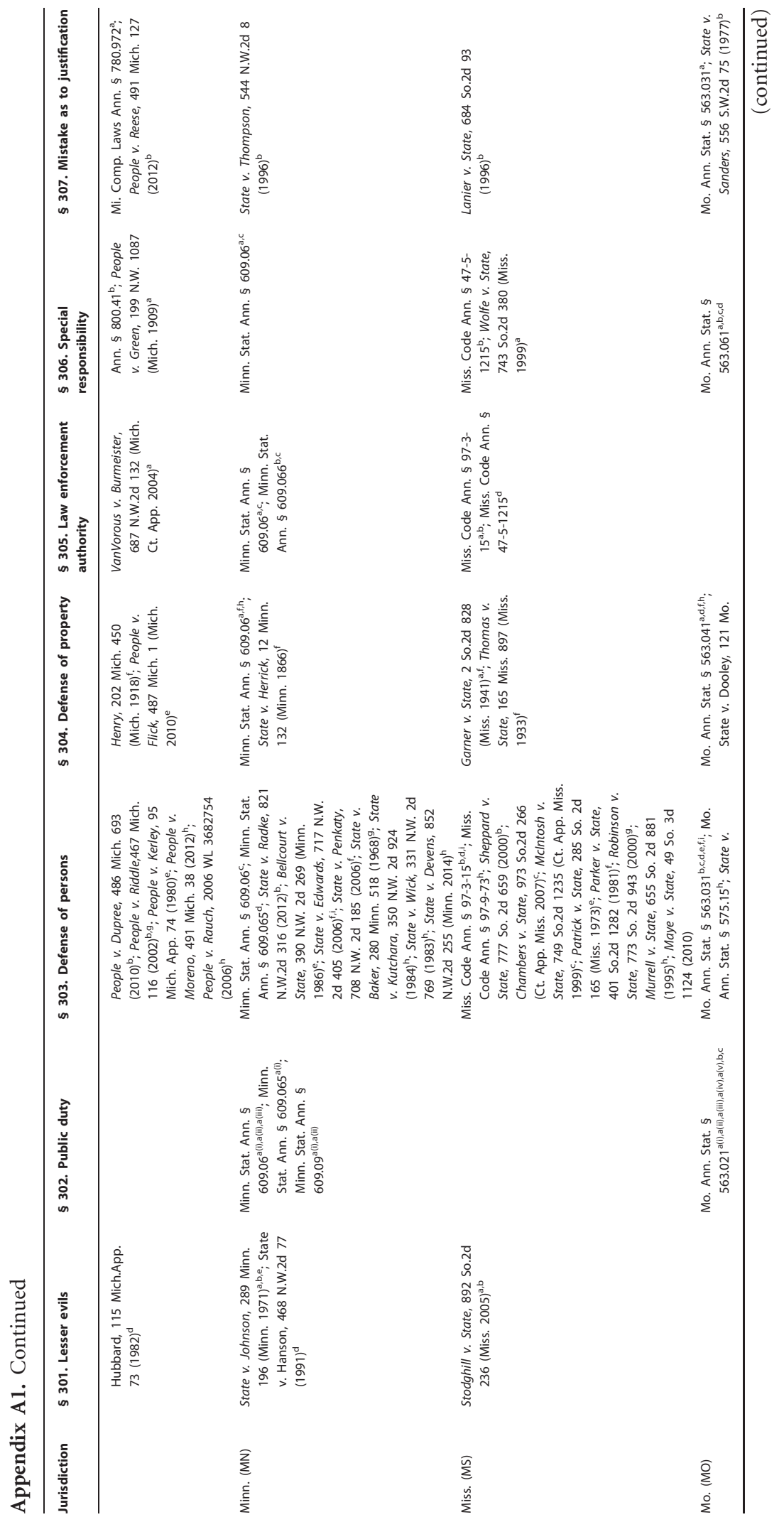

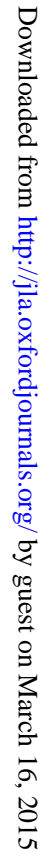




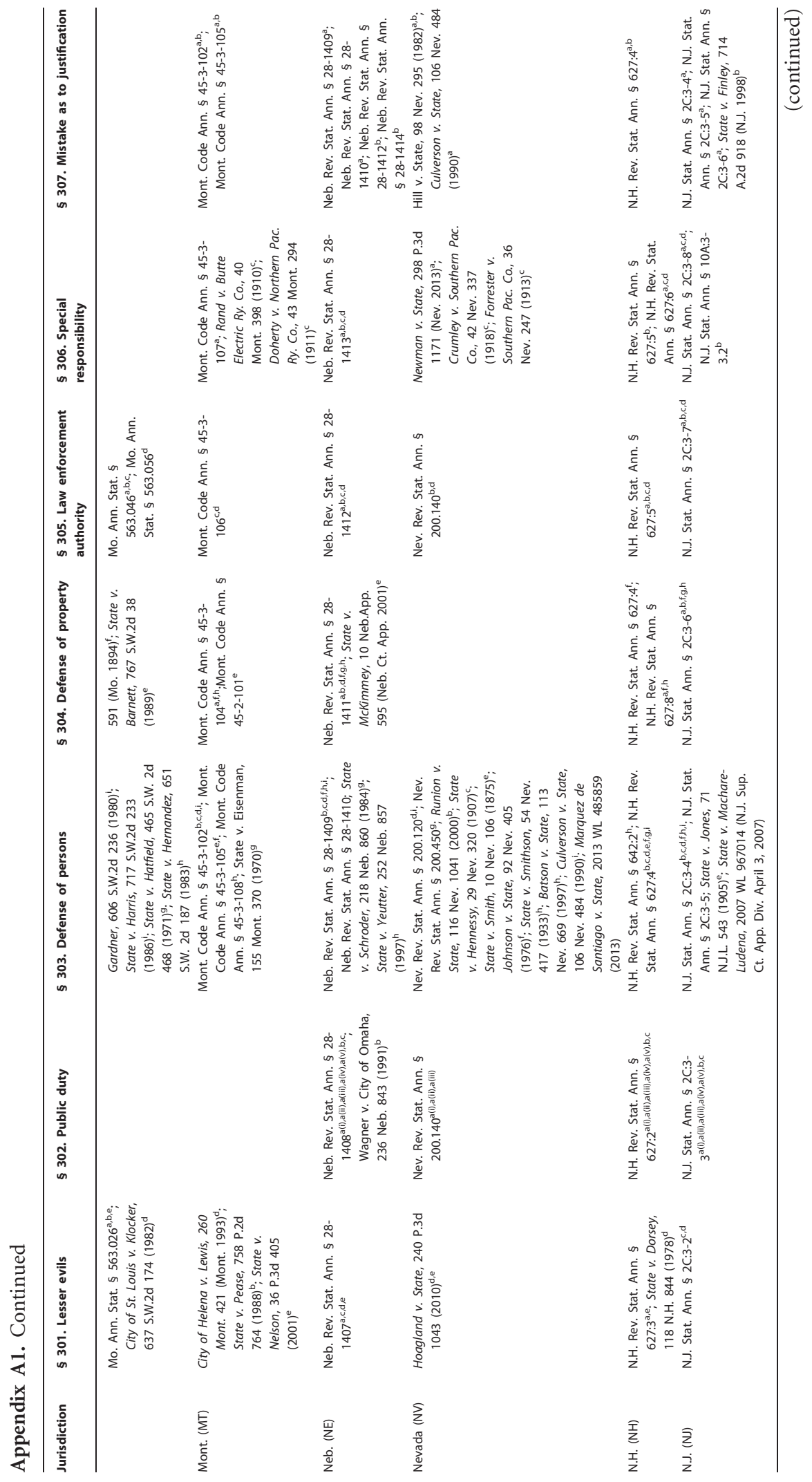

0
0
0
0
0
0
0
0
0
0
0
0
0
0
0
0
00
0
0
0
0
0
0
0
0
0
0
0
00
0
0
0
0
0
0
0
3
3
0
0
0
0
0
0
0 


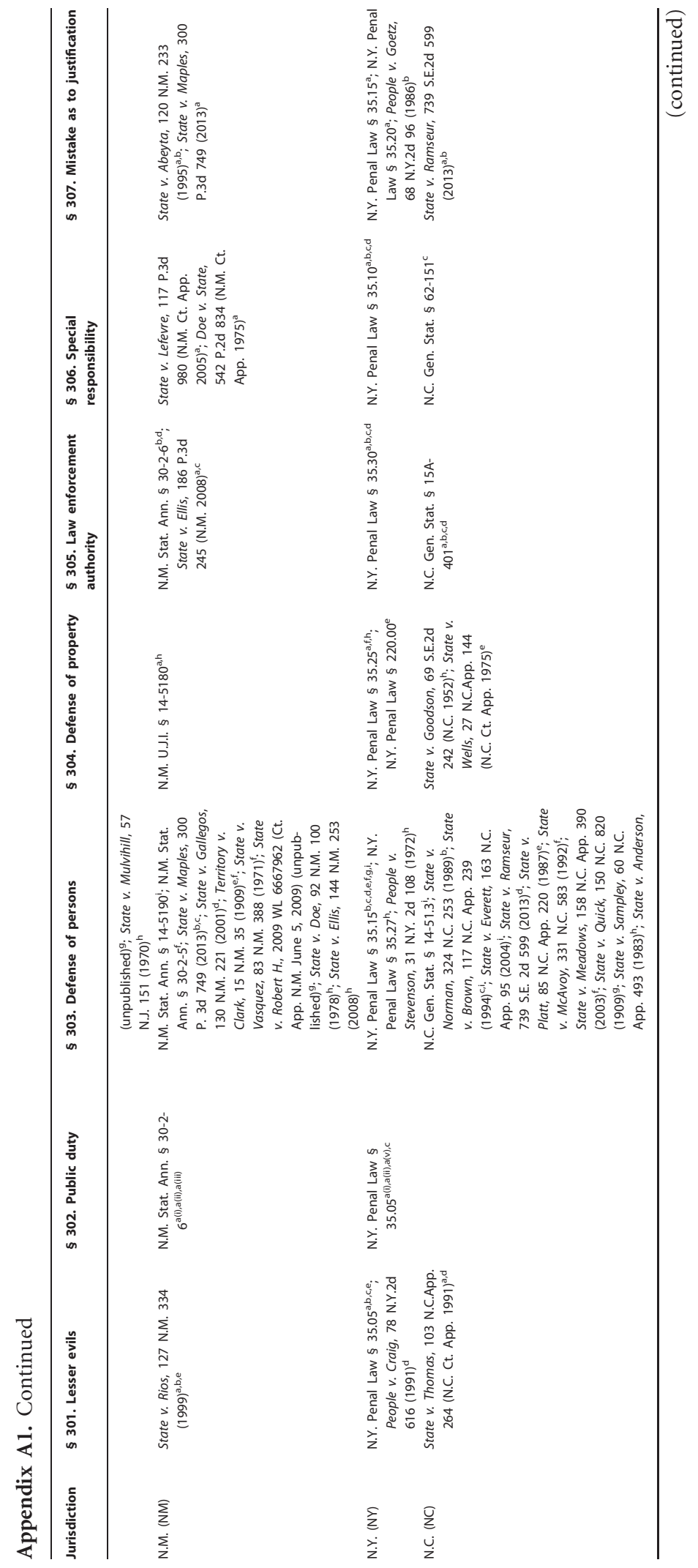

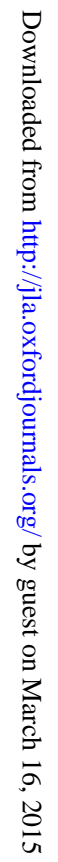




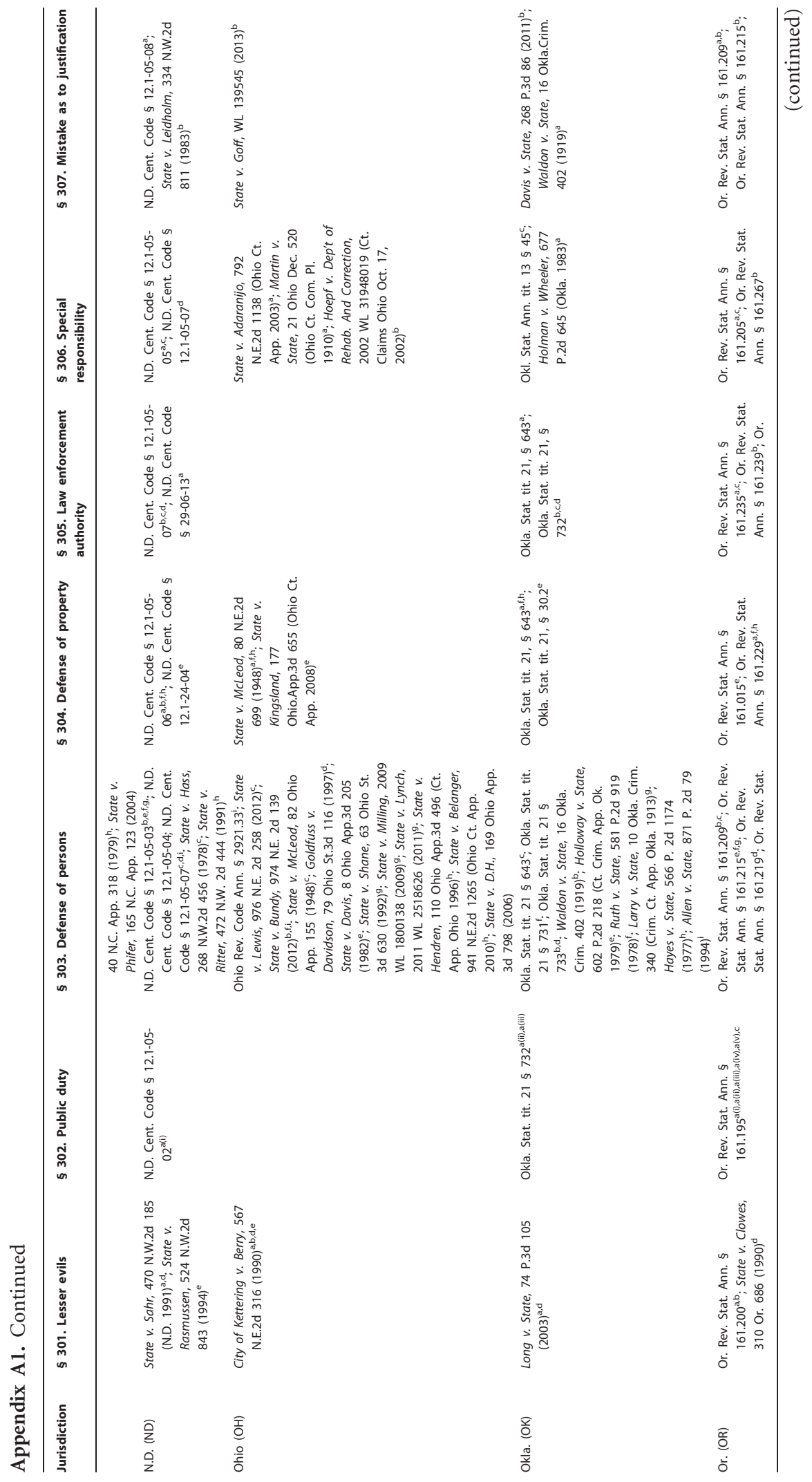

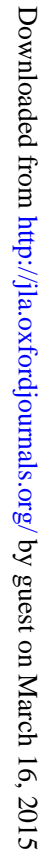




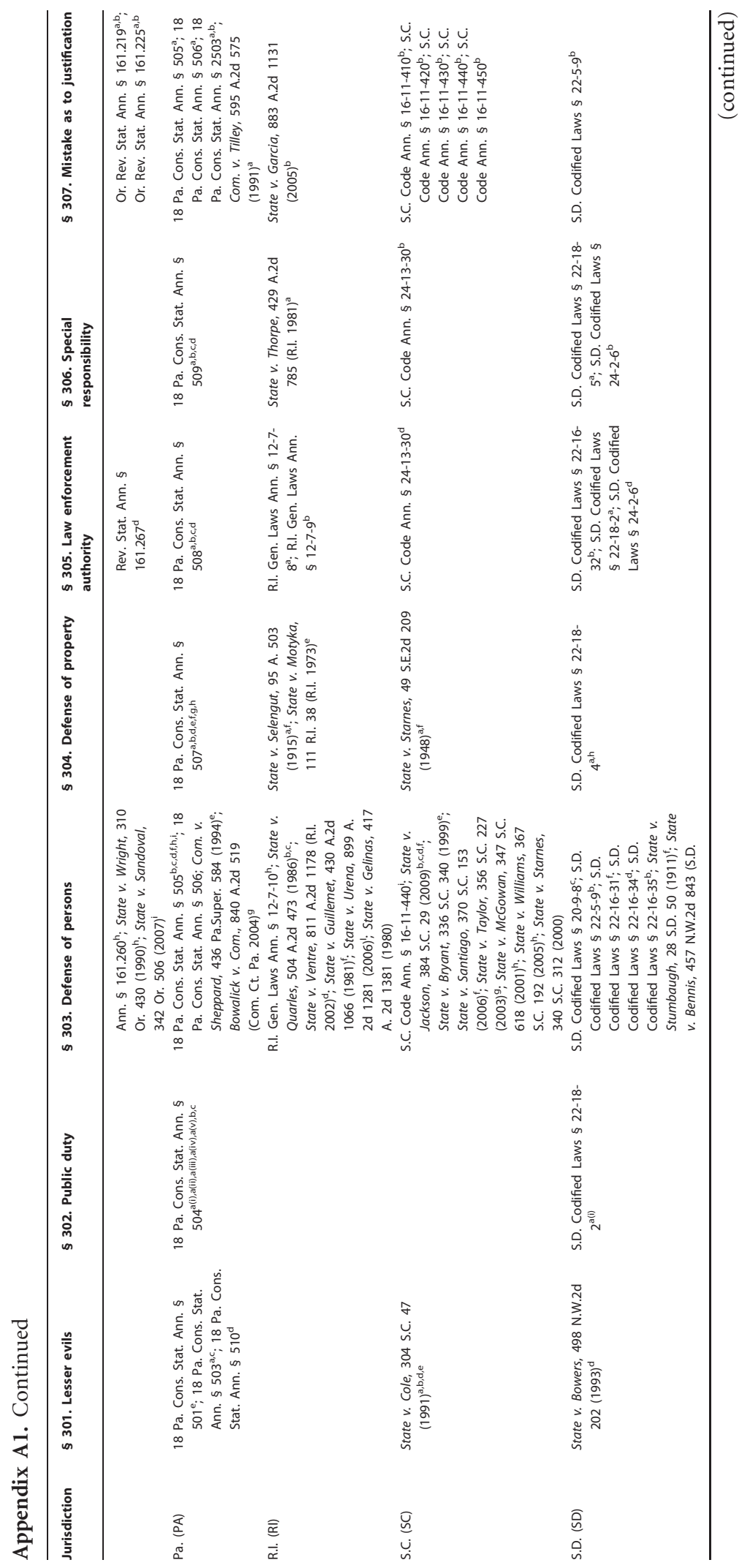




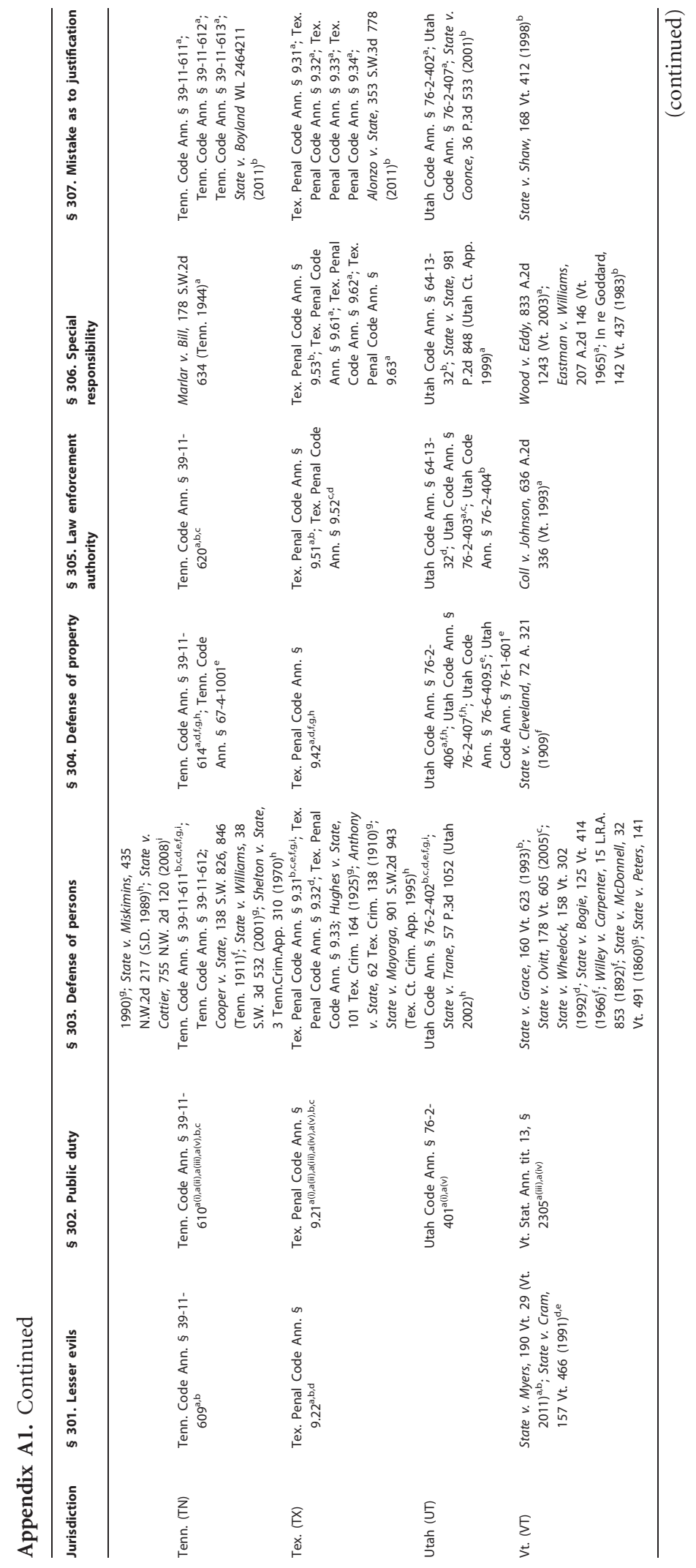

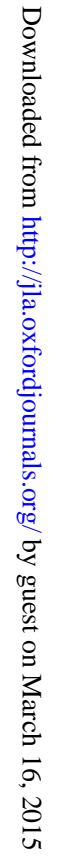




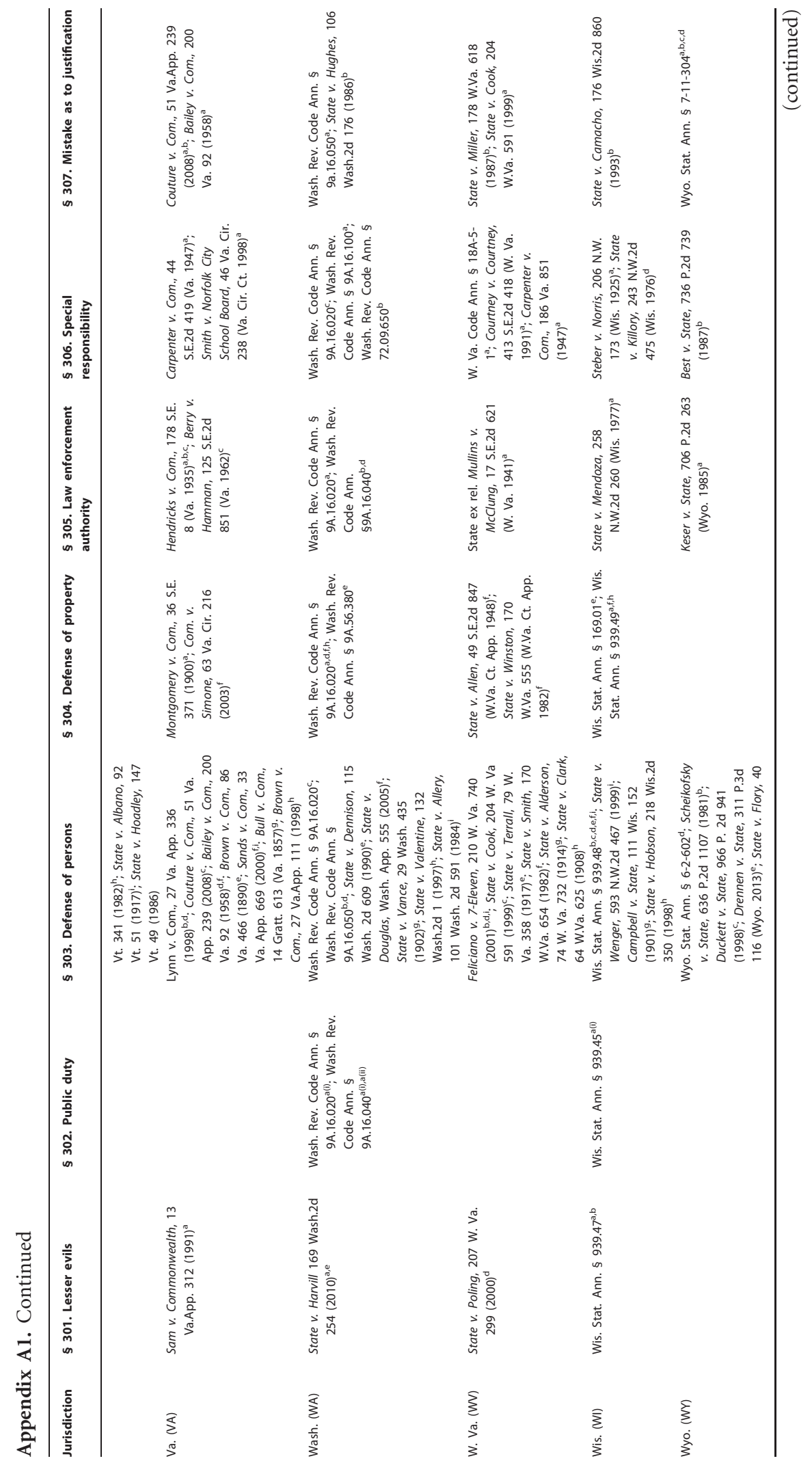

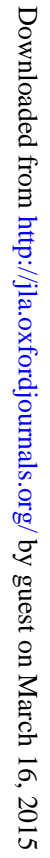




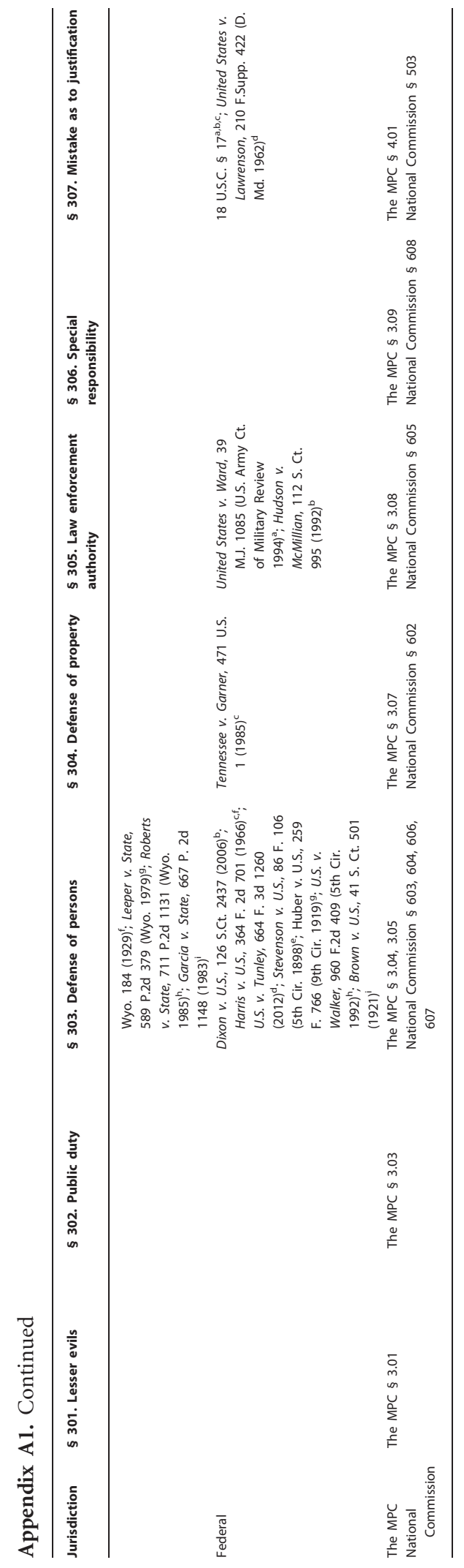




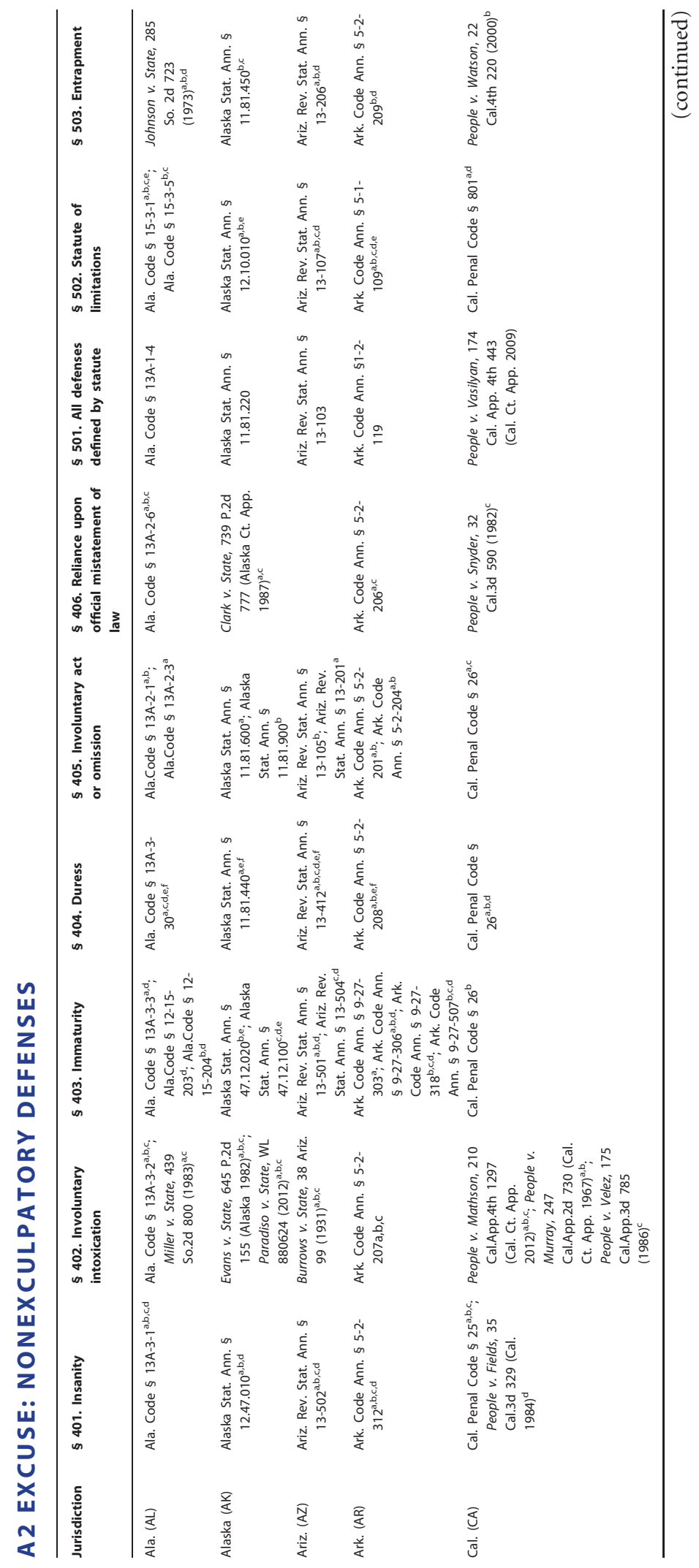

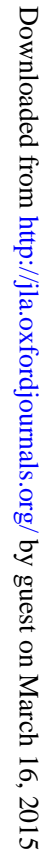




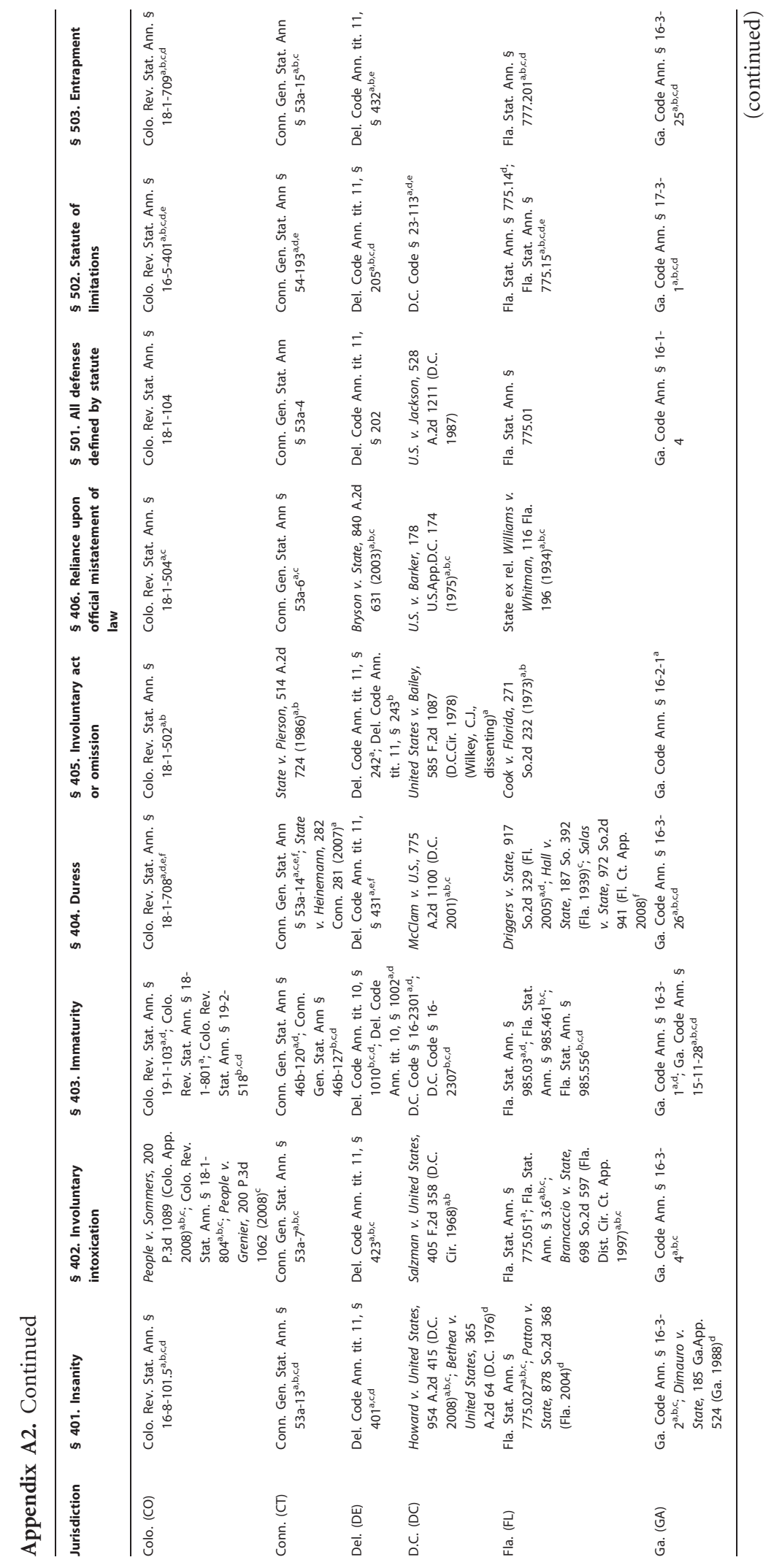

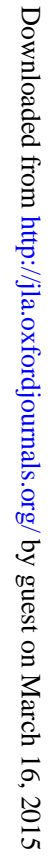




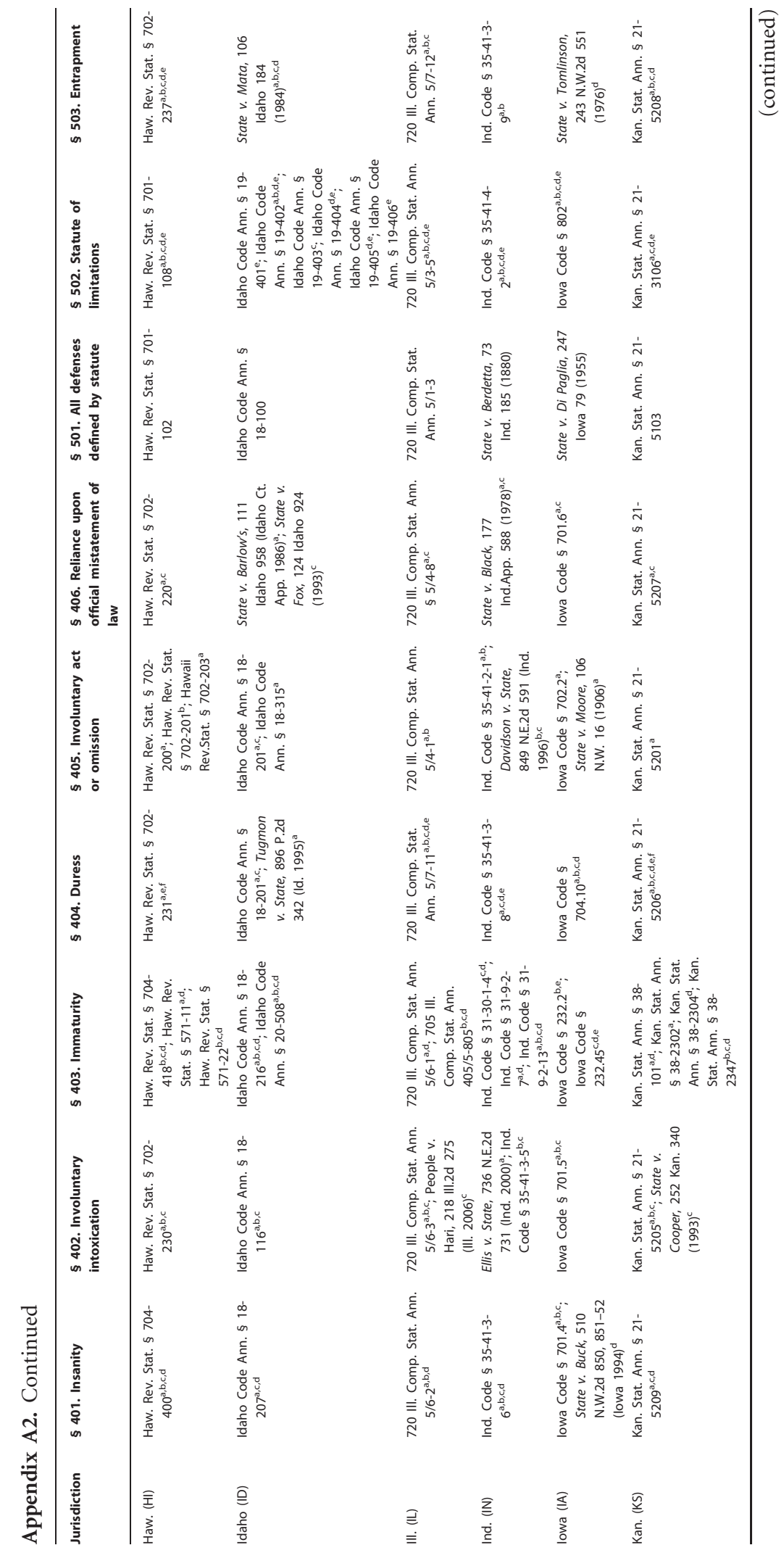

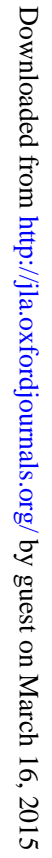




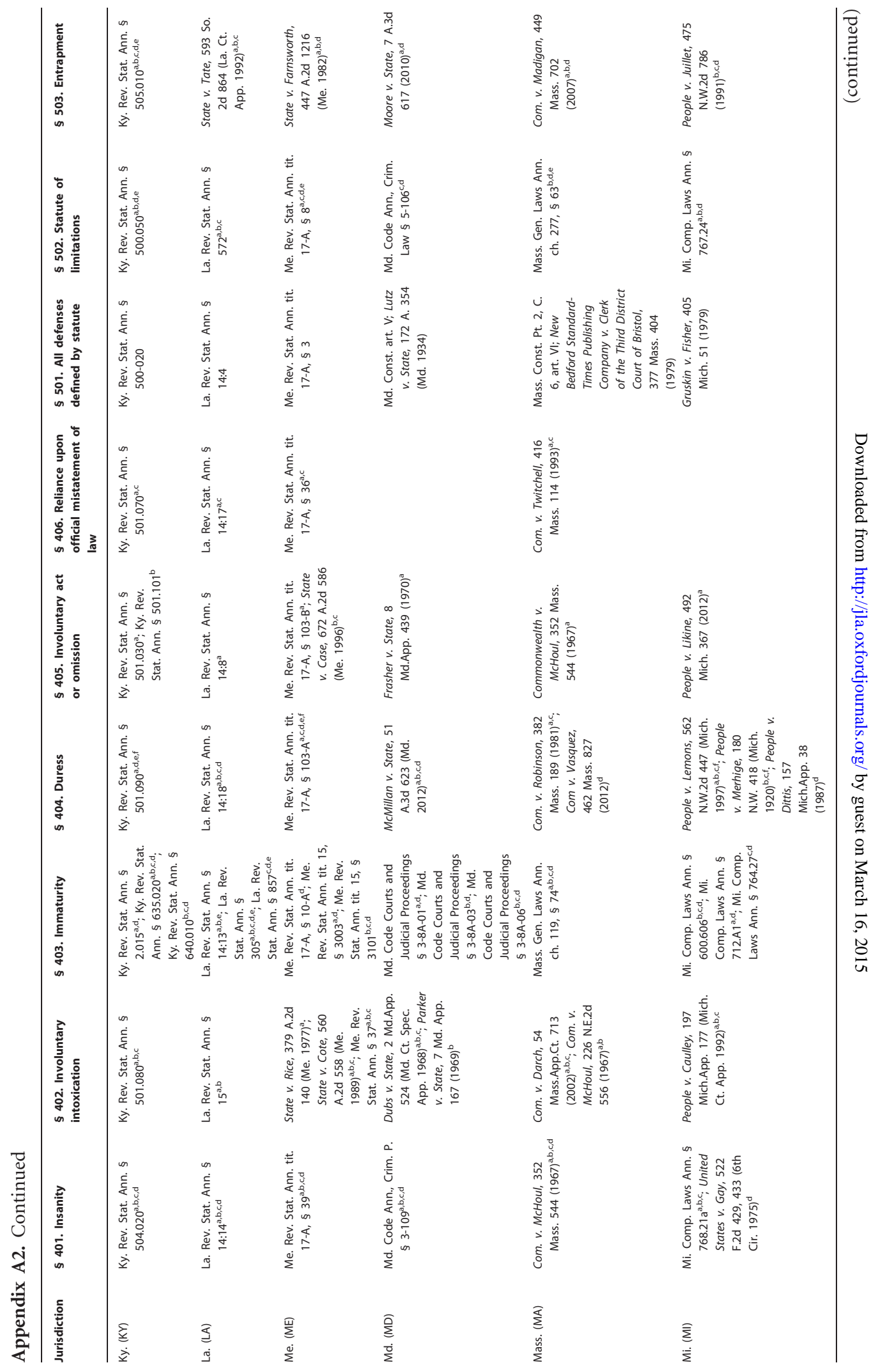




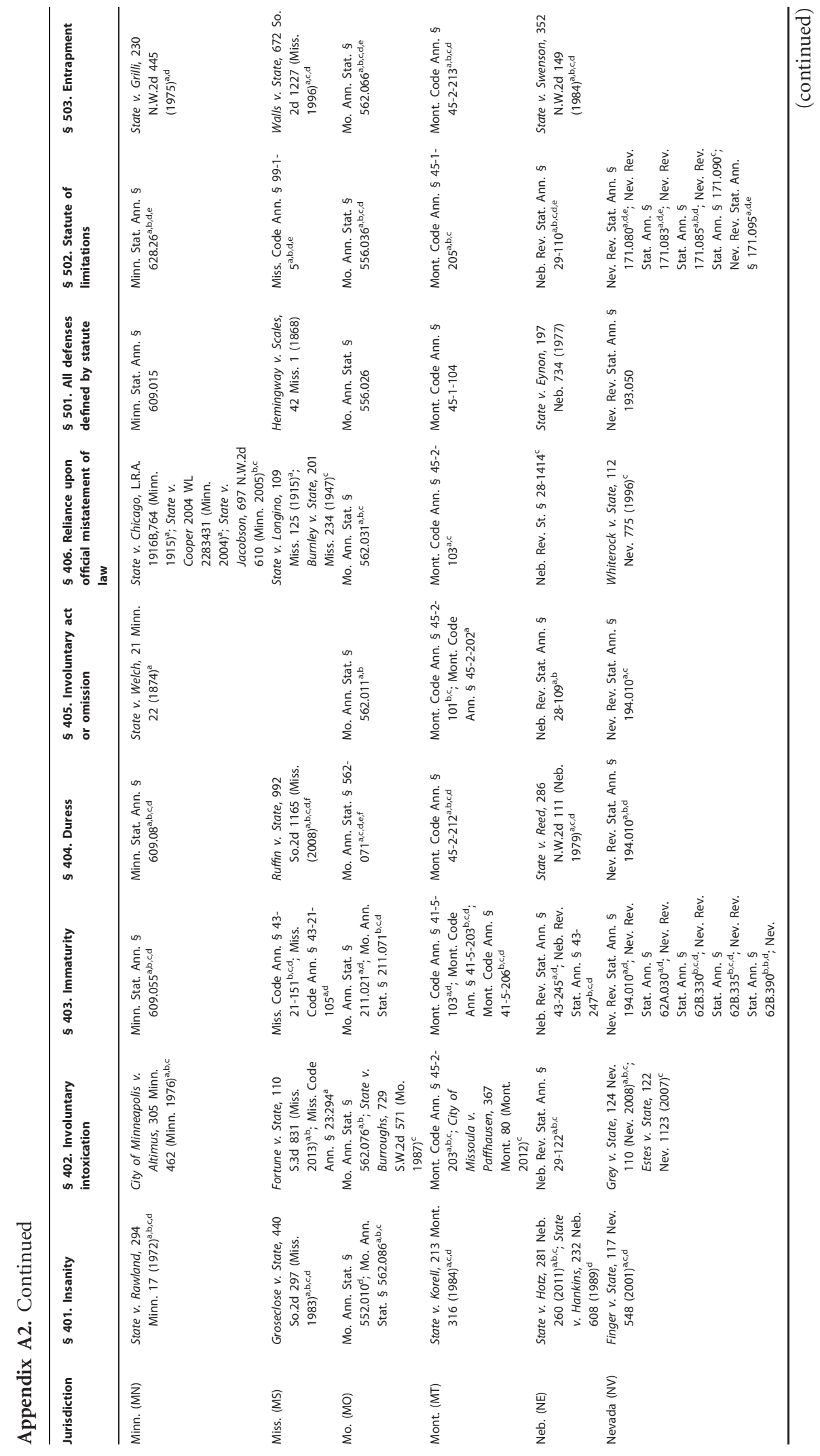

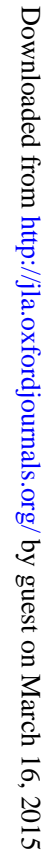




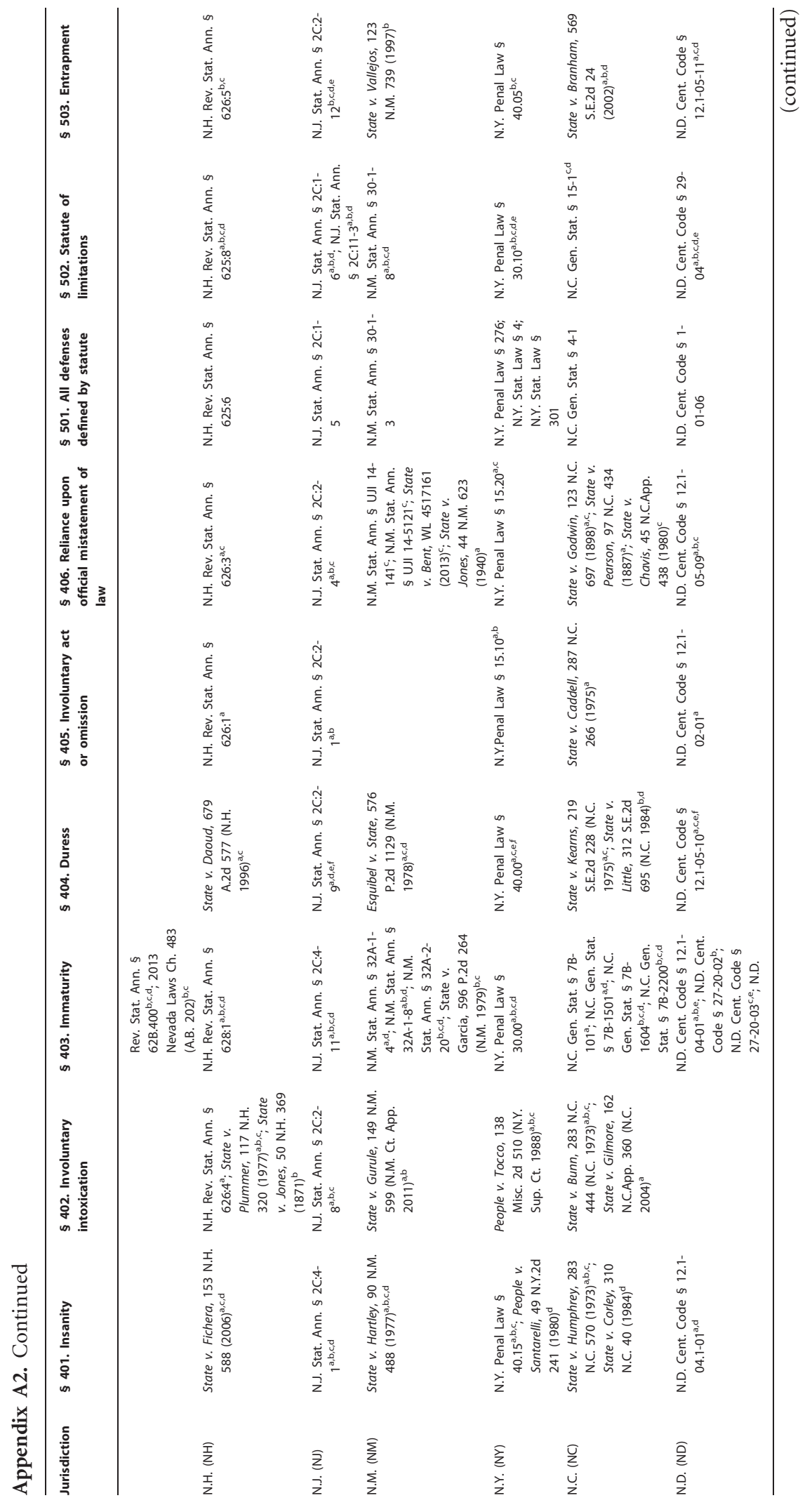

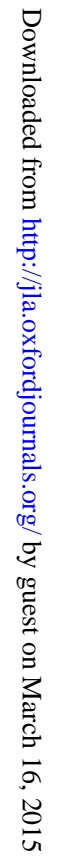




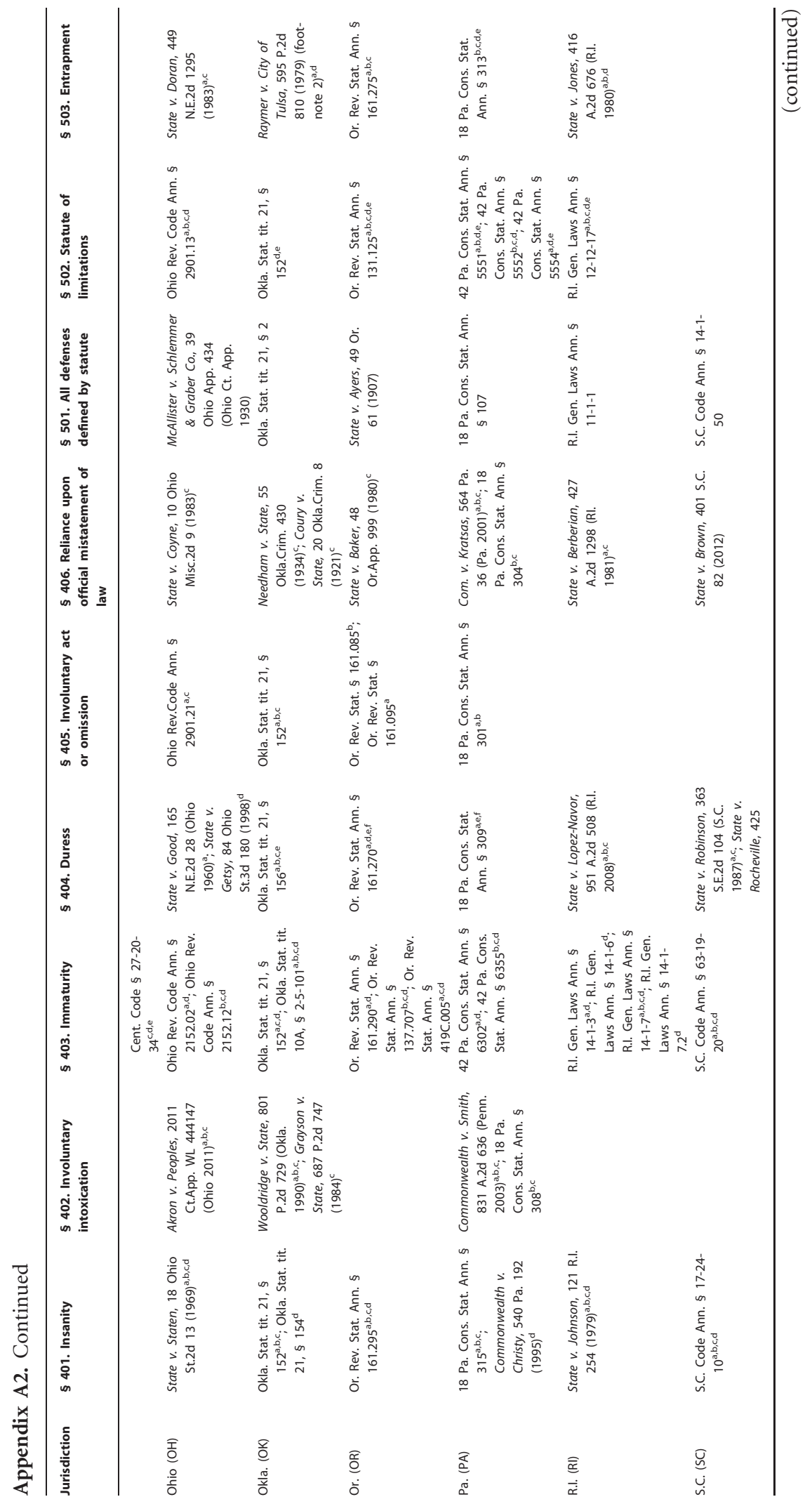

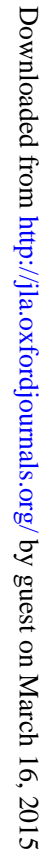




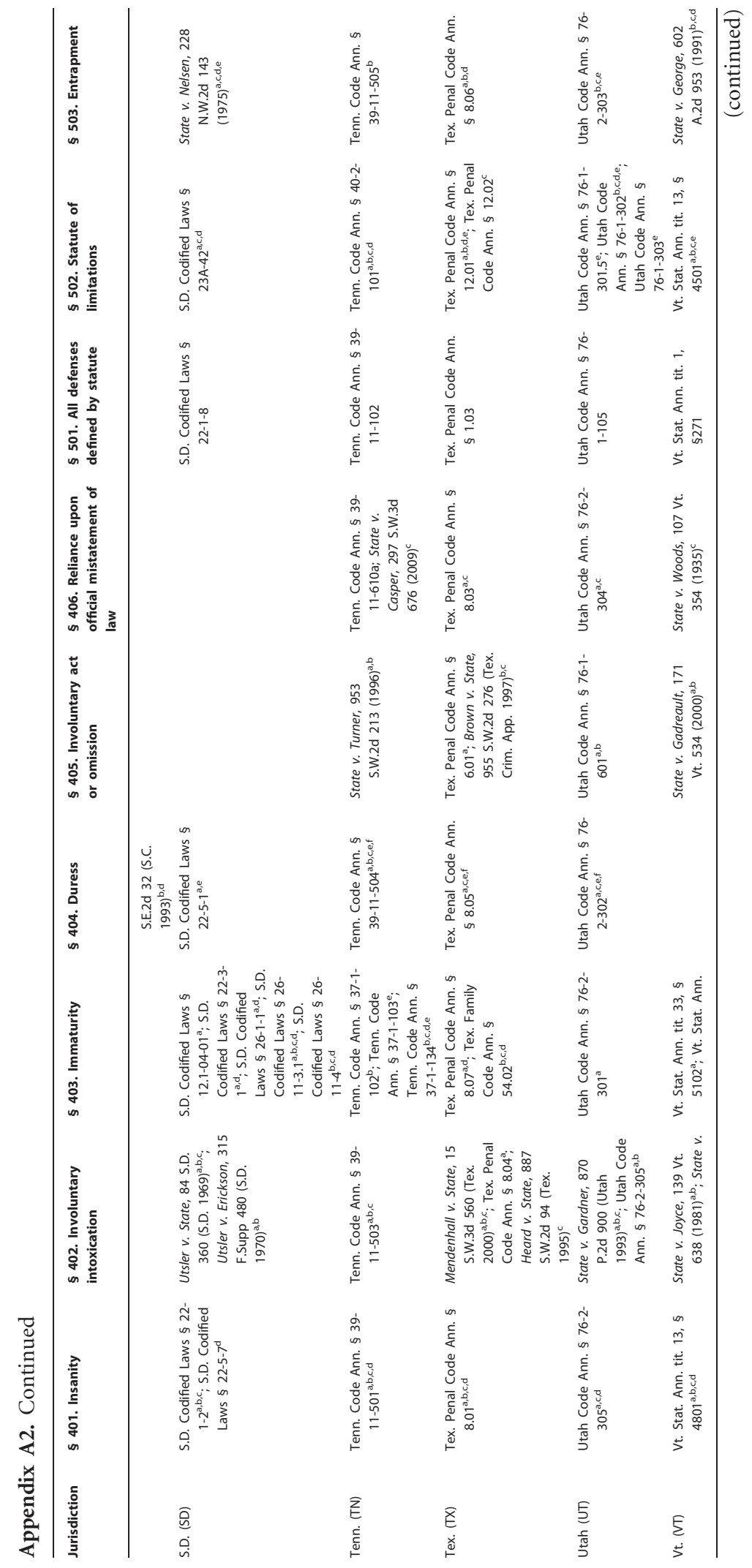

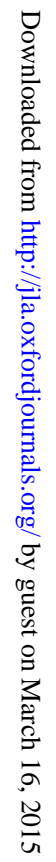




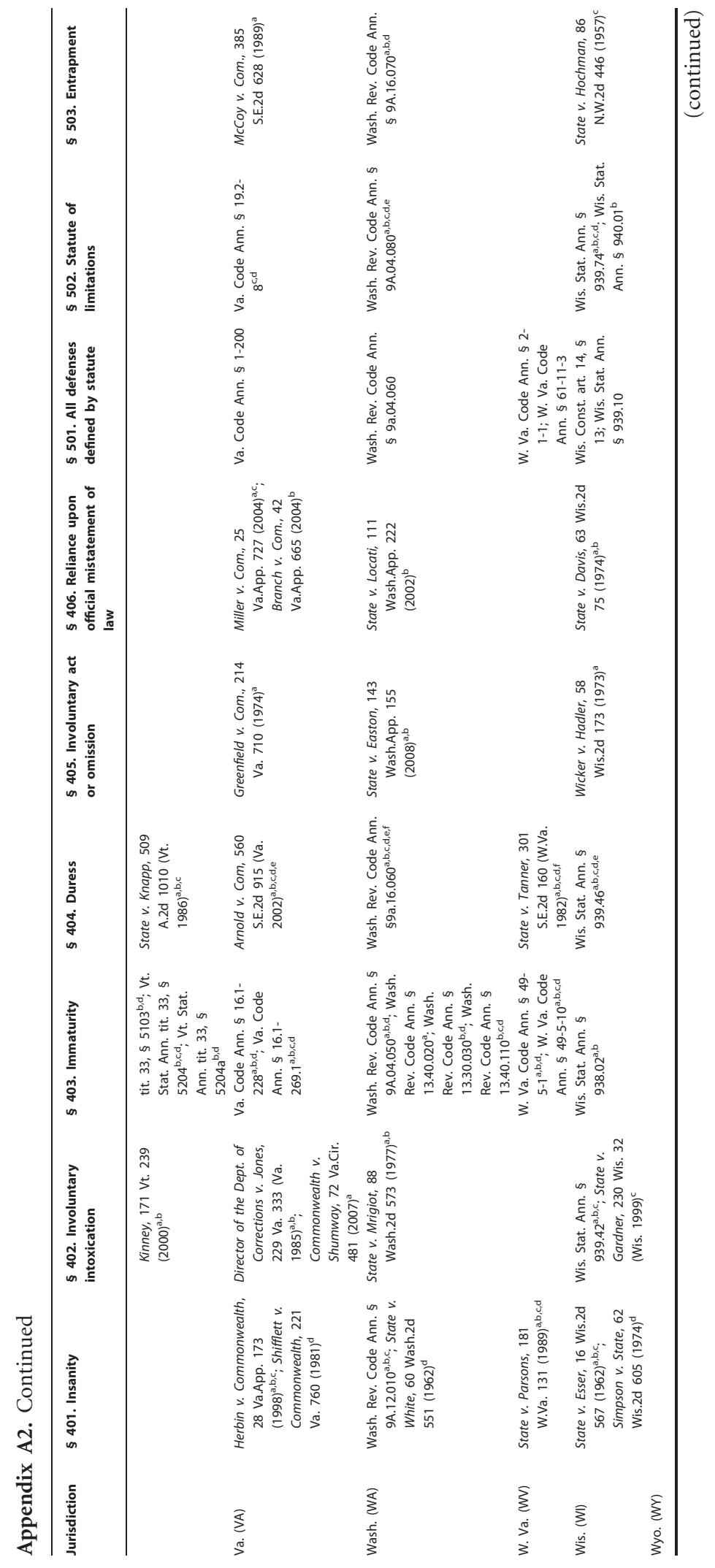




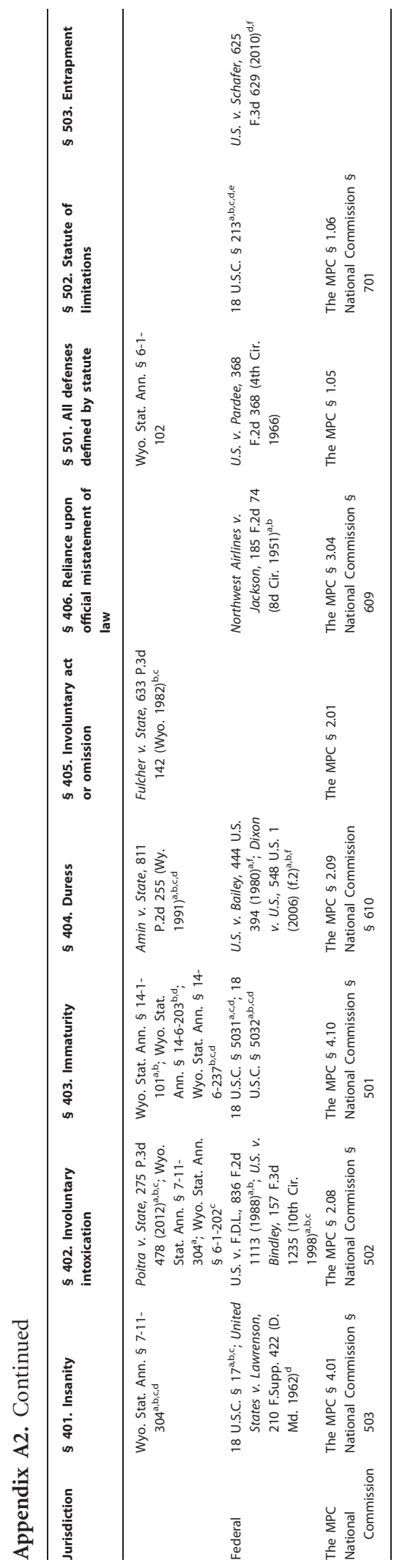

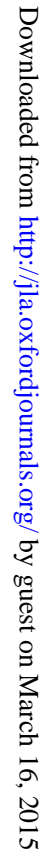

